\section{REFERENCE}

NIST

PUBLICATIONS

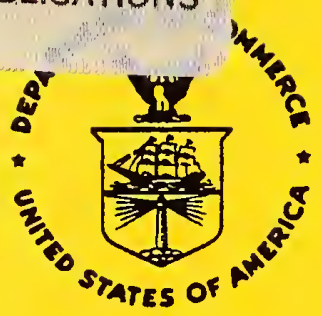

NISTIR 86-3473-1

\title{
The Internal Revenue Service Post-Of-Duty Location Modeling System: Programmer's Manual for FORTRAN Driver Version 5.0
}

\author{
Paul D. Domich \\ Richard H. F. Jackson \\ Marjorie A. McClain
}

U.S. DEPARTMENT OF COMMERCE

National Institute of Standards and Technology

(Formerly National Bureau of Standards)

Center for Computing and Applied Mathematics

Gaithersburg, MD 20899

February 1989

A Report to:

The Research Division Internal Revenue Service

Washington, DC 20224

I

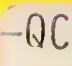


NATIONAL INSTTTUTE OF STANDARDS \&

TEOMNOTOG

Research Intorniation Center

Gaithersburg, MD 20899 


\title{
The Internal Revenue Service Post-Of-Duty Location Modeling System: Programmer's Manual for FORTRAN Driver Version 5.0
}

\author{
Paul D. Domich \\ Richard H. F. Jackson \\ Marjorie A. McClain
}

U.S. DEPARTMENT OF COMMERCE

National Institute of Standards and Technology

(Formerly National Bureau of Standards)

Center for Computing and Applied Mathematics

Gaithersburg, MD 20899

February 1989

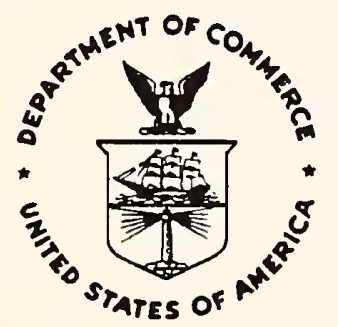

National Bureau of Standards became the National Institute of Standards and Technology on August 23, 1988, when the Omnibus Trade and Competitiveness Act was signed. NIST retains all NBS functions. Its new programs will encourage improved use of technology by U.S. industry.

A Report to:

The Research Division Internal Revenue Service Washington, DC 20224

\section{U.S. DEPARTMENT OF COMMERCE \\ C. William Verity, Secretary \\ Ernest Ambler, Acting Under Secretary for Technology}

NATIONAL INSTITUTE OF STANDARDS

AND TECHNOLOGY

Raymond G. Kammer, Acting Director 



\section{ABSTRACT}

This report is a programmer's manual for a microcomputer package which was designed by the National Institute of Standards and Technology to assist the Internal Revenue Service in choosing locations for its posts-of-duty which will minimize costs to the IRS and to the taxpayer. The package was written in two sections of code, one in FORTRAN and the other in PASCAL. This manual describes the FORTRAN driver which handles graphics displays and controls input and output for the solution procedure. 


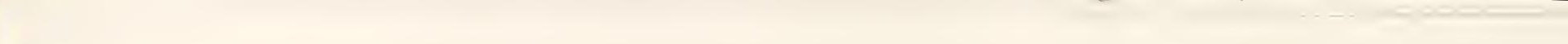

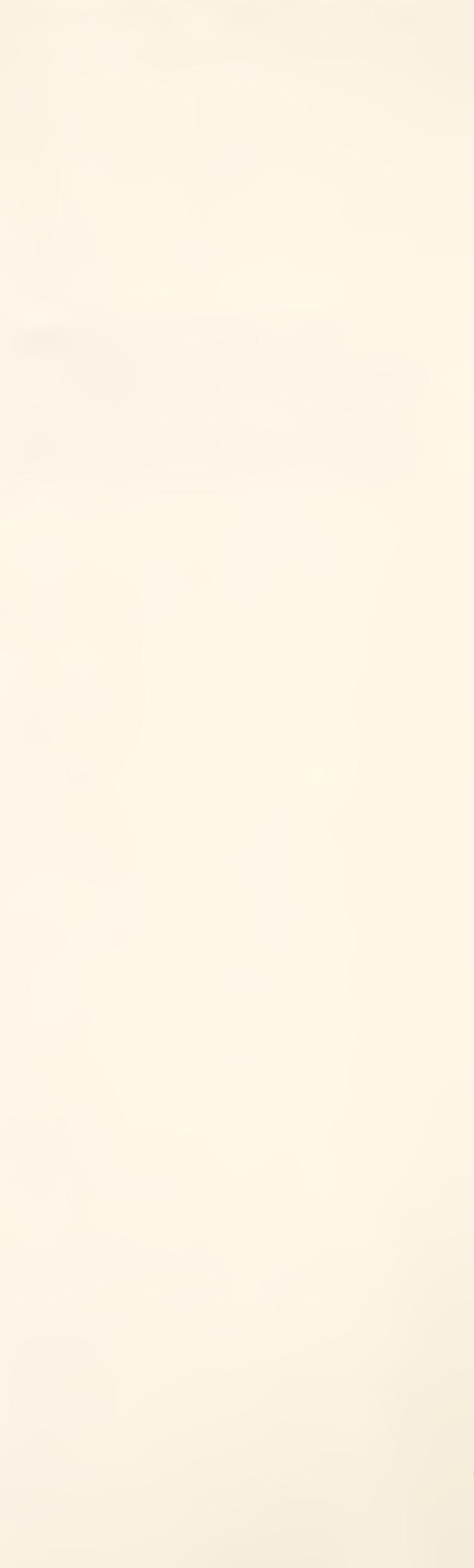


TABLE OF CONTENTS

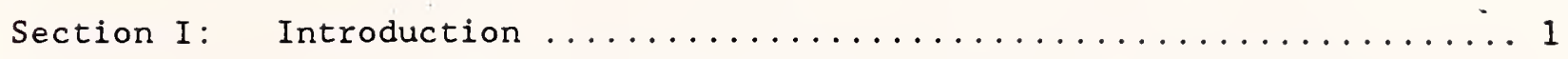

Section II: Software Requirements $\ldots \ldots \ldots \ldots \ldots \ldots \ldots \ldots \ldots \ldots \ldots \ldots \ldots \ldots \ldots \ldots$

Section III: Overview of FORTRAN Routines $\ldots \ldots \ldots \ldots \ldots \ldots \ldots \ldots \ldots$

Section IV: Description of Individual FORTRAN Routines ...........4

Section V: Changing the Program to Correspond to Changes in the

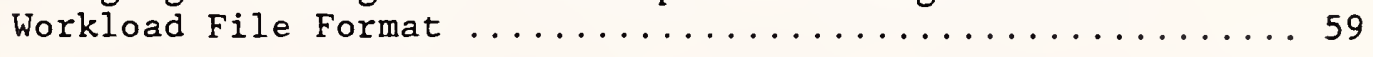



This paper is one of a series of reports documenting the Internal Revenue Service Post-of-Duty Location Modeling System, which was developed for the IRS Research Division by the Center for Computing and Applied Mathematics of the National Institute of Standards and Technology. The reports in the series are as follows.

1) The Internal Revenue Service Post-of-Duty Location Modeling System: Final Report

This report describes the post-of-duty location problem and its mathematical model. It discusses the types of data wich are considered in calculating costs, describes the methods used to solve the location problem, and gives a brief introduction to the computer implementation of the model. (NIST Contact: Paul D. Domich)

2) The Internal Revenue Service Post-of-Duty Location Modeling System: User's Manual

This report is a user's guide for the post-of-duty location computer system. It gives hardware and software requirements, instructions for installing the system, descriptions of data files, and detailed instructions for operating the system. (NIST Contact: Marjorie A. McClain)

3) The Internal Revenue Service Post-of-Duty Location Modeling System: Programmer's Manual for FORTRAN Driver

The post-of-duty location program is written in two sections of code, one in FORTRAN and the other in PASCAL. This report describes the FORTRAN driver which handles graphics displays and controls input and output for the solution procedure. The report includes an alphabetical list of the FORTRAN routines, describing the purpose, the calling sequence and the variables of each routine. (NIST Contact: Marjorie A. McClain)

4) The Internal Revenue Service Post-of-Duty Location Modeling System: Programmer's Manual for PASCAL Solver

This report describes the second part of the post-of-duty location program, the PASCAL solver. It discusses the algorithms and data structures used to solve a location problem. (NIST Contact: Paul D. Domich)

It is assumed that the reader of this programmer's manual is thoroughly familiar with IBM-PC DOS, with the FORTRAN language, and with the POD location system user's manual. 
The following software is required to be able to use and make changes to the POD location system programs.

1) IBM-PC DOS (Version 2.1 or later)

2) IBM Professional FORTRAN (Version 1.19)

3) Turbo PASCAL (Version 5.0)

4) IBM Graphical Kernel System (Version 1.00)

(GKS includes the Virtual Device Interface and device drivers. See the user's manual for information on how to set up the device drivers in the AUTOEXEC.BAT and CONFIG.SYS files.)

5) Source code for the POD location system, contained in the following files.

Geographic Data Initialization Programs .. GDTINST1. FOR

GDTINST2. FOR

System Driver Programs --

LOCATE. BAT

DRIVER. FOR

GKSUTIL.FOR

IOSUBS . FOR

MAPSUBS . FOR

MENUSUBS . FOR

System Solver Programs -.

SOLVER. PAS

DSTRUCT. PAS

FIVCLR. PAS

GREEDY.PAS

INIT. PAS

INTCHG. PAS

LGRN. PAS

PODCLR. PAS

6) Executable code for the POD location system, contained in the following files.

Geographic Data Initialization Programs - -

GDTINST1.EXE

GDTINST2.EXE

System Driver Programs --

LOCATE.BAT

DRIVER. EXE

System Solver Program --

SOLVER. EXE

Only a subset of this software is required for a user who just wants to run the system and not make any changes to it. See the user's manual for user software requirements and also for general hardware requirements.

Note: Reference to a tradename or product in this report does not imply endorsement by the National Institute of Standards and Technology. 
The POD location system requires the use of geographic data files obtained from Geographic Data Technology, Inc. (GDT). This data must be processed before it is distributed to the end user, in order to convert it to a useable format. The files GDTINST1.FOR and GDTINST2.FOR contain the source code for processing the GDT data. The use of these programs is described more completely in "Instructions for Preparing the IRS Post-ofDuty Location System for Distribution to District Offices".

The POD location system itself is written in two separate sections of code. One section is written in FORTRAN and contains the code for drawing maps and initializing location problems. It allows the user to display workload, set up a location problem, display a map of the solution, and create a report file. The second section is written in PASCAL and contains the code for solving a location problem. Data is passed between the two sections of code using files.

A batch file called LOCATE.BAT controls the flow of execution between the two sections of code. LOCATE.BAT first checks to see if files called ERRORS.GKS and EXITFILE.BAT exist from a previous run. If so, it erases them. Then LOCATE.BAT enters a loop which passes control between the FORTRAN section (stored in DRIVER.EXE) and the PASCAL section (stored in SOLVER.EXE). DRIVER is always entered first. Then, depending on actions taken by the user, either SOLVER is entered or an exit is taken from the loop. In the first case, after SOLVER has completed, control returns to DRIVER and the loop repeats. In the second case, a file called EXITFILE.BAT is created by DRIVER. It contains instructions for deleting work files created during the run and for printing the report file. This new batch file is executed, and then LOCATE.BAT terminates.

The FORTRAN source code is contained in five files: DRIVER.FOR, GKSUTIL.FOR, IOSUBS.FOR, MAPSUBS.FOR and MENUSUBS.FOR. DRIVER.FOR contains the main program DRIVER along with most of the high-level subroutines. The other files contain various lower-level subroutines. A complete description of each subroutine is given in Section IV.

If a change is made in a subroutine, it must be recompiled by typing "PROFORT filename", where "filename" is the name of the source code file containing the changed routine. Then the program must be relinked by typing "LINK DRIVER GKSUTIL IOSUBS MAPSUBS MENUSUBS \GKS\PFGKS, ,NUL, $\backslash$ PROFORT \PROFORT \GKS \GKS \GKS \PFGKS /S:5000/X:350". (This assumes that the POD location system source files are stored in the current directory, Professional FORTRAN files are in a directory called \PROFORT, and GKS files are in a directory called \GKS. These path names may be changed.) The result is a new executable file called DRIVER.EXE.

The PASCAL solver routines are described in "The Internal Revenue Service Post-of-Duty Location Modeling System: Programmer's Manual for PASCAL Solver". 
This section contains a brief description of each of the FORTRAN routines. Information is provided on the purpose of the routine, the name of the file containing its source code, names of input and output variables, and names of programs called by the routine and programs which call it. The routines are listed in alphabetical order.

\section{SUBROUT INE ADU (IERR, ID , MAXIND, NINDEX, INDEX, MAXZPS , PNTR) :}

This subroutine reads the GDT zip code boundary file (in DIME format) and creates a binary direct-access adjacency file ADJACENT.id. For each zip code that appears in both the centroid file and the workload file, two records are created in the adjacency file. The first record contains the index of the zip code, the number of adjacent zip codes, and the zip code number. The second record contains a list of the adjacent zip code indices.

Note: This routine should be compiled with the Profort /B option because of the large size of the index array.

Source Code Location -GDTINST2.FOR

Input Variables ..

ID :

CHARACTER $* 2$

MAXIND: $\quad$ INTEGER $* 4$

Two-digit district identification number

MAXZPS :

Maximum allowed number of elements in INDEX array INTEGER $* 4$

Maximum allowed number of elements in PNTR array

Output Variables -.

\begin{tabular}{|c|c|}
\hline IERR: & INTEGER *4 \\
\hline & Error flag -. \\
\hline & IERR $=0$ for normal return \\
\hline & IERR $=1$ if an error was encountered \\
\hline NINDEX: & INTEGER *4 \\
\hline & Number of elements in index array \\
\hline $\operatorname{INDEX}(N I N D E X)$ & INTEGER *4 \\
\hline & $\begin{array}{l}\text { Array of } z \text { ip code index numbers -- } \\
\text { INDEX }(I)=J \diamond 0 \text { means that } z \text { ip code MINZIP+I-I }\end{array}$ \\
\hline PNTR (MAXZPS) : & $\begin{array}{l}\text { appears in both the centroid file and the } \\
\text { workload file and is assigned index number } \mathrm{J} \\
\text { INTEGER } 4 \text {. }\end{array}$ \\
\hline & $\begin{array}{l}\text { Array of pointers from index numbers to positions } \\
\text { of zip codes in centroid file }\end{array}$ \\
\hline
\end{tabular}

Programs Called ..

COMP

Calling Programs - -

GDTINST2 
SUBROUTINE BEEP:

This subroutine beeps the speaker.

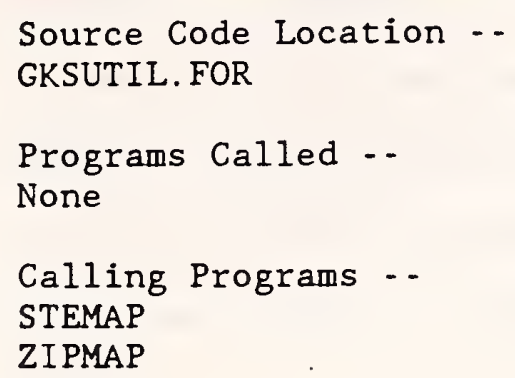

\section{SUBROUTINE BORDER (XMIN, XMAX, YMIN, YMAX):}

This subroutine draws a border around the current screen window. The provided window limits are slightly reduced before the border is drawn; otherwise some sides of the border may not appear because of roundoff error in the conversion from world coordinates to screen coordinates. (See the GKS manual for definitions of graphics terms.)

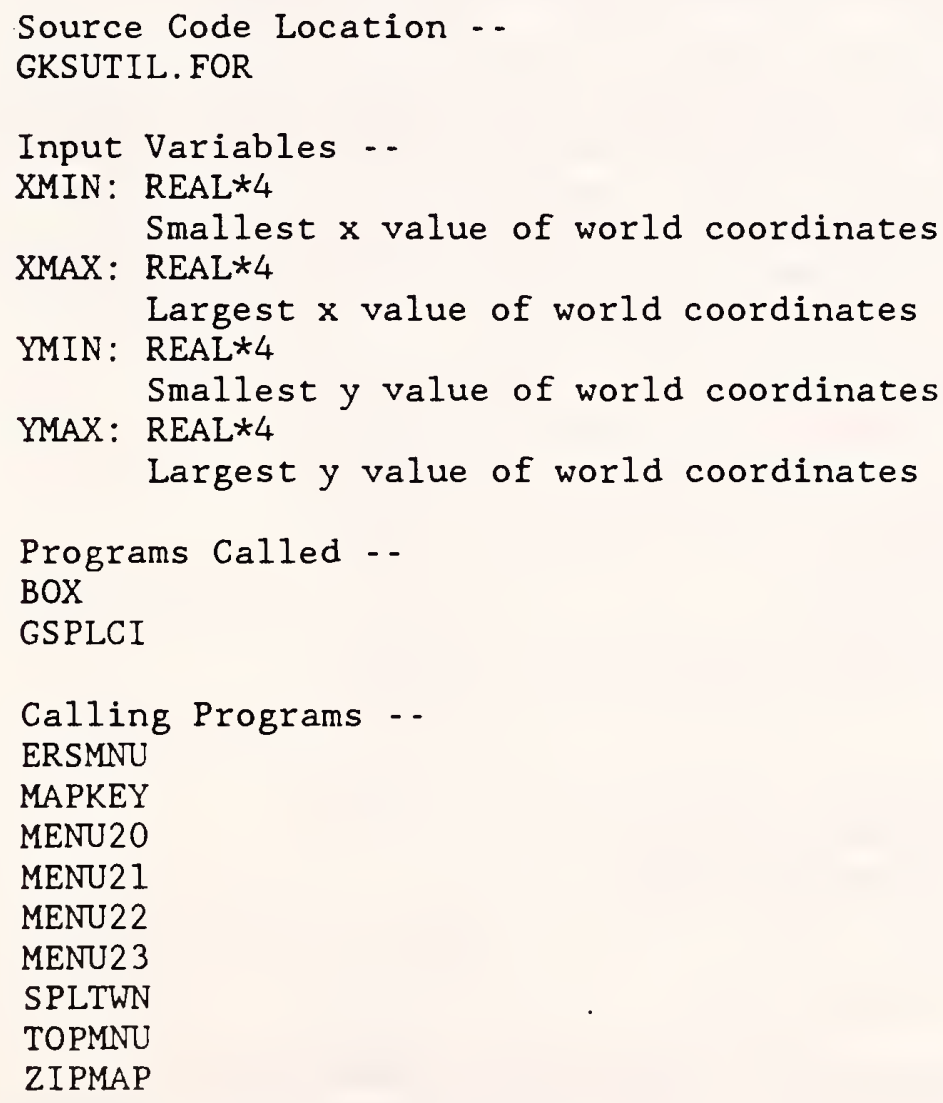

SUBROUTINE BOX(XMIN, XMAX, YMIN, YMAX):

This subroutine draws a box. (See the GKS manual for definitions of graphics terms.) 


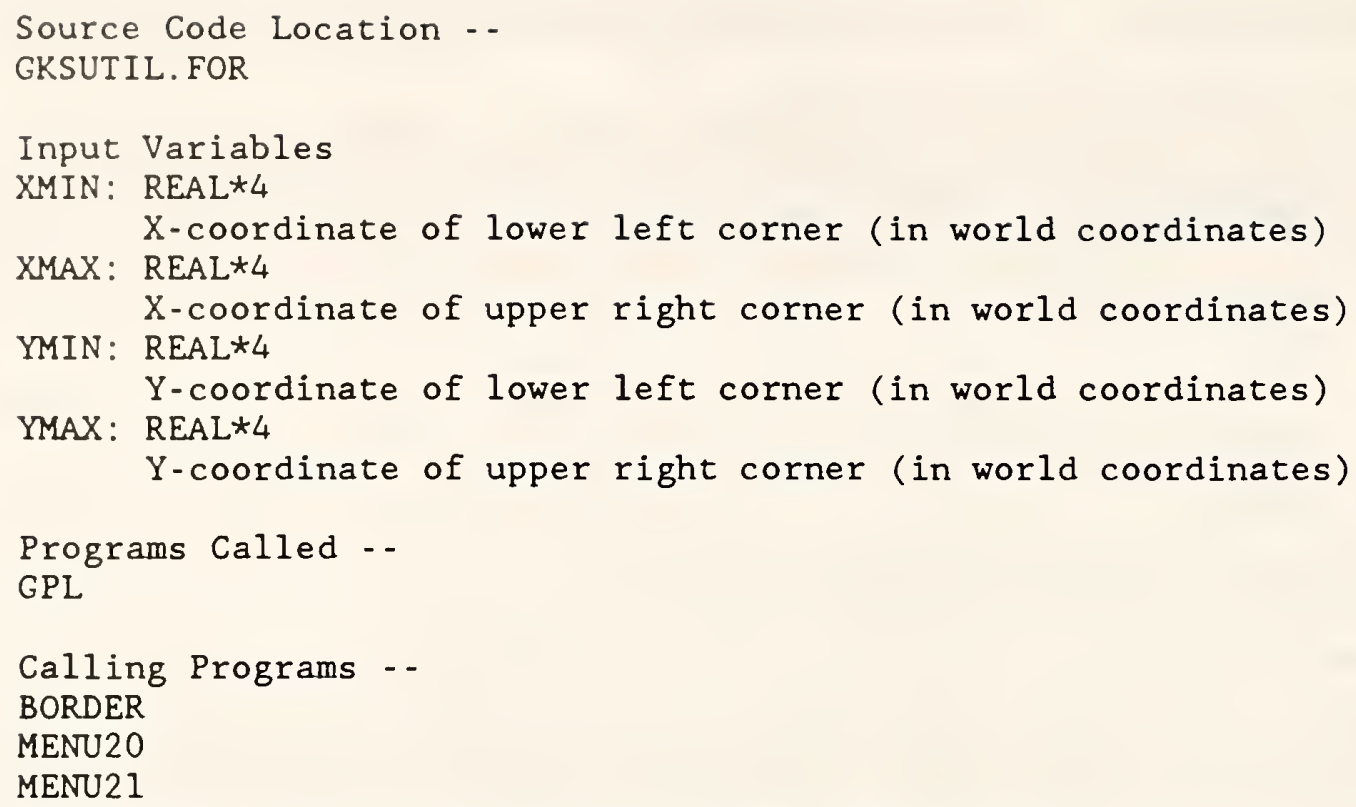

SUBROUTINE CENSRT (IERR, ID , MAXM , M, XCENT, YCENT , INDEX , PNT , ZIP5) :

This subroutine reads the centroid file CENTROID.id and calls a heapsort program to sort the centroids according to increasing $\mathrm{x}$ and $\mathrm{y}$ coordinates. (This is done to speed up the process of searching for zip codes on a map. It also speeds up the drawing of maps.) Arrays are set up to store the following information from the file: centroids, pointers to the zip code boundary file, zip code index numbers, and five-digit zip code numbers. This subroutine is executed whenever the program DRIVER is entered.

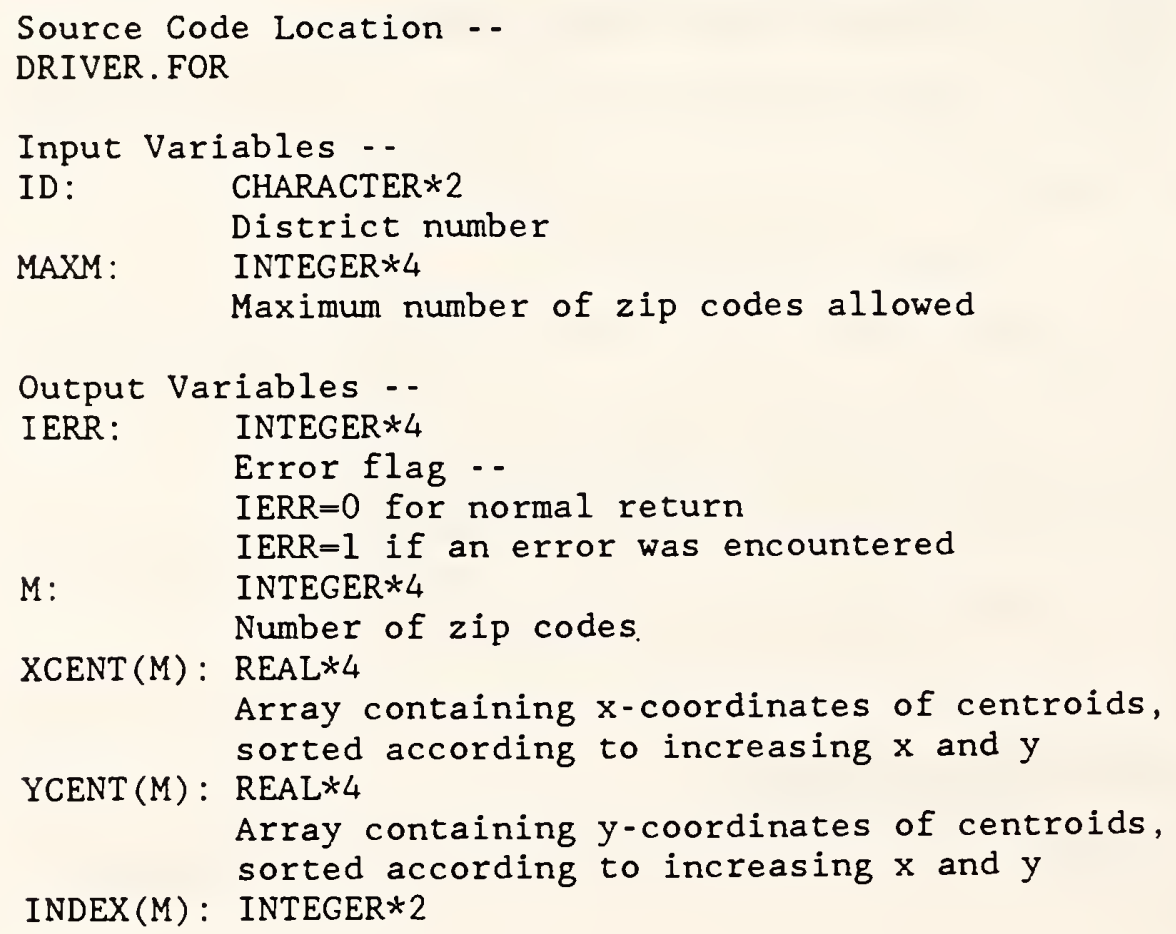




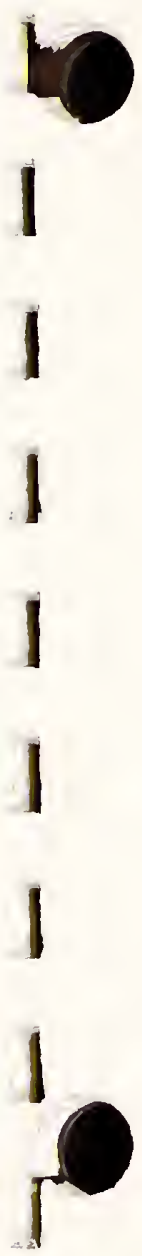

$\operatorname{PNT}(M): \quad$ INTEGER $* 2$

Zip code index array -.

INDEX(I) is the original index of the zip code with centroid (XCENT(I), YCENT(I)) before sorting

Pointer array -.

PNT(I) points to the beginning of information on the zip code with centroid (XCENT(I), YCENT(I)) in the zip code boundary file

ZIP5(M): INTEGER *4

Array of five-digit zip codes, in original sequential order

Programs Called .-

PAUSE

SORT

Calling Programs -.

DRIVER

\section{SUBROUTINE CENTRD (IERR, ID, NZIPS , ZIP5, PNTR, NCENT) :}

This subroutine reads the GDT zip code inventory file and creates a binary direct-access centroid file CENTROID.id. Zip codes with zero area (point zips) are not included in the centroid file. A pointer is included with each centroid which points to the corresponding zip code in the zip code boundary file ZIPCODE.id. A post office name file PONAMES.id is also created, listing each $z i p$ code and its name.

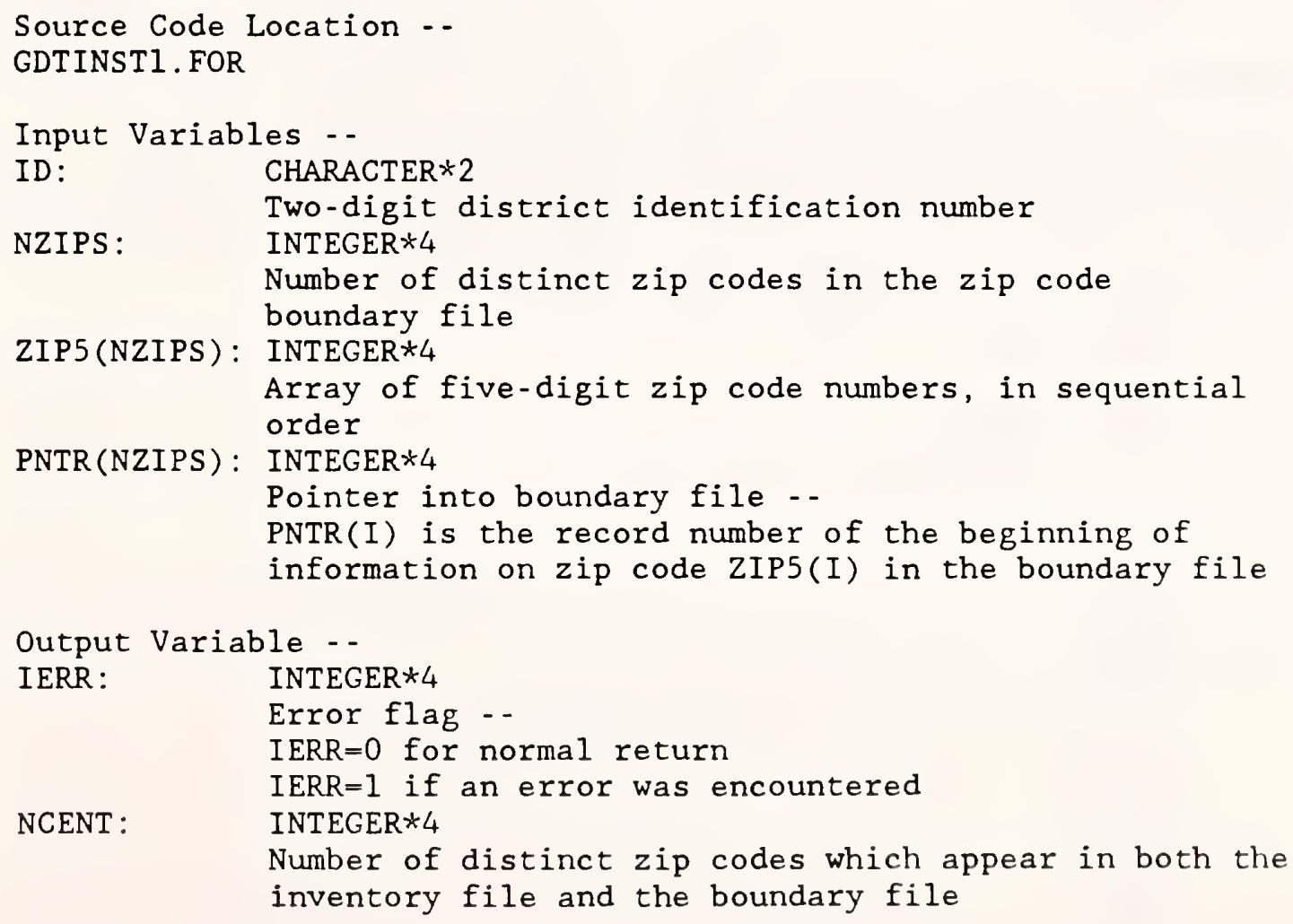

Programs Called - - 
Calling Programs -.

GDTINST1

SUBROUTINE CHOICE (WKID, CHDNR):

This subroutine initializes choice mode (function keys). To use the function keys, call GRQCH ("Request Choice"). (See the GKS manual for definitions of graphics terms.)

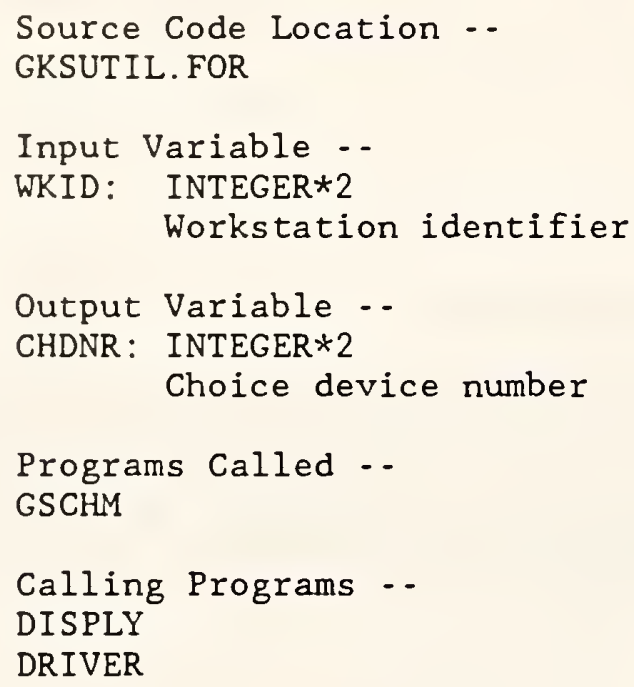

\section{SUBROUTINE CLSGKS (WKID):}

This subroutine closes GKS and resets the screen mode for text. (This requires the presence of ANSI.SYS in the CONFIG.SYS file. See the GKS manual for definitions of graphics terms.)

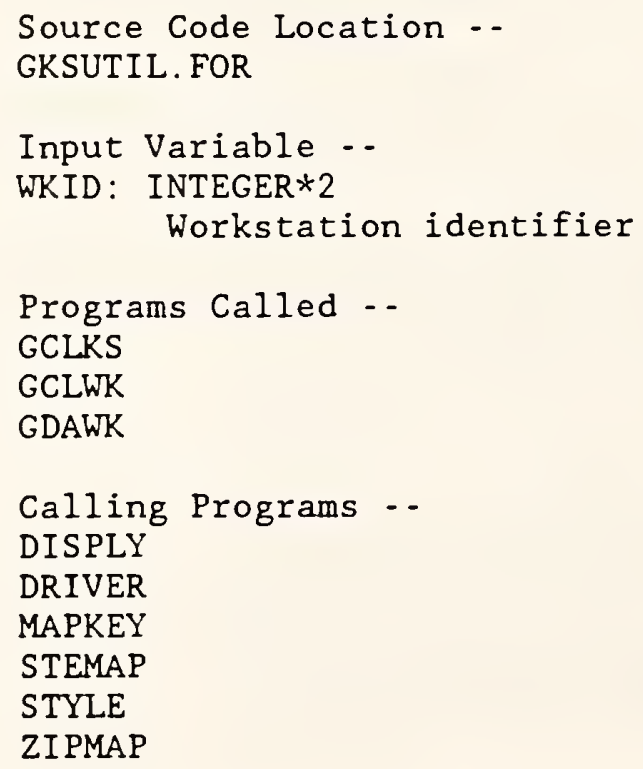




\section{SUBROUTINE COMP (IERR, ID , MINZIP, MAXIND, NINDEX, INDEX, MAXZPS, PNTR) :}

This subroutine compares zip codes in the centroid file with zip codes in the workload file. It assigns an index number to each zip code which appears in both files. It also creates a file COMPARE.id listing $z$ ip codes which appear in only one of the files.

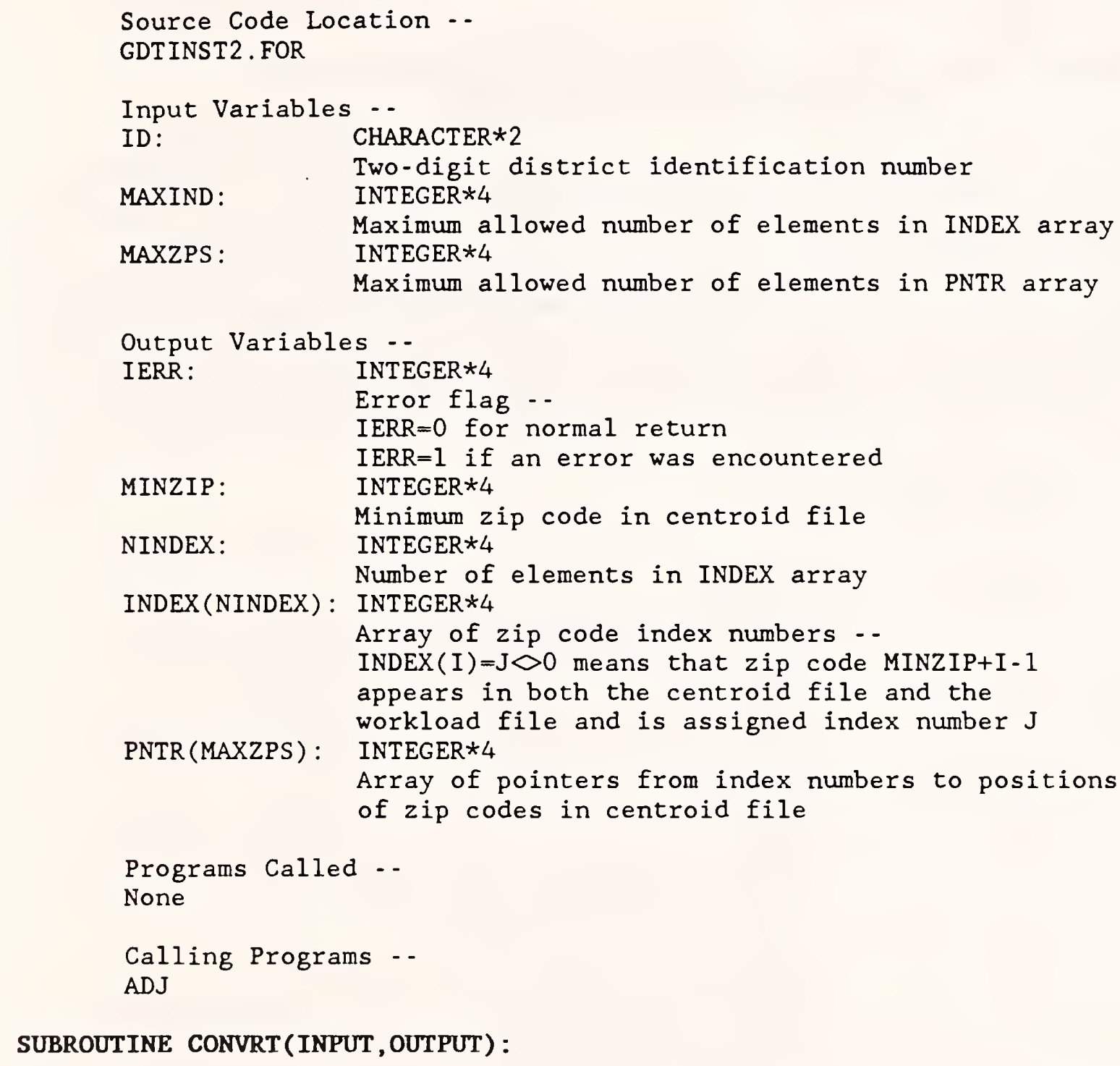

This subroutine converts a one- or two-digit integer into a two-character string (used for printing out the date and time).

Source Code Location --

IOSUBS . FOR

Input Variable - -

INPUT: INTEGER *2

Integer between 0 and 99 
Output Variable - -

OUTPUT: CHARACTER $* 2$

Two-character string version of input integer

Programs Called .-

None

Calling Programs -.

REPFIL

FUNCTION COSTFN (NCLASS, SWITCH, WRK, IRSWT, IRSFCT, TXPWT, TXPFCT, MILCST , TRVDIF, DIST, SQFCST , SQFT) :

This function calculates the cost of assigning a zip code to a POD site. The cost is made up of travel costs and office space costs. Travel costs are based on the Individual Master File (IMF) and Business Master File (BMF) workload generated by the zip code, its distance from the POD site, and the cost per mile. However, the cost may be weighted by several user-supplied factors. Office space costs are based on the amount of space required to handle the workload and the rental cost per square foot for office space at the POD site. For further information on how costs are computed, see "The Internal Revenue Service Post-of-Duty Location Modeling System: Final Report".

Source Code Location --

DRIVER.FOR

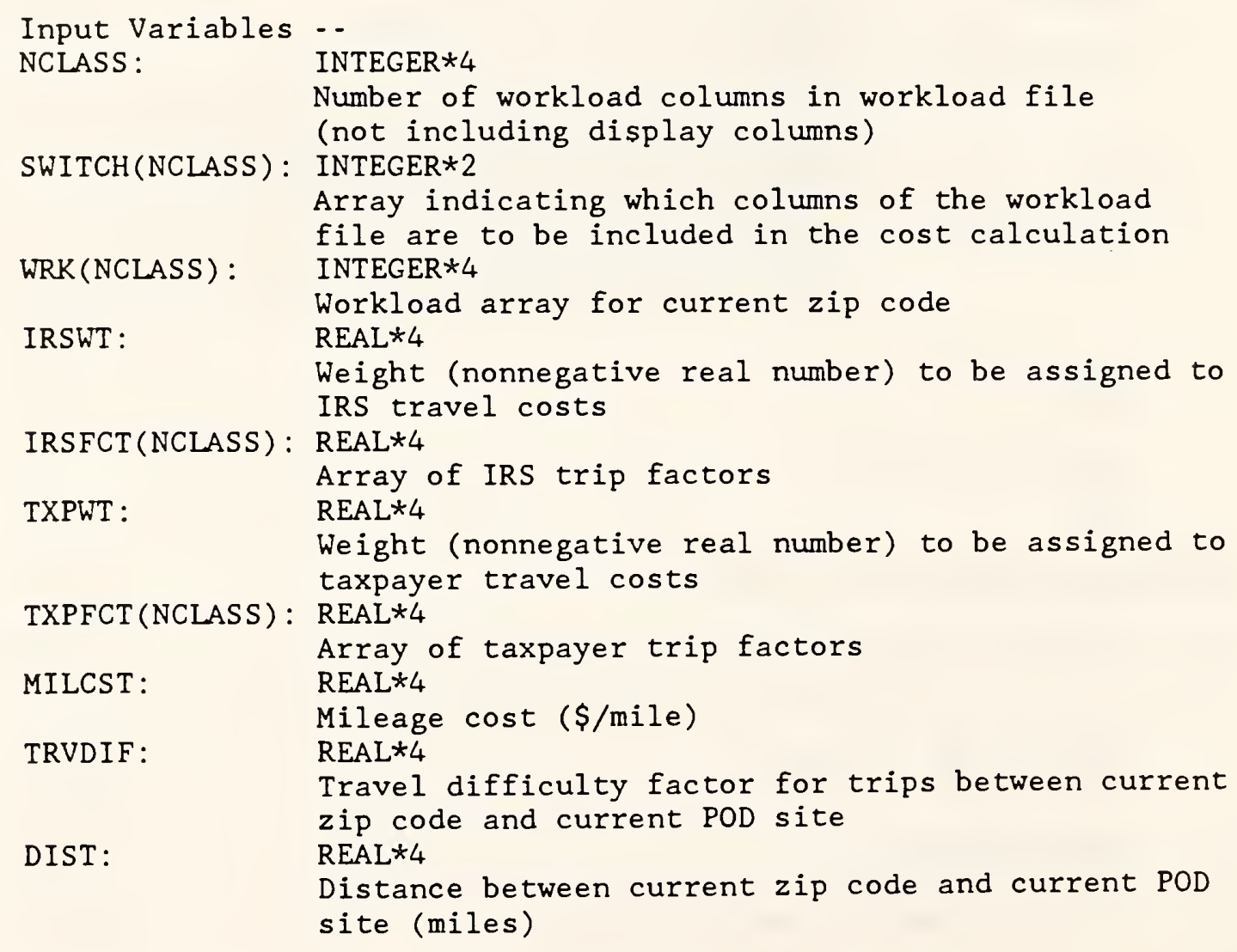




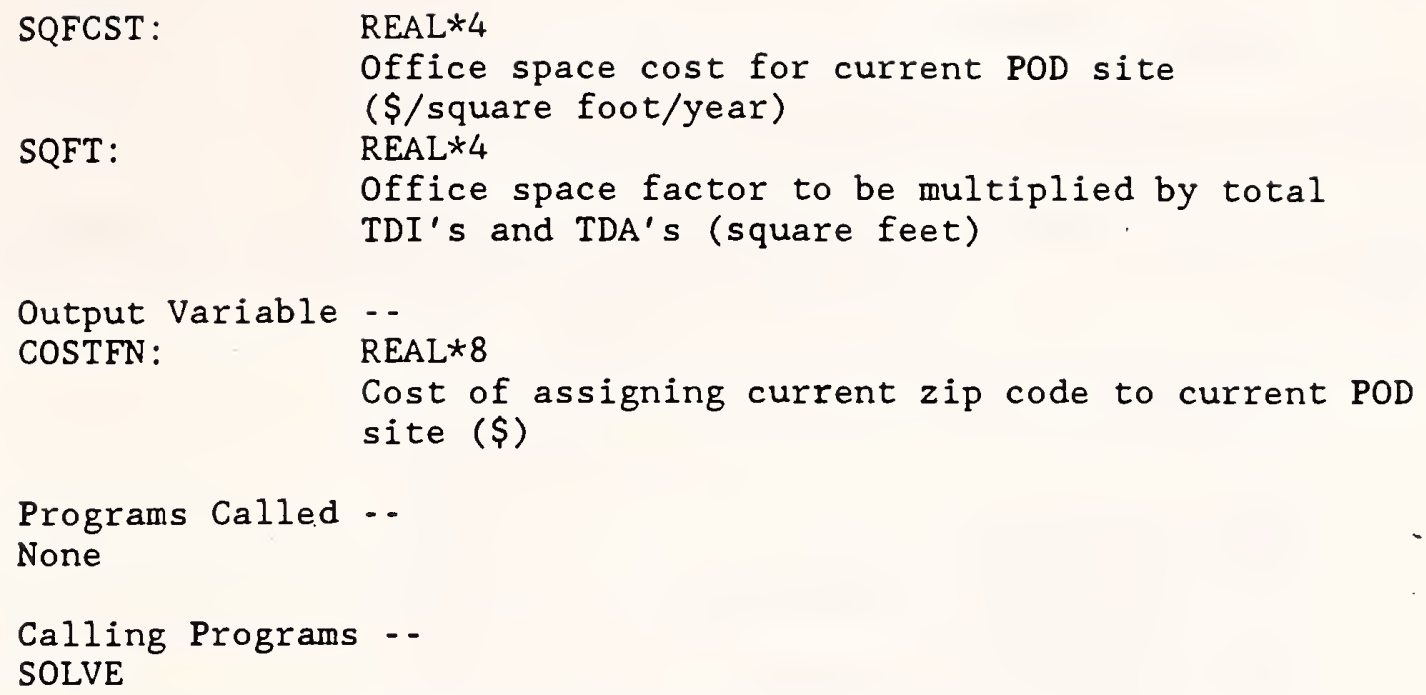

\section{SUBROUTINE CRSBOX (WKID, TRN, STAT, XIMIN, XMAX, YMIN, YMAX):}

This subroutine creates a cursor box. To use the cursor, first move the crosshair cursor to one corner of the desired box and enter this point. Then a rectangular cursor will appear which can be used to enter the opposite corner of the box. (See the GKS manual for definitions of graphics terms.)

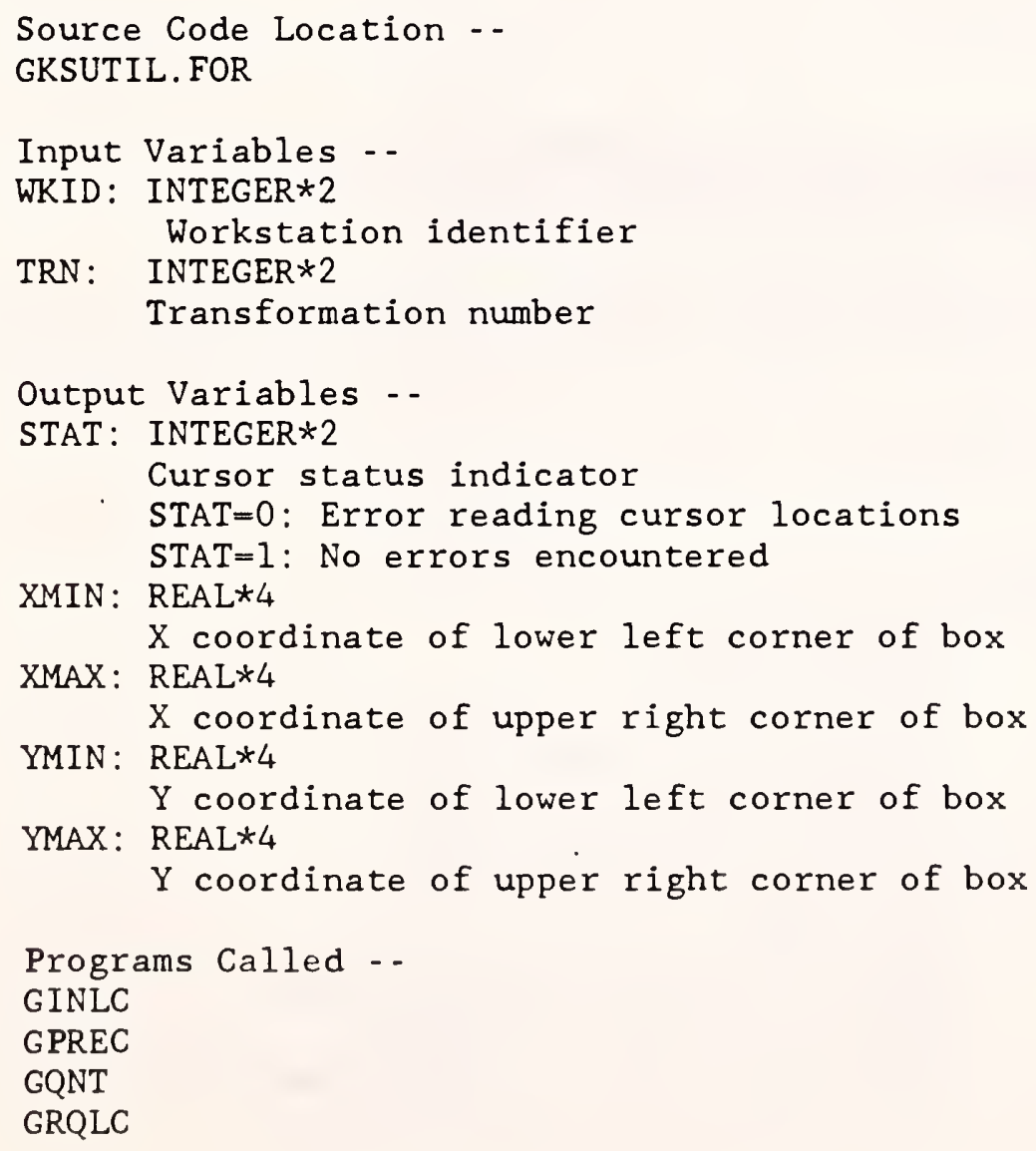


Calling Programs ..

ZOOMIN

SUBROUTINE CURSOR(WKID, TRN, IPX, IPY):

This subroutine initializes a cursor. To use the cursor, call GRQLC ("Request Locator"). (See the GKS manual for definitions of graphics terms.)

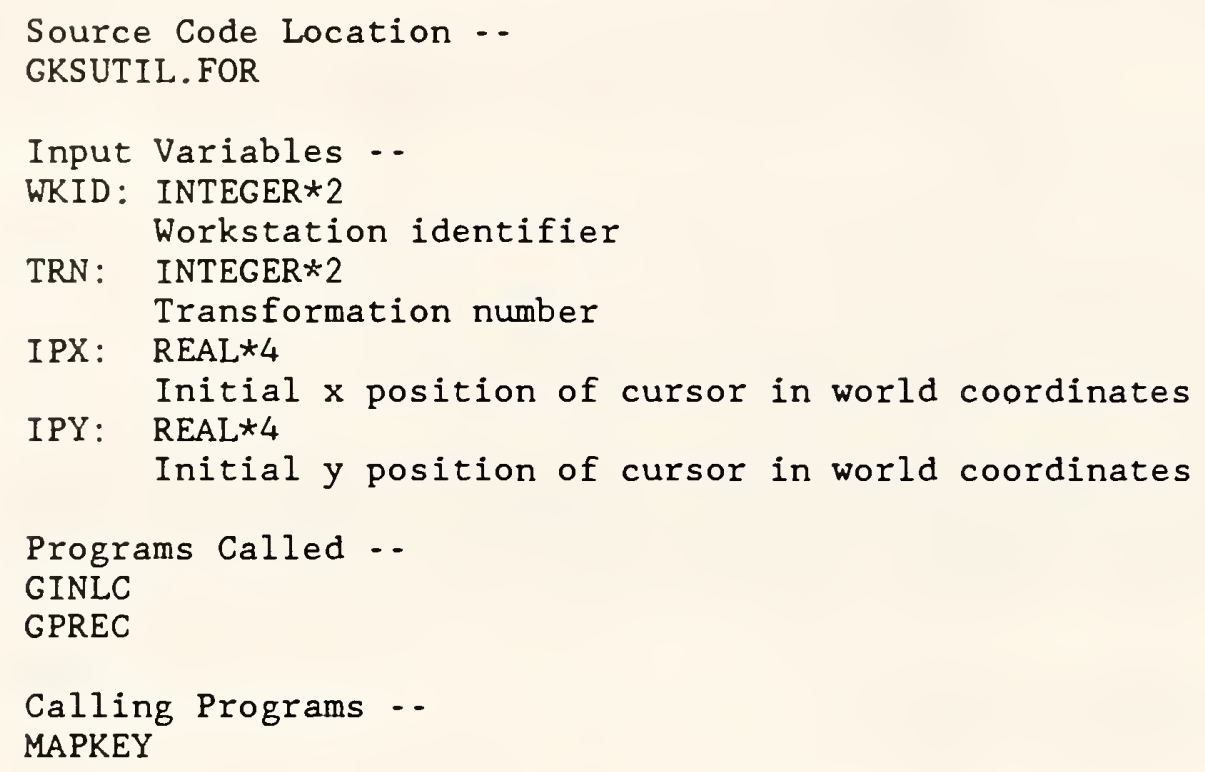

SUBROUTINE DISPLY (IERR, ID, PALETT, NCLRS, MENU, COLOR, MODIFY, M, XCENT, YCENT, INDEX, PNT, ZIPCLR, ZIP5, MAXPLT, XPLOT, YPLOT, LONG, PERM) :

This subroutine is the driver for the map-drawing routines. It uses GKS to display a state map and then allows the user to zoom in or modify the colors on the map.

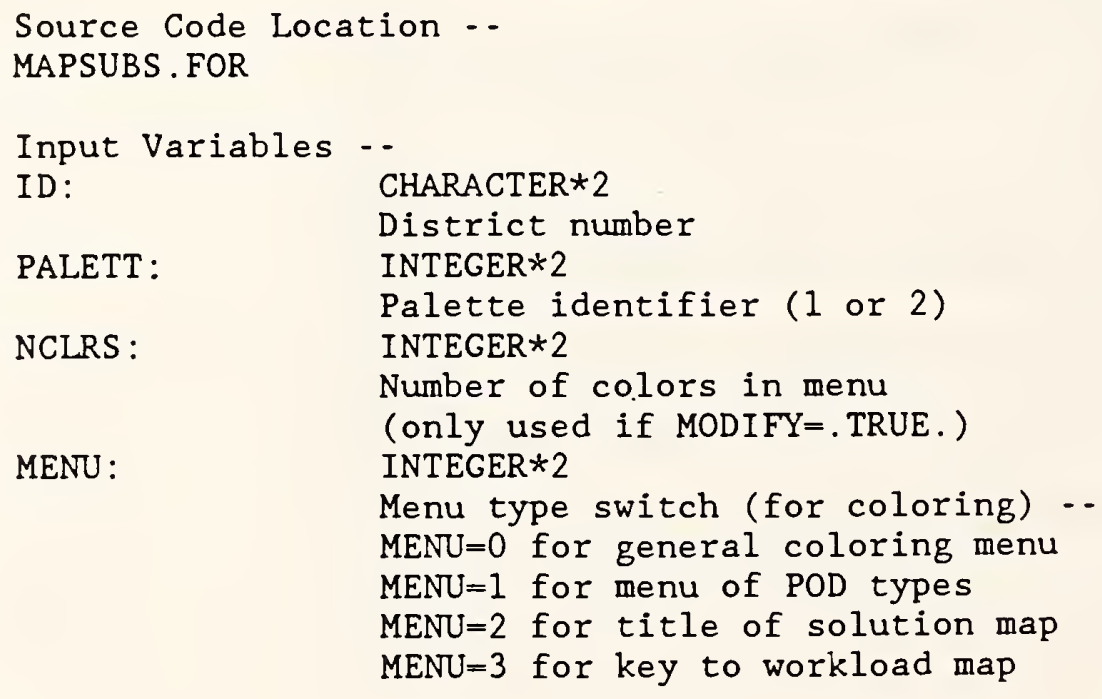




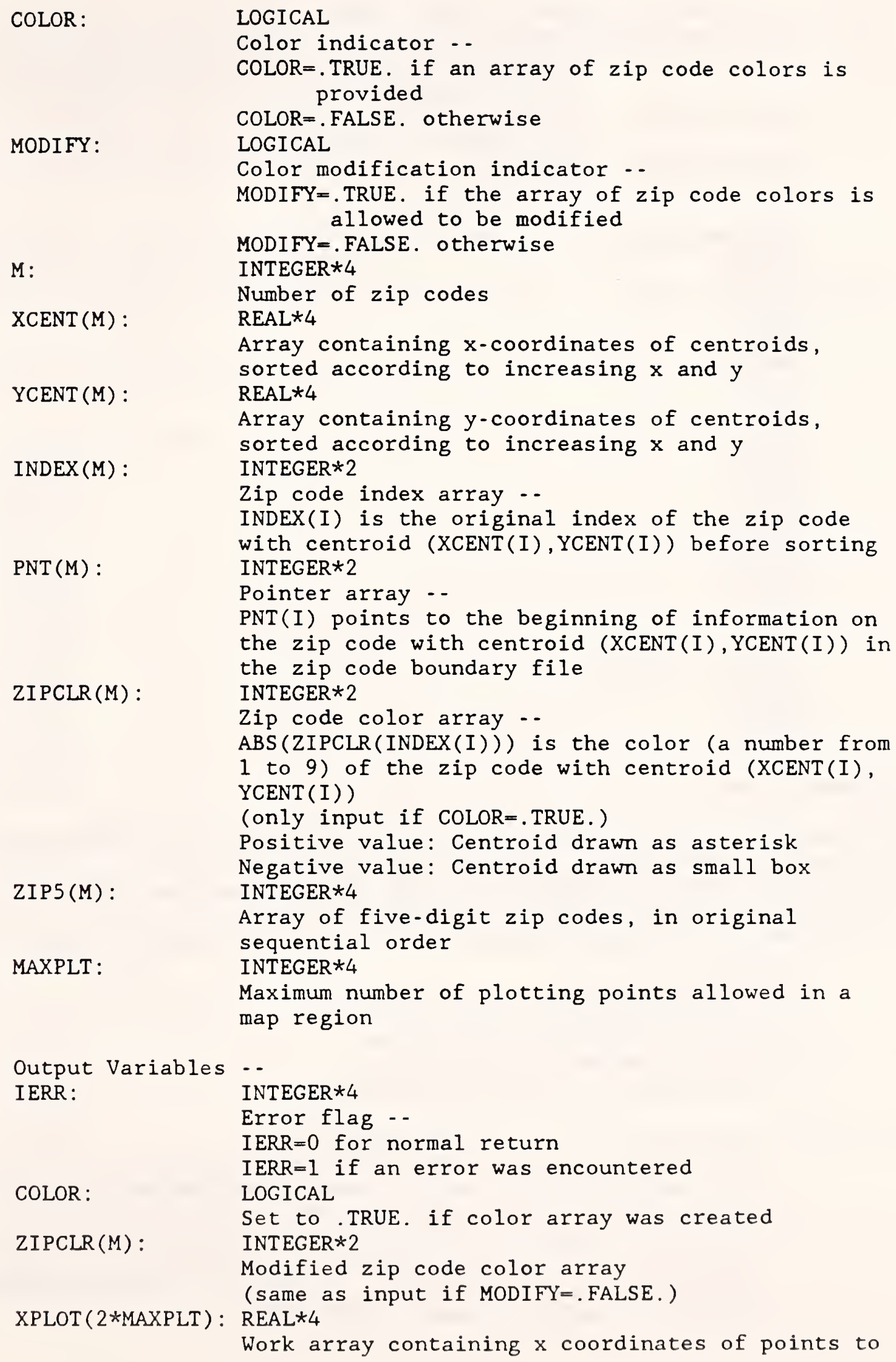




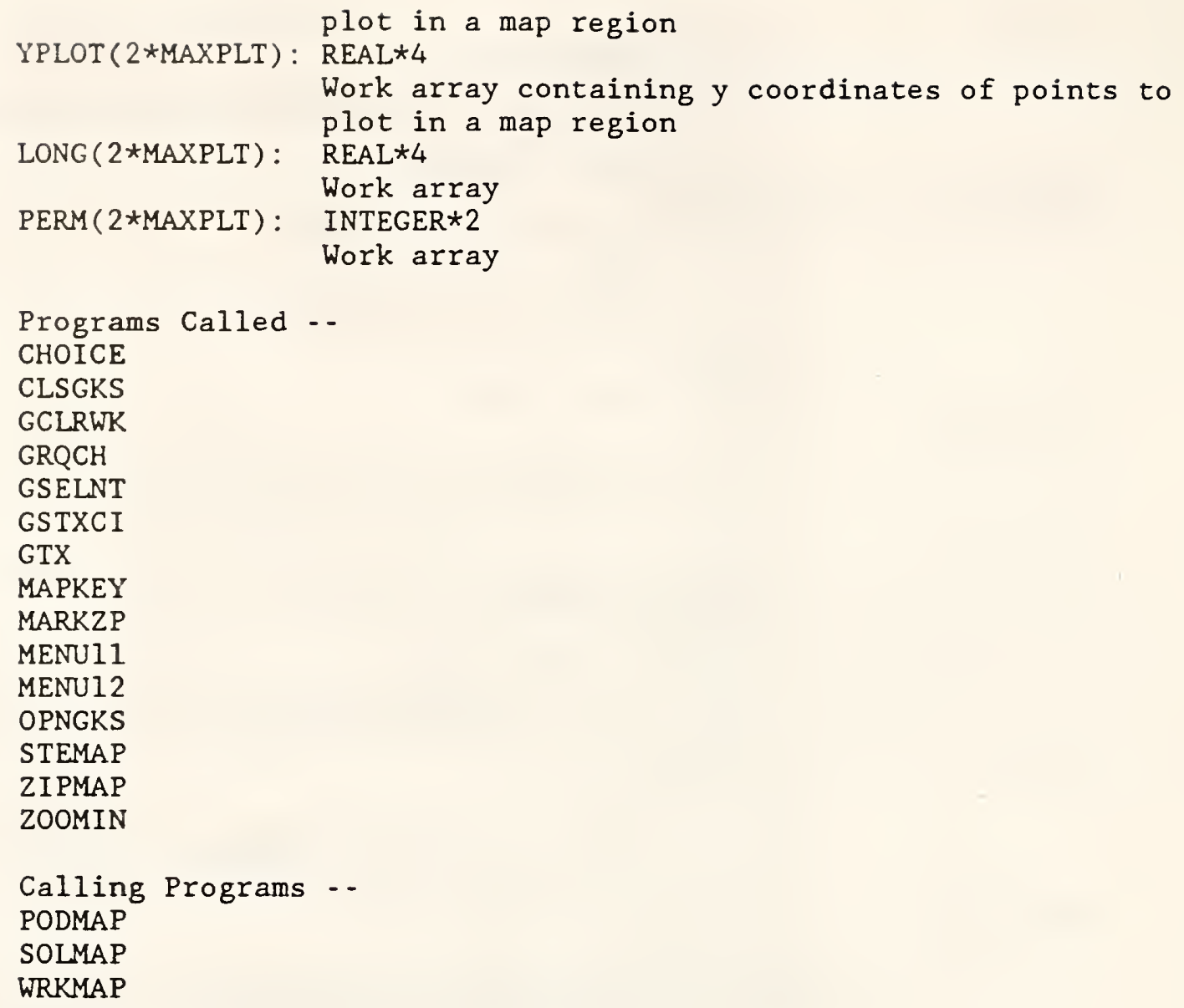

PROGRAM DRIVER:

This program is the driver for the IRS post-of-duty location system. It first writes a title page on the screen, initializes the report file, and sets up data structures for storing zip code information. Then it uses GKS to write the top-level menu on the screen and allows the user to choose which phase of a location problem to work on. The possible choices are:

(1) Exit.

(2) Display workload.

(3) Display or modify initial POD sites.

(4) Solve for optimal POD locations.

(5) Display optimal POD locations.

(6) Report zip code and staff assignments.

The driver terminates in one of two possible ways:

(1) The user chooses "Fl - Exit" from the top menu. In this case, a file called EXITFILE. BAT is created which signals the batch program LOCATE. BAT to leave the POD location system.

(2) The user chooses "F4 - Solve for optimal POD locations" from the top menu. In this case, LOCATE. BAT passes control to the solution procedure SOLVER.EXE. When the solution program is finished, control returns to DRIVER. EXE. 
The following data files must exist to run the package (the "id" extension should be replaced by the district identification number):
(1) OUTLINE.id: State outline file
(2) ZIPCODE.id: Zip code boundary file
(3) CENTROID.id: Zip code centroid file
(4) PODSITE.id: POD site and fixed cost file
(5) WORKLOAD.id: Workload file

(See the user's manual for information on the format of these files.)

The following common block is required by the graphics package GKS: COMMON /GRACOM/ SIZE, INTARY

SIZE is an INTEGER $* 4$ variable set equal to 9000 , and INTARY is an INTEGER*4 array of length 9000 .

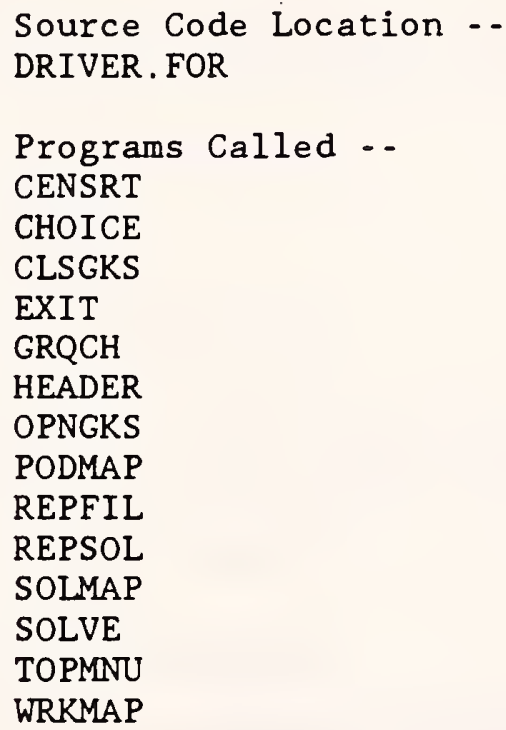

SUBROUTINE ERSMNU:

This subroutine erases a menu from the left window of the screen.

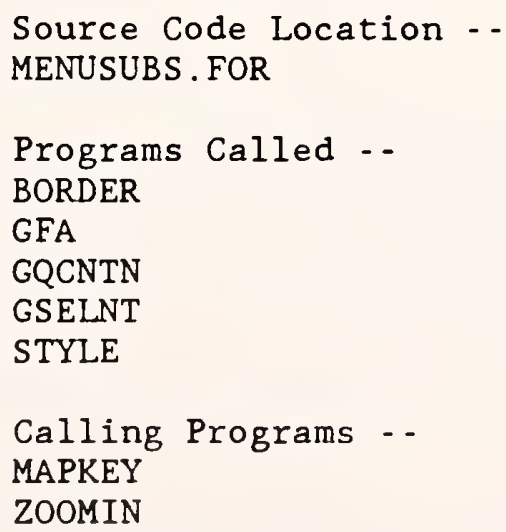

SUBROUTINE EXIT(ID): 
This subroutine is executed when the user chooses "Fl - Exit" from the top menu. It creates a batch file called EXITFILE.BAT which contains instructions for deleting work files created by the rest of the program. It also saves modifications to the PODSITE.id file and sends the report file to the 1 ine printer if the user requests it. After this subroutine has been completed, control returns to the batch file LOCATE.BAT, which checks to see if EXITFILE.BAT exists, executes it, and leaves the system.

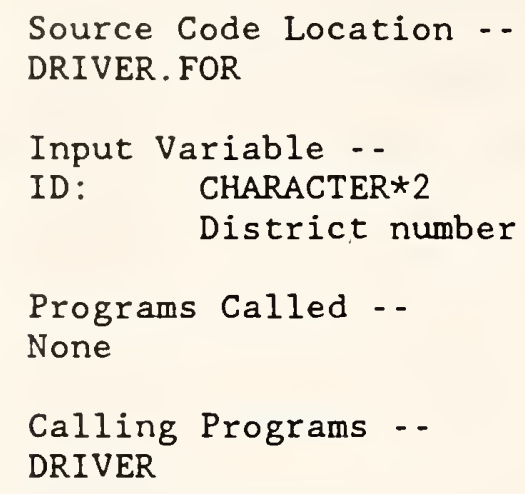

SUBROUTINE GACWK(WKID):

GKS routine -. "ACTIVATE WORKSTATION"

(See GKS manual for further information.)

Calling Programs - -
OPNGKS

FUNCTION GCDIST(LAT1, LONG1, LAT2, LONG2) :

This function calculates the great circle distance (in miles) between two points on the earth, given the latitude and longitude of each point. The formula was provided by Rand McNally.

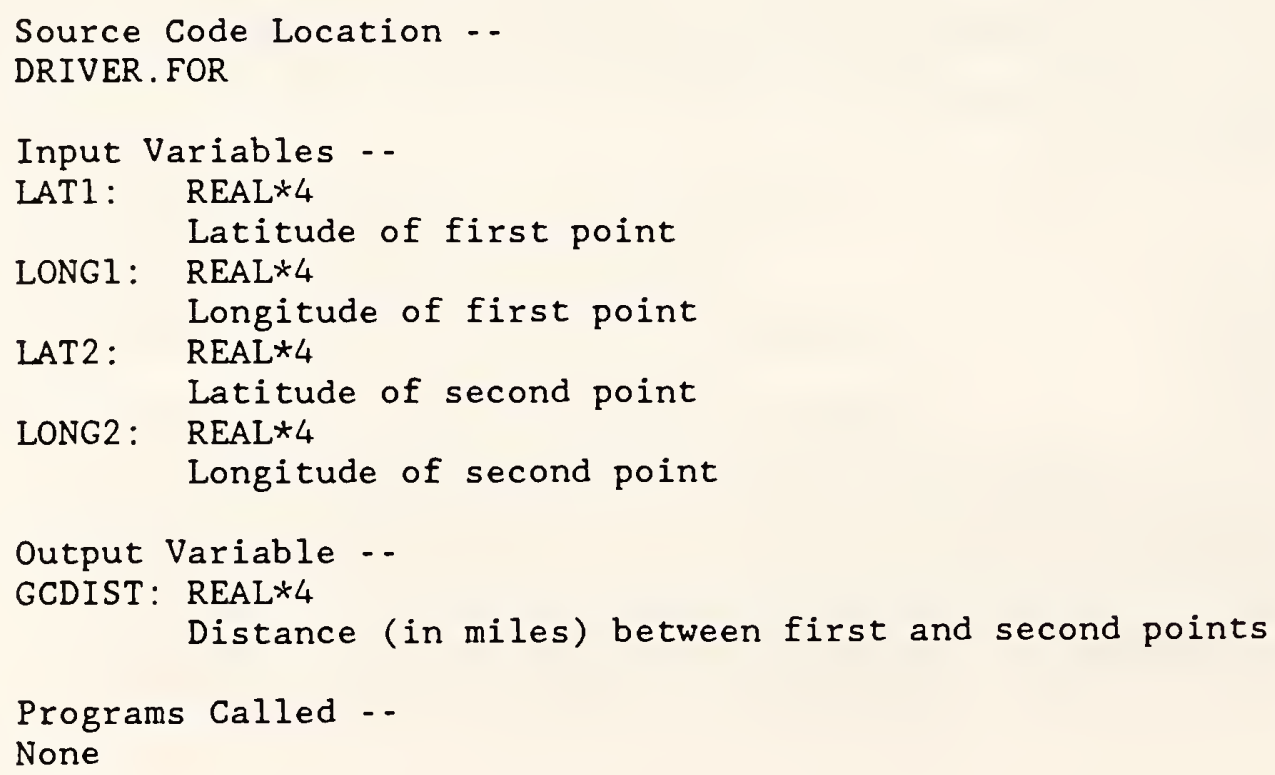


Calling Programs -.

SOLVE

SPLTWN

SUBROUTINE GCLKS:

GKS routine -- "CLOSE KERNEL SYSTEM"

(See GKS manual for further information.)

Calling Programs --

CLSGKS

SUBROUTINE GCLRWR (WRID, COFL) :

GKS routine -- "CLEAR WORKSTATION"

(See GKS manual for further information.)

Calling Programs - -

DISPLY

SPLTWN

ZOOMIN

SUBROUTINE GCLUK(WKID):

GKS routine -. "CLOSE WORKSTATION"

(See GKS manual for further information.)

Calling Programs --

CLSGKS

SUBROUTINE GDAWK(WKID):

GKS routine -- "DEACTIVATE WORKSTATION"

(See GKS manual for further information.)

Calling Programs --

CLSGKS

\section{PROGRAM GDTINST1:}

This program converts Geographic Data Technology (GDT) map data into a format to be used by the IRS POD location system. Following the use of this program, GDTINST2 should be run to complete the installation. This program should be used only by the person preparing the data files for distribution, not by the end user of the system.

Source Code Location - -

GDTINST1.FOR

Programs Called -.

CENTRD

OUTLIN

ZIPBND 
PROCRAM GDTINST2:

This program creates a zip code adjacency file using GDT's DIME format boundary file. It also compares zip codes in the IRS workload file with zip codes in the centroid file (created by GDTINSTl), and creates a file listing any mismatches. This program should be used only by the person preparing the data files for distribution, not by the end user of the system.

Note: This program should be compiled with the Profort / B option.

Source Code Location --

GDTINST2.FOR

Programs Called ..

ADJ

SUBROUTINE GEOFAC(DIFZIP,DIFPOD, DIFFAC, K1, NREC, ID) :

This subroutine allows the user to enter factors indicating the degree of difficulty of travel between a $z$ ip code and a POD site. The values are stored in the file DIFFACT.id.

Source Code Location --

IOSUBS . FOR

Input Variables -.

Kl: $\quad$ INTEGER*4

ID: $\quad$ Maximum num

District number

Output Variables -.

DIFZIP(NREC): INTEGER*4

five-digit zip code array for use with travel difficulty factors

DIFPOD (NREC): INTEGER*4

POD $z$ ip code array for use with travel difficulty

factors

DIFFAC (NREC): REAL*4

Array of travel difficulty factors - -

DIFFAC(I) is the factor associated with $z$ ip code DIFZIP(I) and POD site DIFPOD(I)

NREC: $\quad$ INTEGER $\times 4$

Number of non-unit travel difficulty factors

Programs Called ..

READBF

Calling Programs --

SOLVE

SUBROUTINE GETDAT (IYEAR, IMONTH, IDAY):

Professional FORTRAN routine -- "GET DATE" 
(See Professional FORTRAN manual for further information.)

Calling Programs -.

REPFIL

SUBROUTINE GETTIM (IHOUR, IMINUTE, ISECOND, IHUNDREDSECOND) :

Professional FORTRAN routine - - "GET TIME"

(See Professional FORTRAN manual for further information.)

Calling Programs .-

REPFIL

SUBROUTINE GFA(N, PX, PY):

GKS routine -. "FILL AREA"

(See GKS manual for further information.)

Calling Programs --

ERSMNU

MAPKEY

MENU20

MENU21

MENU22

MENU23

ZIPMAP

SUBROUTINE GINKS (NTYPES, WNAMES, WTYPES, VERNUM) :

GKS routine -. "INITIALIZE GKS"

(See GKS manual for further information.)

Calling Programs - -

OPNGKS

SUBROUTINE GINLC (WKID , LCDNR, TNR, IPX, IPY , PET , XMIN , XMAX, YMIN, YMAX, LDR, DATREC) :

GKS routine - - "INITIALIZE LOCATOR"

(See GKS manual for further information.)

Calling Programs -.

CRSBOX

CURSOR

SUBROUTINE GINST (WKID , STDNR, ISTR, PET , XMIN, XMAX, YMIN, YMAX, BUFLEN, INIPOS , LDR, DATREC) :

GKS routine - - "INITIALIZE STRING"

(See GKS manual for further information.)

Calling Programs - -

MARKZP

ZOOMIN 
SUBROUTINE GOPKS (ERRFIL, SIZE):

GKS routine - - "OPEN KERNEL SYSTEM"

(See GKS manual for further information.)

Calling Programs ..

OPNGKS

SUBROUTINE GOPWK(WKID, CONID, WTYPE):

GKS routine -. "OPEN WORKSTATION"

(See GKS manual for further information.)

Calling Programs .-

OPNGKS

SUBROUTINE GPL(N, PX, PY):

GKS routine -- "POLYLINE"

(See GKS manual for further information.)

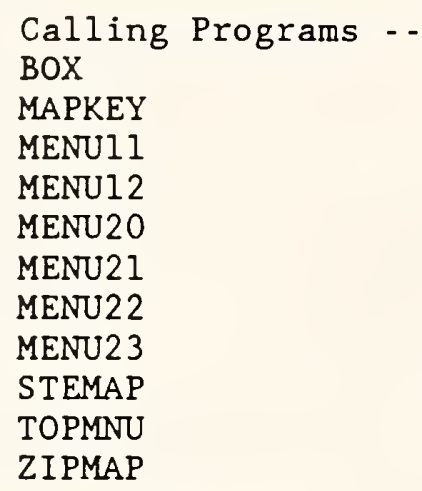

SUBROUTINE GPY(N, PX, PY):

GKS routine -. "POLYMARKER"

(See GKS manual for further information.)

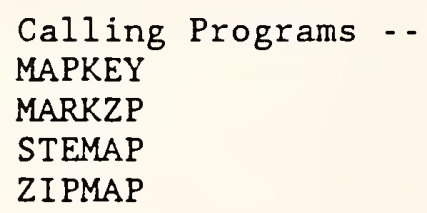

SUBROUTINE GPREC (IL, IA , RL, RA, SL, MSTR, STR, MIDR , ERRIN , LDR , DATREC) :

GKS routine -. "PACK DATA RECORD"

(See GKS manual for further information.)

Calling Programs --

CRSBOX

CURSOR 
SUBROUTINE GQCF (WTYPE, ERRIND, NCOLI, COLA, NPCI) :

GKS routine -- "INQUIRE COLOR FACILITIES"

(See GKS manual for further information.)

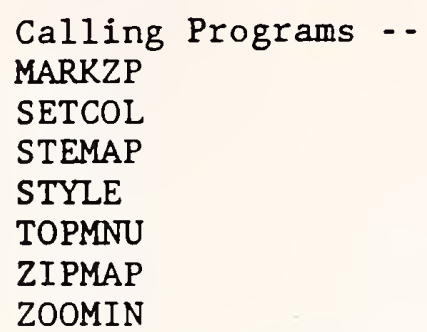

SUBROUTINE GQCNTN(ERRIND, CTNR):

GKS routine -. "INQUIRE CURRENT NORMALIZATION TRANSFORMATION NUMBER" (See GKS manual for further information.)

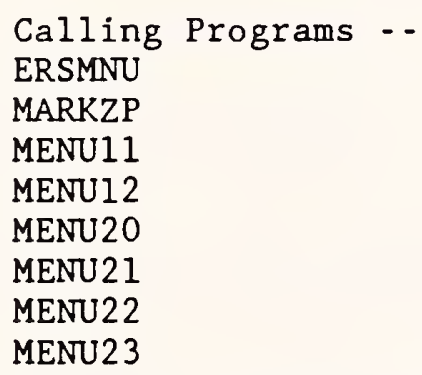

SUBROUTINE GQMDS (WTYPE, ERRIND, DCUNIT , RX, RY, LX, LY) :

GKS routine -- "INQUIRE MAXIMUM DISPLAY SURFACE SIZE"

(See GKS manual for further information.)

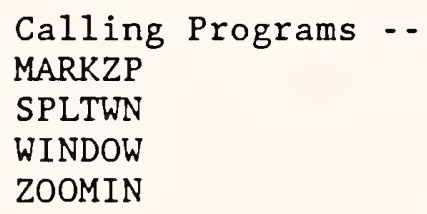

SUBROUTINE GQNT (TNR, ERRIND, WINDOW, VIEWPT) :

GKS routine -- "INQUIRE NORMALIZATION TRANSFORMATION"

(See GKS manual for further information.)

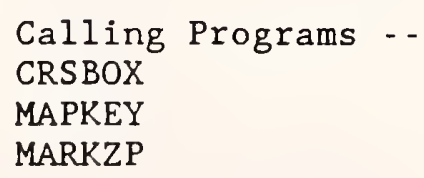

SUBROUTINE GQTXX (WKID , PX, PY , STR , ERRIND , CPX , CPY , TXFXPX , TXEXPY):

GKS routine - - "INQUIRE TEXT EXTENT"

(See GKS manual for further information.) 
Calling Programs - .

SPLTWN

ZIPMAP

SUBROUTINE GRQCH (WKID, CHDNR, STAT , CHNR) :

GKS routine -. "REQUEST CHOICE"

(See GKS manual for further information.)

Calling Programs - -

DISPLY

DRIVER

MAPKEY

SUBROUTINE GRQLC (WKID, LCDNR, STAT , TNR, PX, PY) :

GKS routine -. "REQUEST LOCATOR"

(See GKS manual for further information.)

Calling Programs - -

CRSBOX

MAPKEY

SUBROUTINE GRQST (WKID, STDNR, STAT , LOSTR, STR):

GKS routine -. "REQUEST STRING"

(See GKS manual for further information.)

Calling Programs --

MARKZP

ZOOMIN

SUBROUTINE GSCHM (WKID, CHDNR, MODE, ESW) :

GKS routine -- "SET CHOICE MODE"

(See GKS manual for further information.)

Calling Programs .-

CHOICE

SUBROUTINE GSCR(WKID, CI , CR , CG , CB) :

GKS routine - - "SET COLOR REPRESENTATION"

(See GKS manual for further information.)

Calling Programs -.

SETCOL

SUBROUTINE GSELNT(TNR):

GKS routine -. "SELECT NORMALIZATION TRANSFORMATION"

(See GKS manual for further information.)

Calling Programs - - 
DISPLY
ERSMNU
MAPKEY
MARKZP
MENU11
MENU12
MENU20
MENU21
MENU22
MENU23
SPLTWN
WINDOW
ZOOMIN

SUBROUTINE GSFACI (COLI) :

GKS routine - - "SET FILL AREA COLOR INDEX"

(See GKS manual for further information.)

Calling Programs --

STYLE

SUBROUTINE GSFAIS (INTS) :

GKS routine -- "SET FILL AREA INTERIOR STYLE"

(See GKS manual for further information.)

Calling Programs - -

STYLE

SUBROUTINE GSFASI(STYLI) :

GKS routine - - "SET FILL AREA STYLE INDEX"

(See GKS manual for further information.)

Calling Programs - -

STYLE

SUBROUTINE GSMK(KTYPE) :

GKS routine - - "SET POLYMARKER TYPE"

(See GKS manual for further information.)

Calling Programs - -

MAPKEY

MARKZP

STEMAP

ZIPMAP

SUBROUTINE GSPLCI(COLI):

GKS routine -- "SET POLYLINE COLOR INDEX"

(See GKS manual for further information.) 


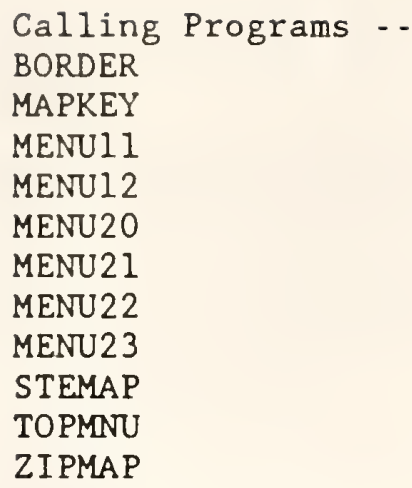

SUBROUTINE GSPACI(COLI):

GKS routine -. "SET POLYMARKER COLOR INDEX" (See GKS manual for further information.)

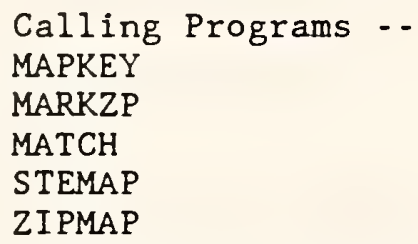

SUBROUTINE GSSTM(WKID, STDNR, MODE, ESW) :

GKS routine - - "SET STRING MODE"

(See GKS manual for further information.)

Calling Programs -.

MARKZP

SUBROUTINE GSTXCI (COLI):

GKS routine -. "SET TEXT COLOR INDEX"

(See GKS manual for further information.)

Calling Programs --

DISPLY

MAPKEY

MARKZP

MENU11

MENU12

MENU20

MENU21

MENU22

MENU23

TOPMNU

ZIPMAP

ZOOMIN

SUBROUTINE GSVP (TNR, XMIN, XMAX, YMIN, YMAX): 


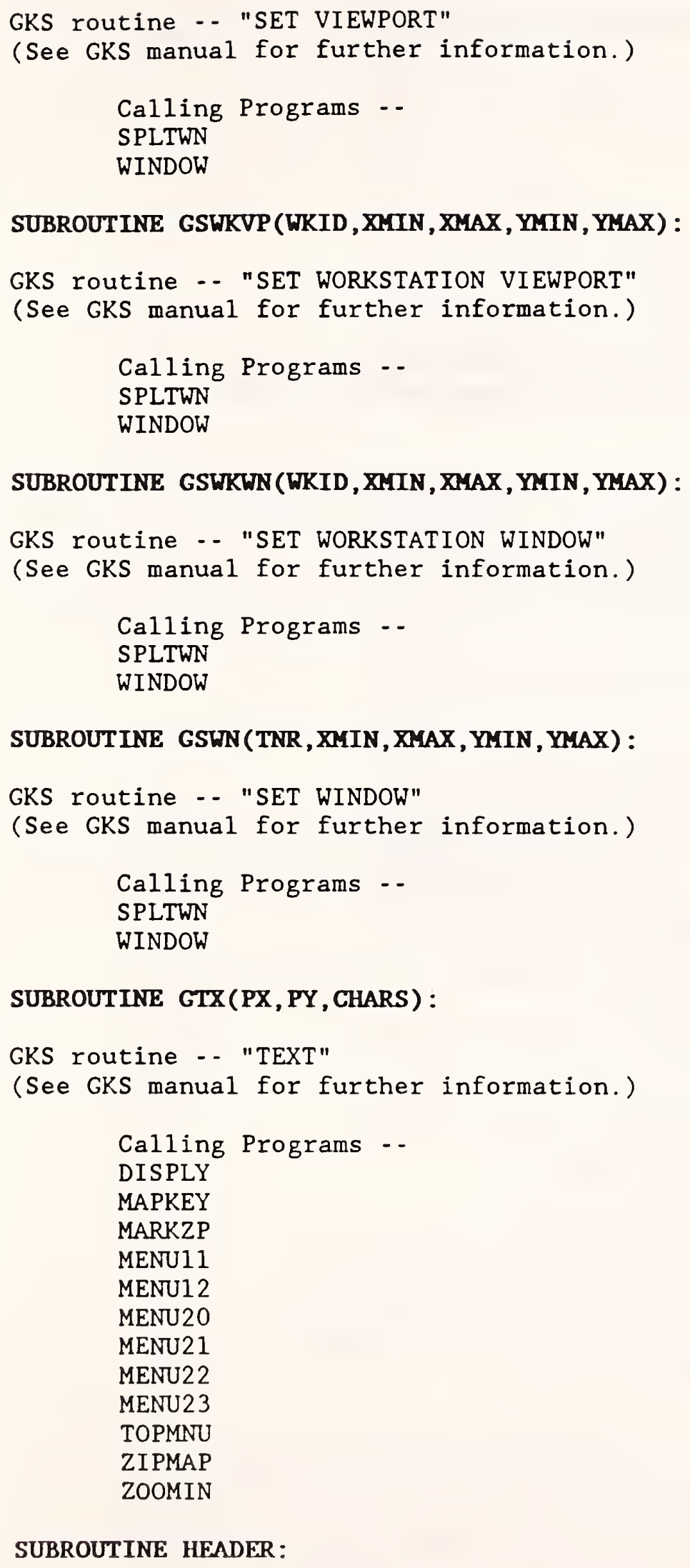

SUBROUTINE HEADER: 
This subroutine prints a title page on the screen when the user enters the system.

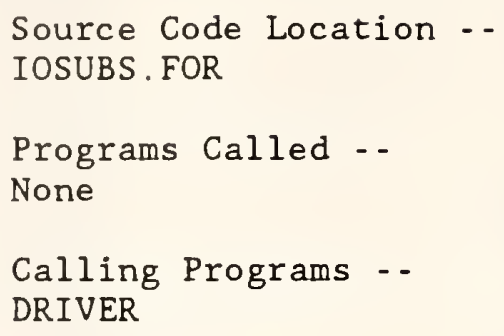

SUBROUTINE MAPKEY (IERR, MODIFY, TRN , PALETT, NCLRS, ID , MENU, MAXPLT,

I , XCENT, YCENT , INDEX, PNT , ZIPCLR, XPLOT, YPLOT, LONG , PERM) :

This subroutine displays a color key for the current zip code map. It allows the user to locate a zip code on the map with the cursor and have its five-digit number printed on the screen. (To do this, a search of the centroid array is done to find the closest centroid to the cursor position.) If the current map is for modifying POD sites, the routine also allows the colors of zip codes to be modified.

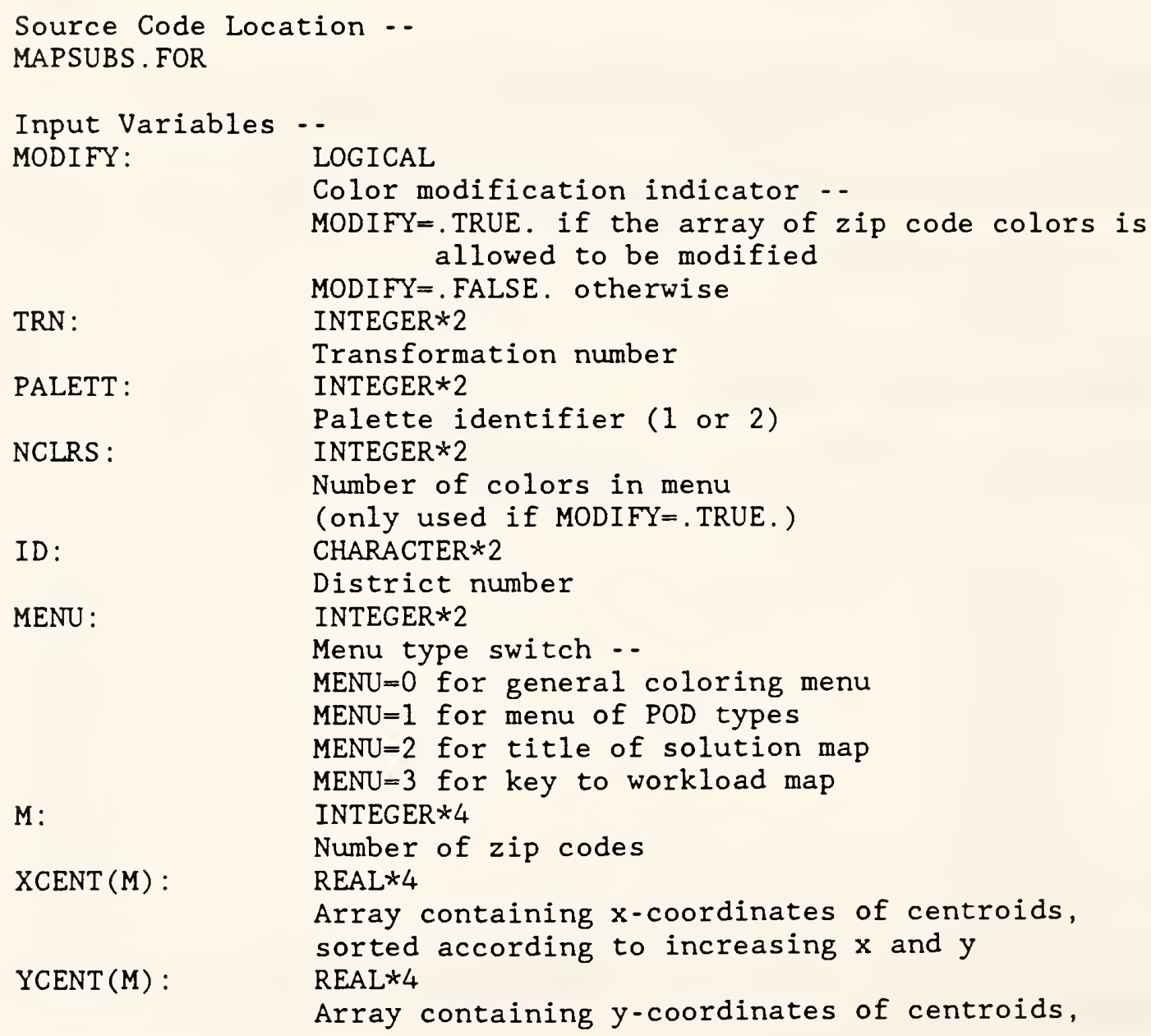




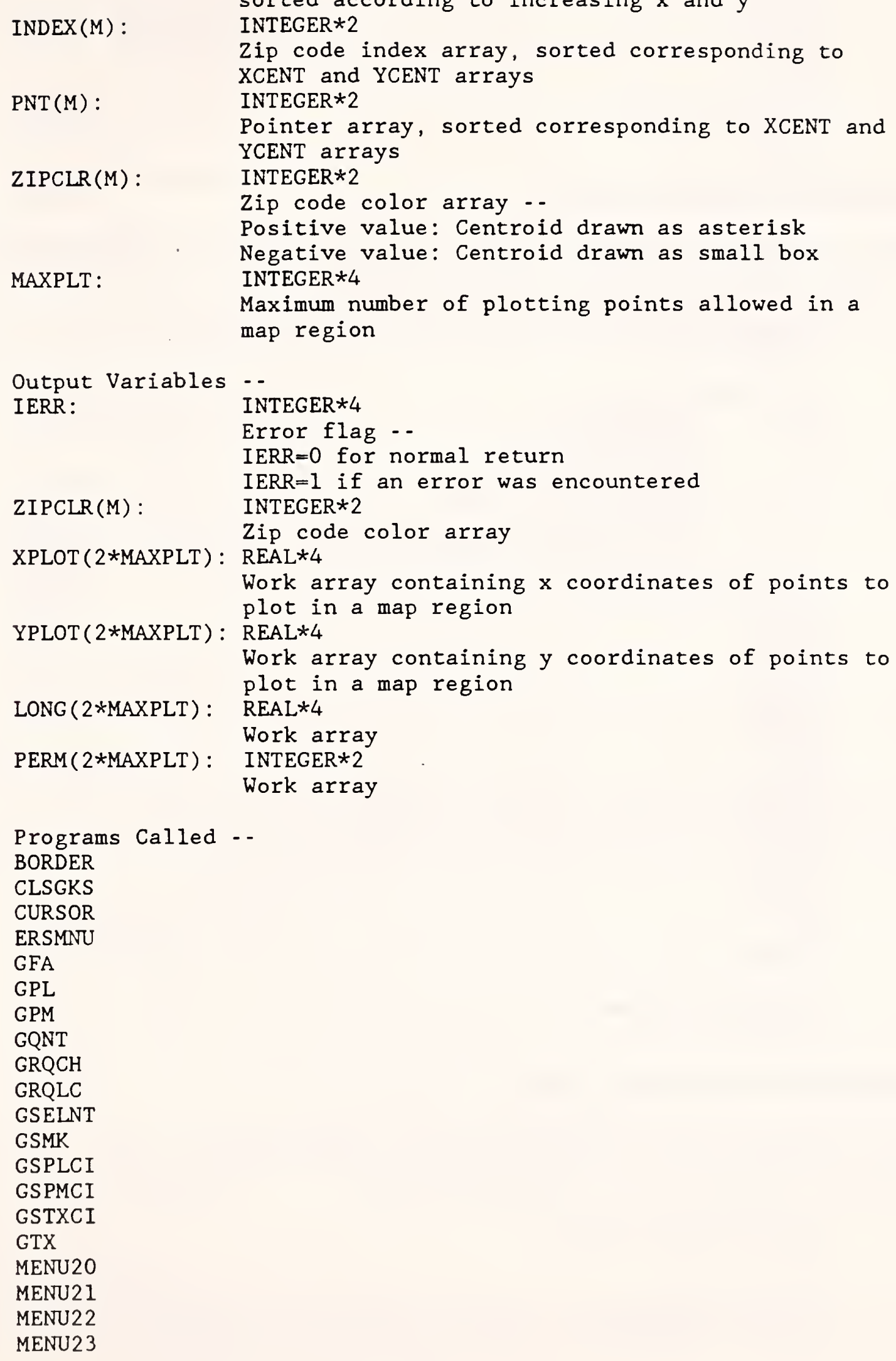


REVERS

SEARCH

STYLE

THIN

Calling Programs -.

DISPLY

SUBROUTINE MARKZP(ID, M, ZIP5):

This subroutine allows the user to type in a zip code number and have its location marked on the state outline map.

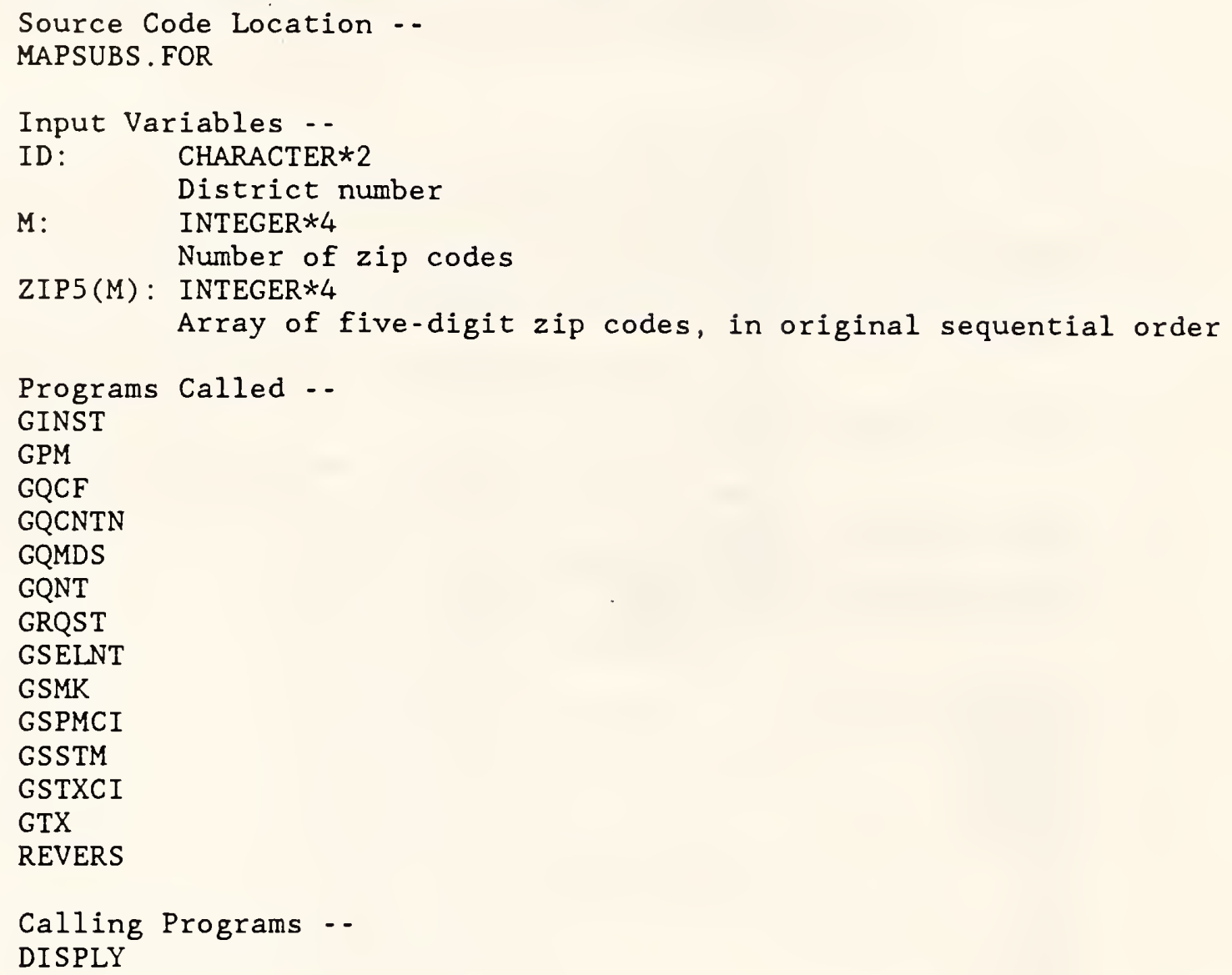

SUBROUTINE MATCH (PALETT, INDEX) :

This subroutine sets a polymarker color index which will match the corresponding fill area color index (for an EGA display only). (See the GKS manual for definitions of graphics terms.)

Source Code Location -GKSUTIL.FOR

Input Variables --

PALETT: INTEGER*2 


\author{
Palette identifier \\ INDEX: INTEGER*4 \\ Index (between 1 and 16) of fill area color
}

Programs Called .-

GSPMCI

Calling Programs --

STEMAP

\title{
SUBROUTINE MENU11:
}

This subroutine writes a menu of display options on the left side of the screen. It lists the meaning of the function keys after a state outline map has been drawn.

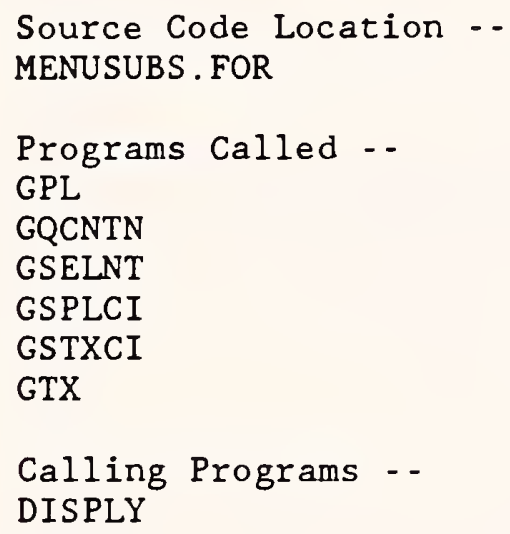

\section{SUBROUTINE MENU12:}

This subroutine writes a menu of display options on the left side of the screen. It lists the meaning of the function keys after a zip code map has been drawn.

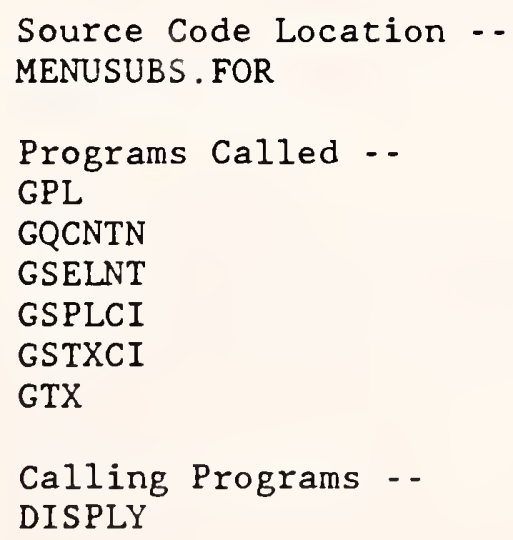

SUBROUTINE MENU20:

This subroutine writes a color key on the left side of the screen. It lists the colors associated with the function keys. 
Source Code Location --

MENUSUBS . FOR

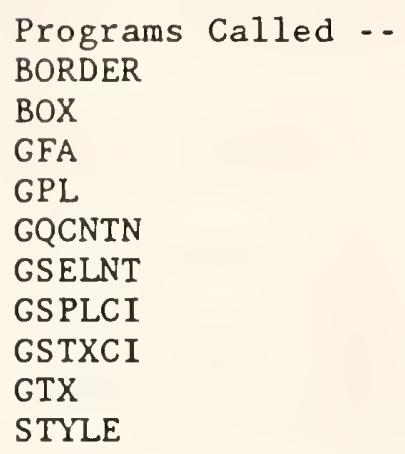

\section{SUBROUTINE MENU21:}

This subroutine writes a color key on the left side of the screen. It lists the colors and function keys associated with different types of POD sites.

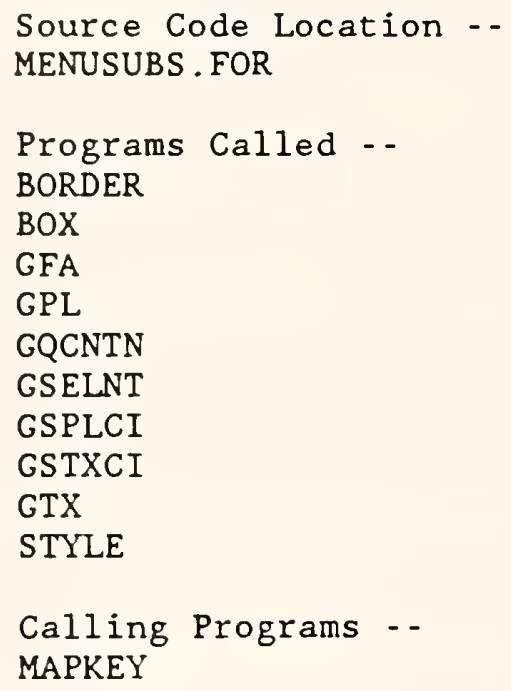

\section{SUBROUTINE MENU22:}

This subroutine displays a title for the solution map on the left side of the screen.

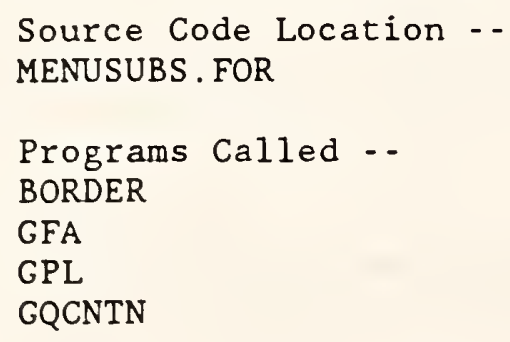


GSELNT

GSPLCI

GSTXCI

GTX

STYLE

Calling Programs -.

MAPKEY

\section{SUBROUTINE KFNU23:}

This subroutine writes a color key on the left side of the screen. It lists the colors and function keys used for displaying workload.

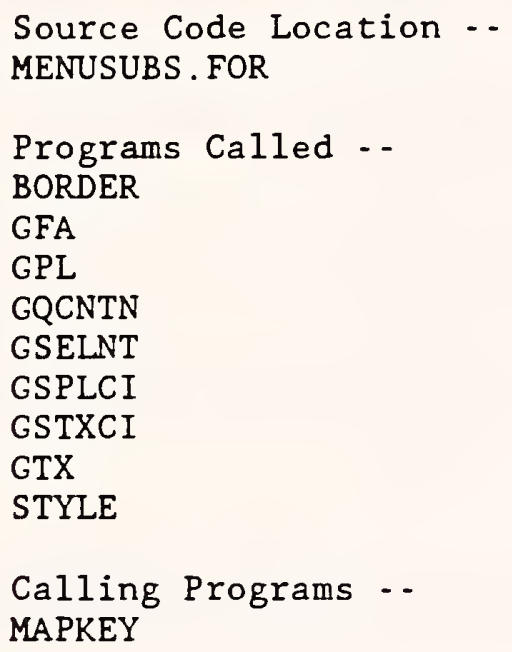

\section{SUBROUTINE OPNGKS (WKID) :}

This subroutine opens GKS with one workstation of type "DISPLAY". Error messages will be written to a file called "ERRORS.GKS". (See the GKS manual for definitions of graphics terms.)

Source Code Location .-

GKSUTIL. FOR

Input Variable - -

WKID: INTEGER $* 2$

Workstation identifier

Programs Called ..

GACWK

GINKS

GOPKS

GOPWK

Calling Programs .

DISPLY

DRIVER 
SUBROUTINE OPTION (IO, DSTLIM, TXPWGT, IRSWGT, IMF, BMF, SWITCH, NCIASS, SQFT , MILCST , STAFF1, STAFF2, STAFF3, PODCHG):

This subroutine displays the default options for the cost calculation and allows the user to make changes.

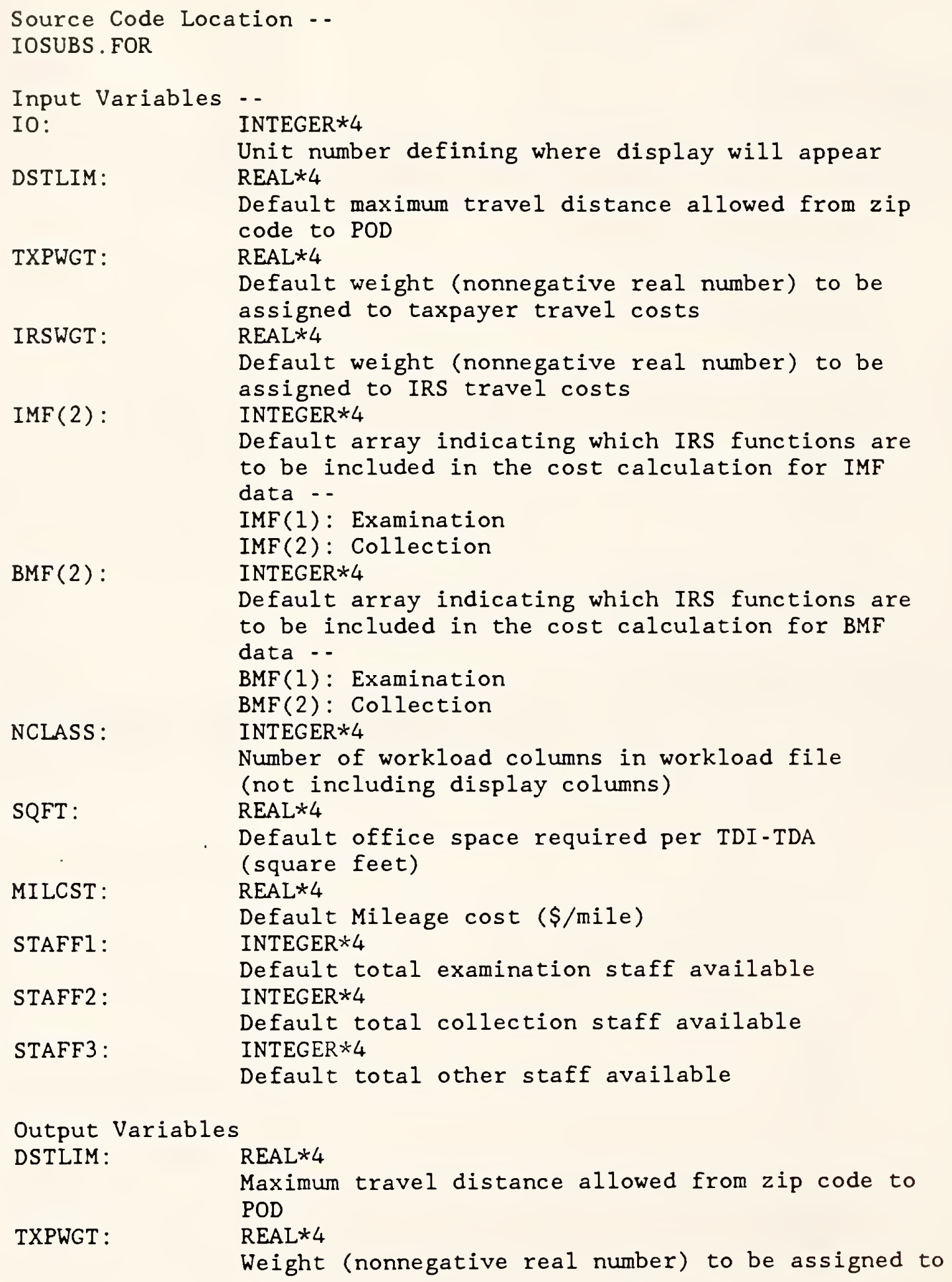




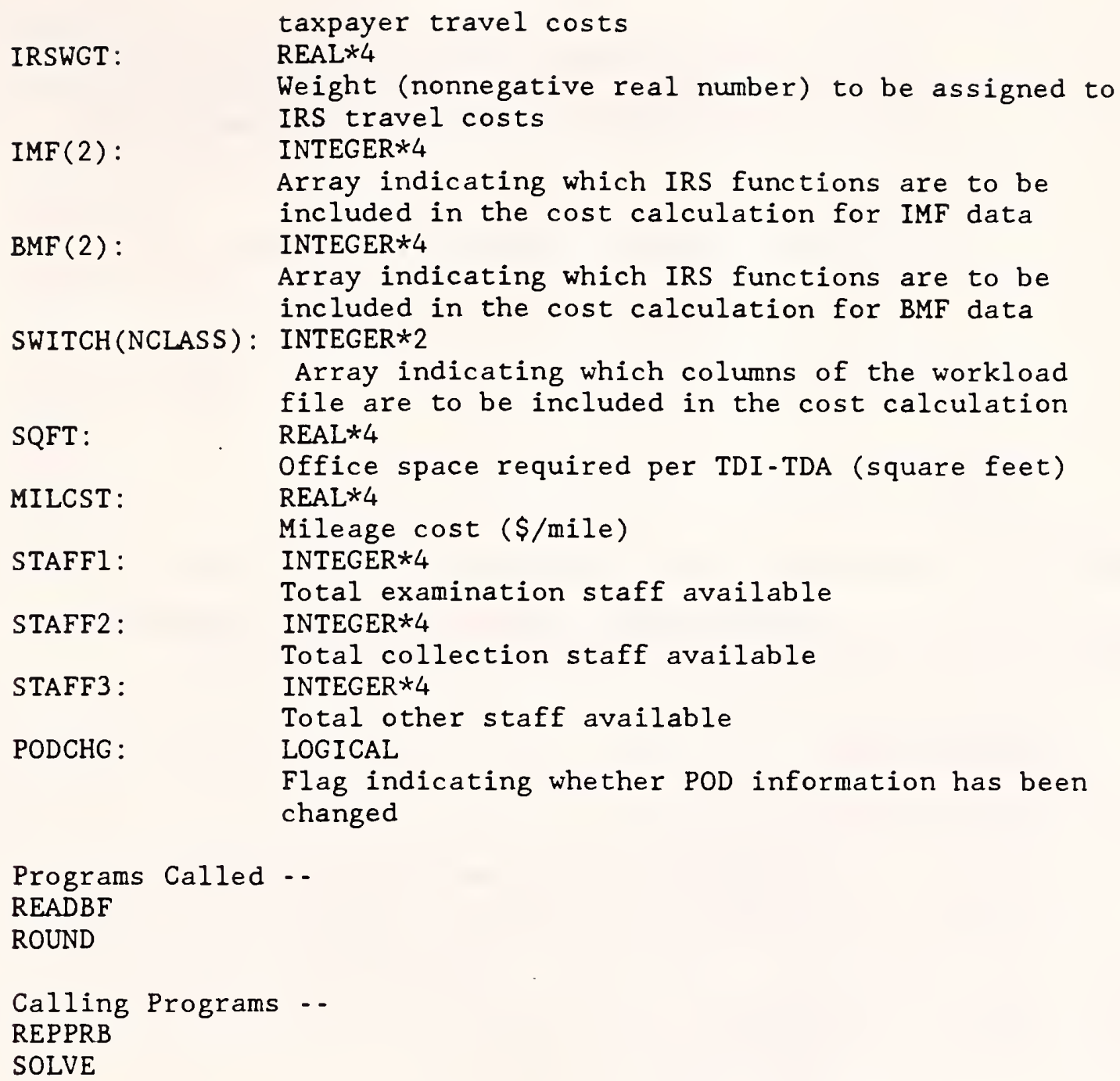

\section{SUBROUTINE ORDER (XINIT, YINIT , N, X, Y) :}

This subroutine reorders the interior points of a zip code with a hole in it so that the connector segment joins the first exterior point with the closest interior point. This is done to avoid problems which arise when the GKS shading ("Fill Area") routine is used with a connector segment that crosses the interior hole. There may still be problems with zip codes which contain several holes.

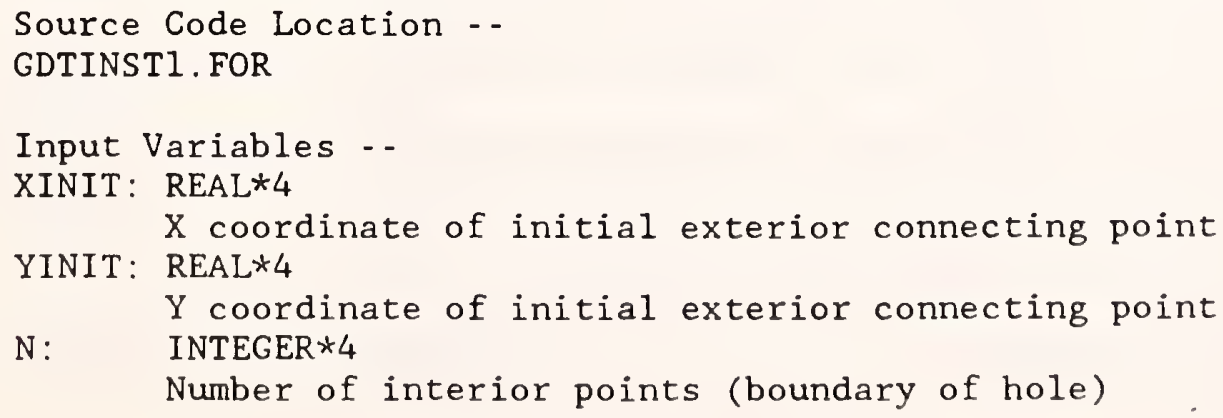




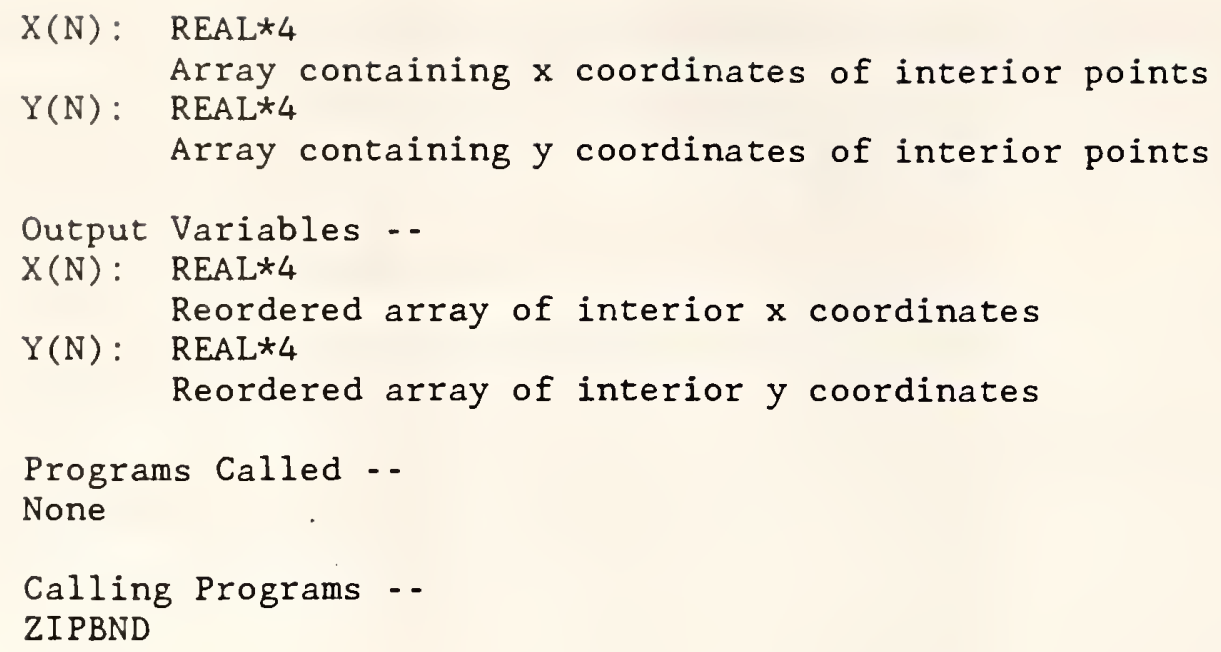

SUBROUTINE OUTLIN (IERR, ID , XMIN, YMIN , XMAX, YMAX, MAXPTS , X, Y) :

This subroutine converts the GDT state boundary file to binary form, thinning out the data in the process.

Source Code Location .. GDTINST1. FOR

Input Variables -.

ID: $\quad$ CHARACTER $* 2$

Two-digit district identification number

Maximum number of points allowed in a map region

Output Variables -.

IERR: INTEGER*4

Error flag -.

$I E R R=0$ for normal return

$I E R R=1$ if an error was encountered

XMIN : $\quad$ REAL *4

Minimum $x$ coordinate of state map

REAL*4

Minimum y coordinate of state map

XMAX: $\quad$ REAL*4

Maximum $x$ coordinate of state map

YMAX: $\quad$ REAL*4

$X$ (MAXPTS): REAL *4

Maximum y coordinate of state map

Work array containing $x$ coordinates of a map region

Y(MAXPTS): REAL*4

Work array containing y coordinates of a map region

Programs Called --

None

Calling Programs - -

GDTINST1 


\title{
SUBROUTINE PAUSE:
}

This subroutine requests the user to press "Enter" to continue. It is used following error messages to allow the user time to see the message.

\author{
Source Code Location -- \\ IOSUBS . FOR \\ Programs Called - - \\ None \\ Calling Programs -- \\ CENSRT \\ PODMAP \\ REPSOL \\ SOLMAP \\ SOLVE \\ WRKMAP
}

SUBROUTINE PODMAP (IERR, ID , PODSET , M, XCENT, YCENT , INDEX, PNT, ZIPS , ZIPCLR , MAXPLT , XPLOT , YPLOT , LONG , PERM) :

This subroutine initializes the display of a map of current and potential POD sites. It is executed when the user chooses "F3 - Display or modify initial POD sites" from the top menu. First it reads the file PODSITE.id (or NEWPOD.id) to find which zip codes are allowed to be POD sites and which $z$ ip codes currently are POD sites. Color \#1 (background) is assigned to $z$ ip codes which cannot be POD sites, color \#2 is assigned to potential POD sites, and color \#3 is assigned to current POD sites. (Note: A negative color number indicates that the centroid will be drawn as a small box; otherwise the centroid is an asterisk.) Then these colors are passed in an array to the subroutine DISPLY, which draws the map and lets the user change the colors. The new colors are returned in the original array. Color \#4 in the new array indicates a zip code which the user has made a fixed POD site.

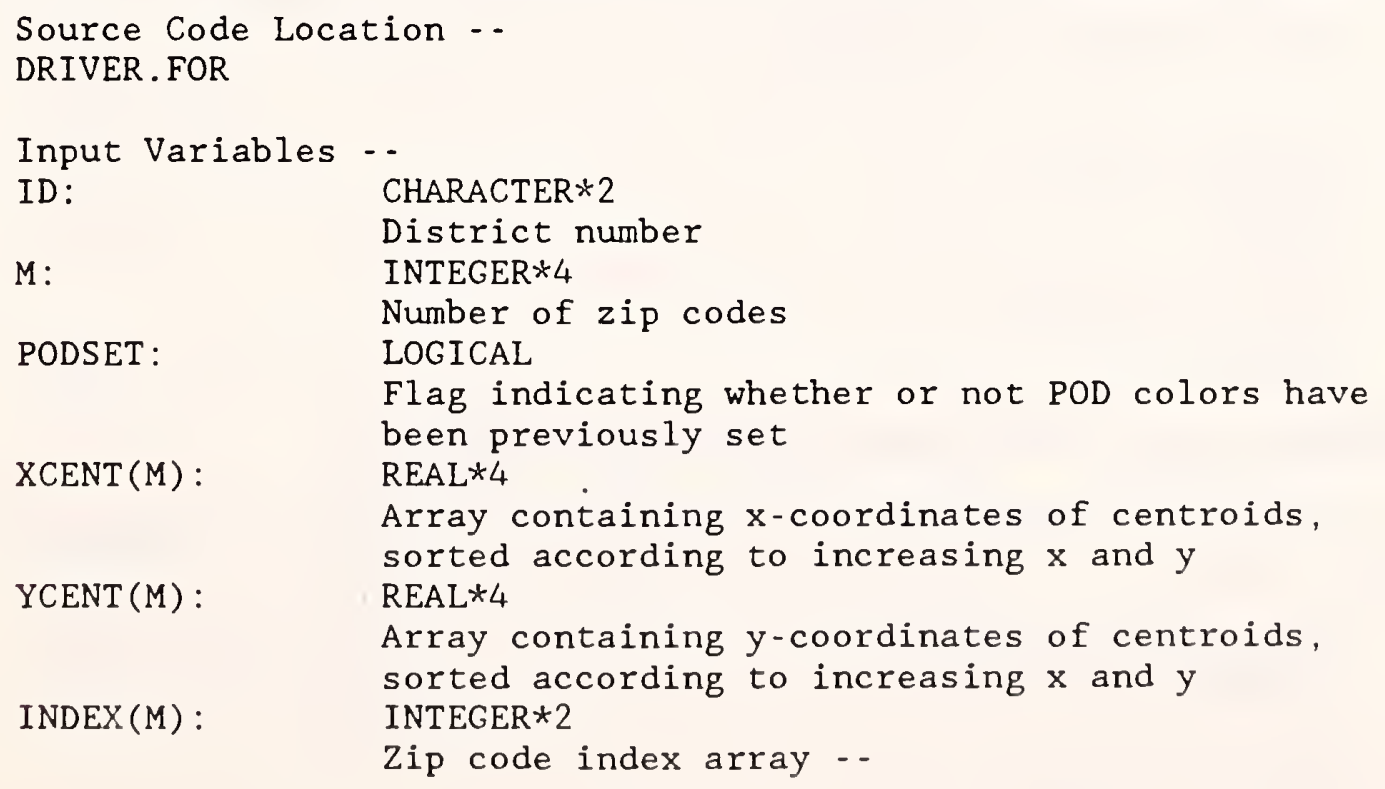




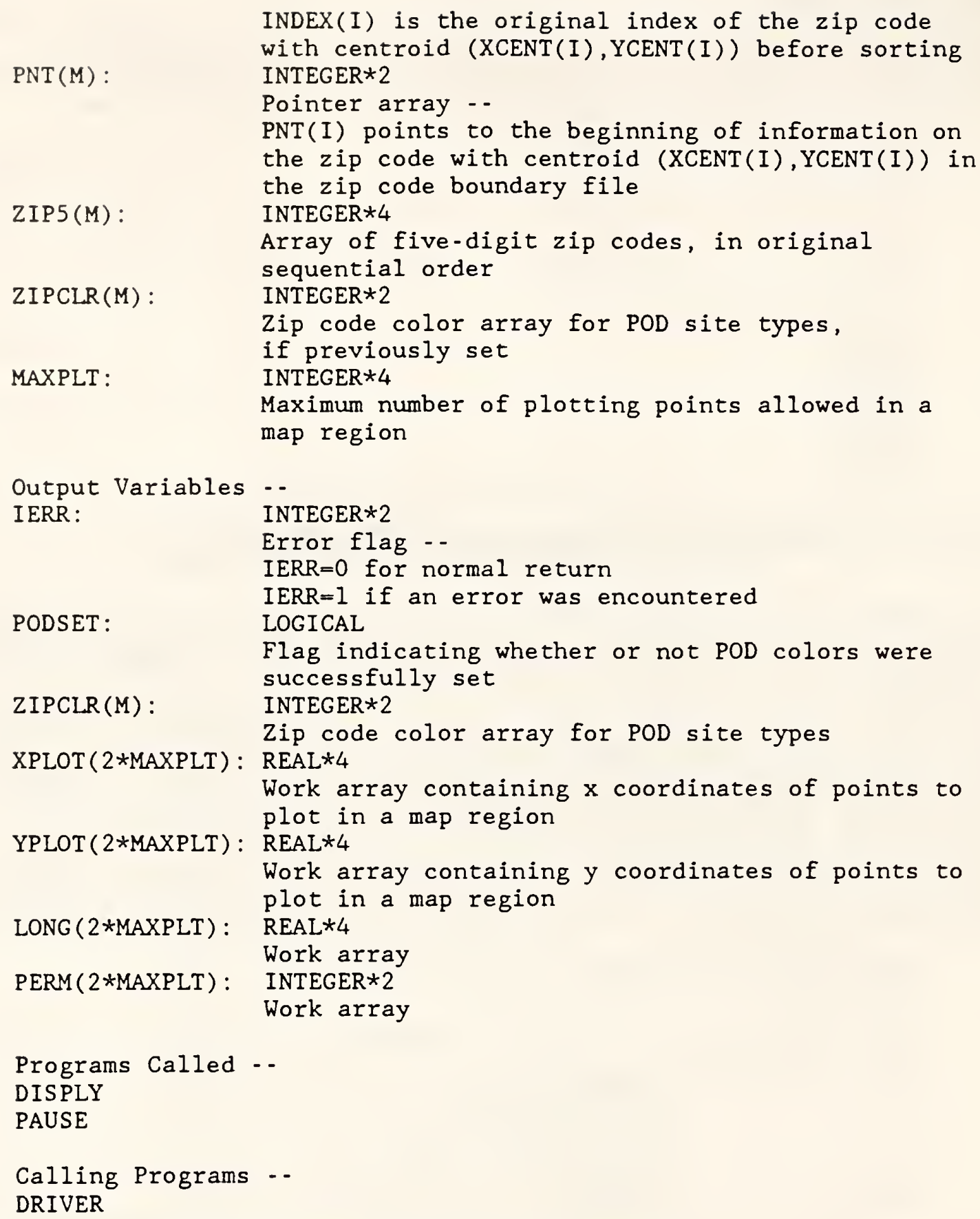

SUBROUTINE RANGES (RNGSET, NRANGE, RANGE, WRKMIN, WRKMAX):

This subroutine sets ranges for the workload display map and allows the user to make changes.

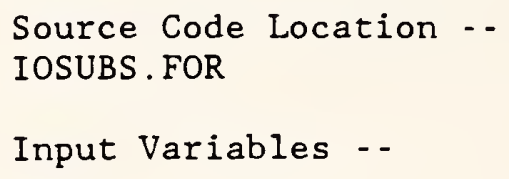




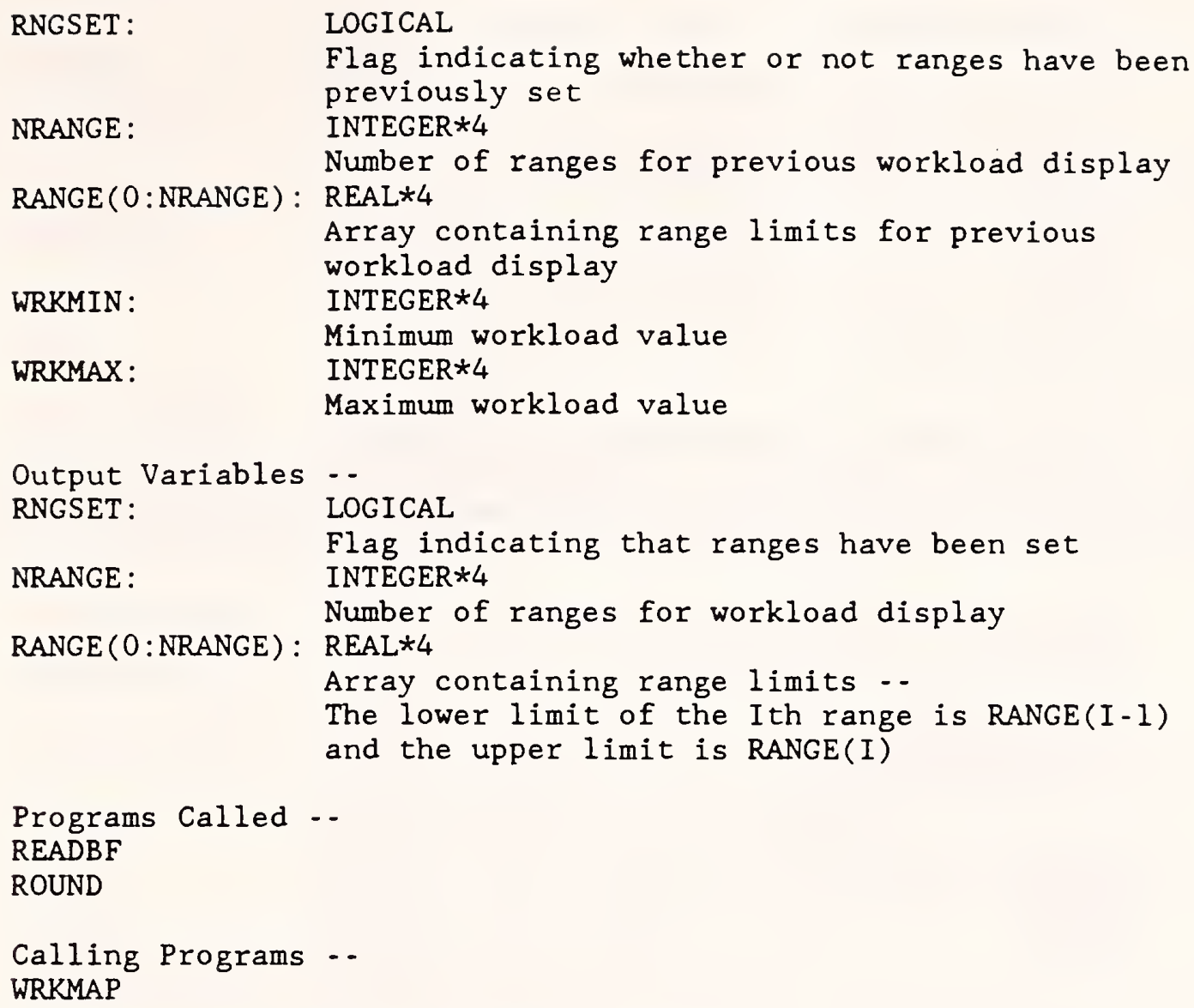

SUBROUTINE READBF (IERR, MXITMS , NITEYS , ITEM):

This subroutine reads an input string from the terminal into a buffer and tries to convert it to a list of real numbers. The items in the string must be separated by spaces or commas.

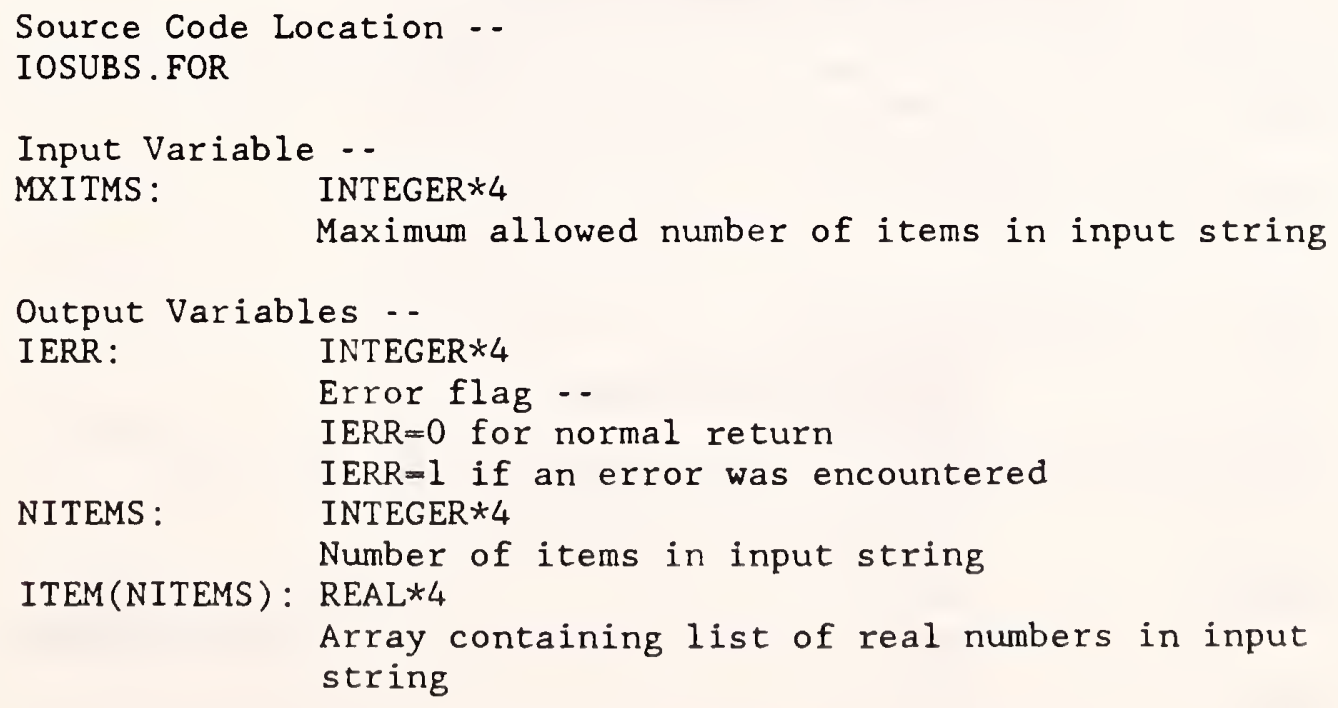


Programs Called ..

None

Calling Programs -.

GEOFAC

OPTION

RANGES

SOLVE

WRKMAP

SUBROUTINE REPFIL(ID):

This subroutine initializes the report file REPORT.id. Either a new report file is created or information is appended to an existing report file. A report header is written giving the date and time. The report file is assigned to unit 12 , which remains open after returning from the subroutine.

Source Code Location -.

IOSUBS. FOR

Input Variable - -

ID: CHARACTER *2

District number

Programs Called -.

CONVRT

GETDAT

GETTIM

Calling Programs - -

DRIVER

SUBROUTINE REPPRB (M, ZIPCLR, ZIP5, DSTLIM, IRSWT, TXPWT, IMFFNC, BMFFNC, NREC , DIFZIP , DIFPOD , DIFFAC, FXCOST , CSQRFT, SQFT, MILCST, IRSFCT, TXPFCT , STFFCT, SWITCH, NCLASS, STAFF1, STAFF2, STAFF3, PODCHG):

This subroutine writes information on the problem initialization into the report file.

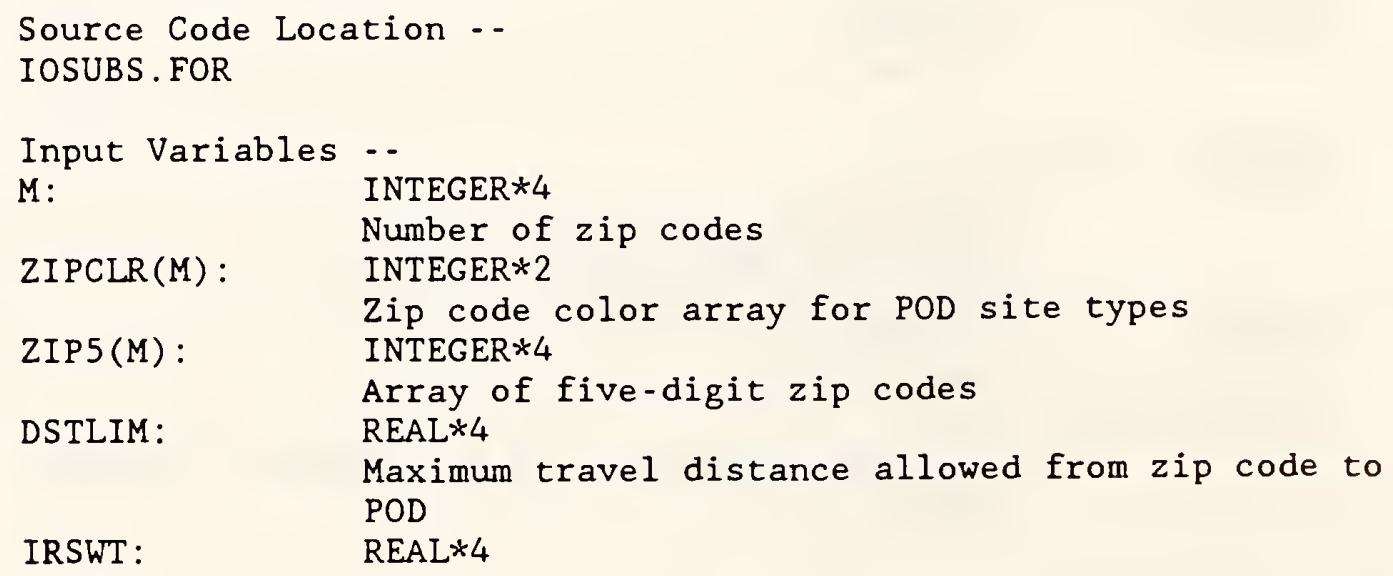




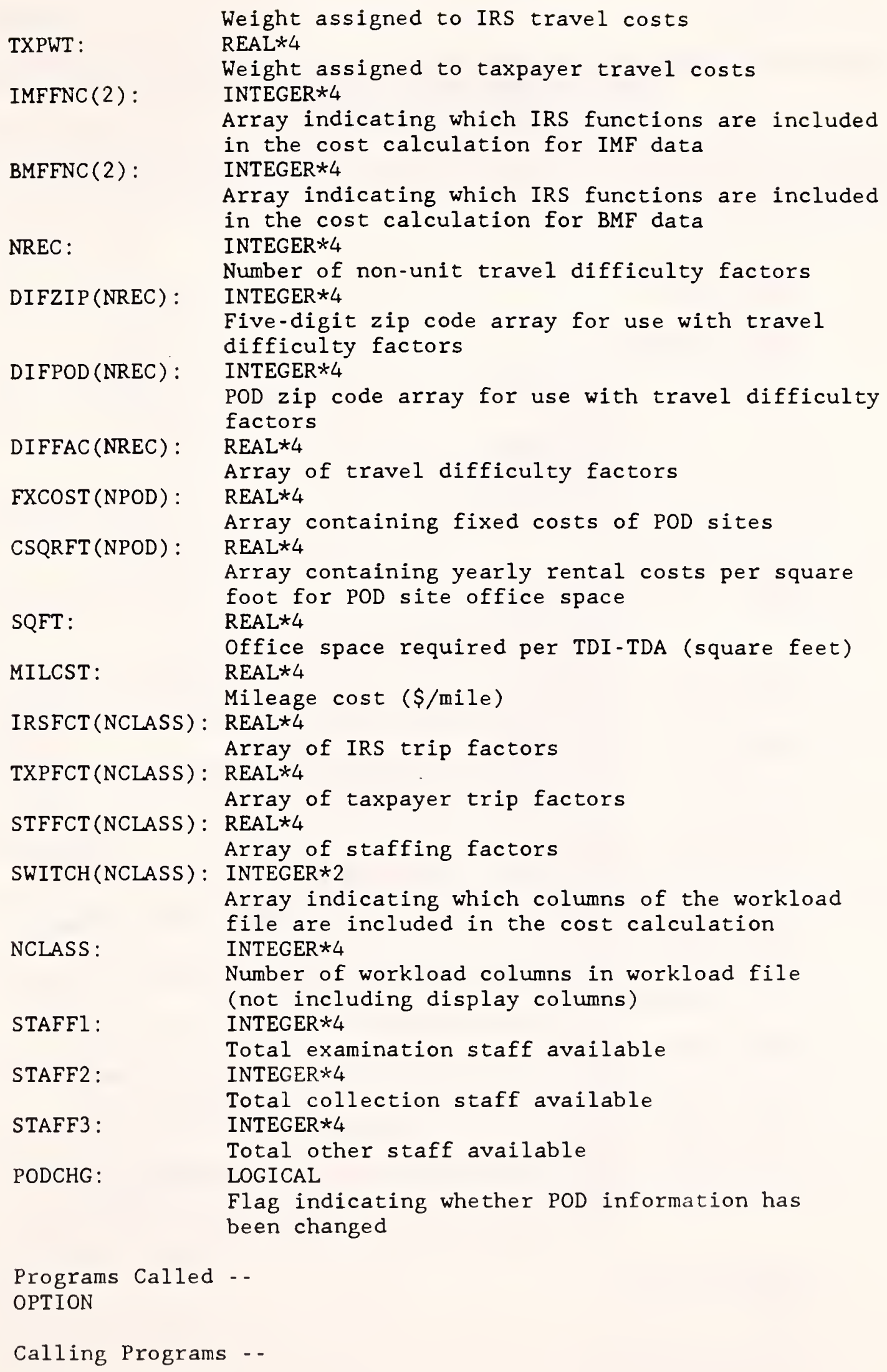


SUBROUTINE REPSOL (IERR, ZIP5, PODLST , M, ZIPIND, ZIPCIR, ID,

IMFEXX , BMFEXIM, TDICOL, TDACOL,

IMFEX2, BMFEX2, TDICO2, TDACO2):

This subroutine is executed when the user chooses "F6 - Report zip code and staff assignments" from the top menu. It writes information on the problem solution into the report file.

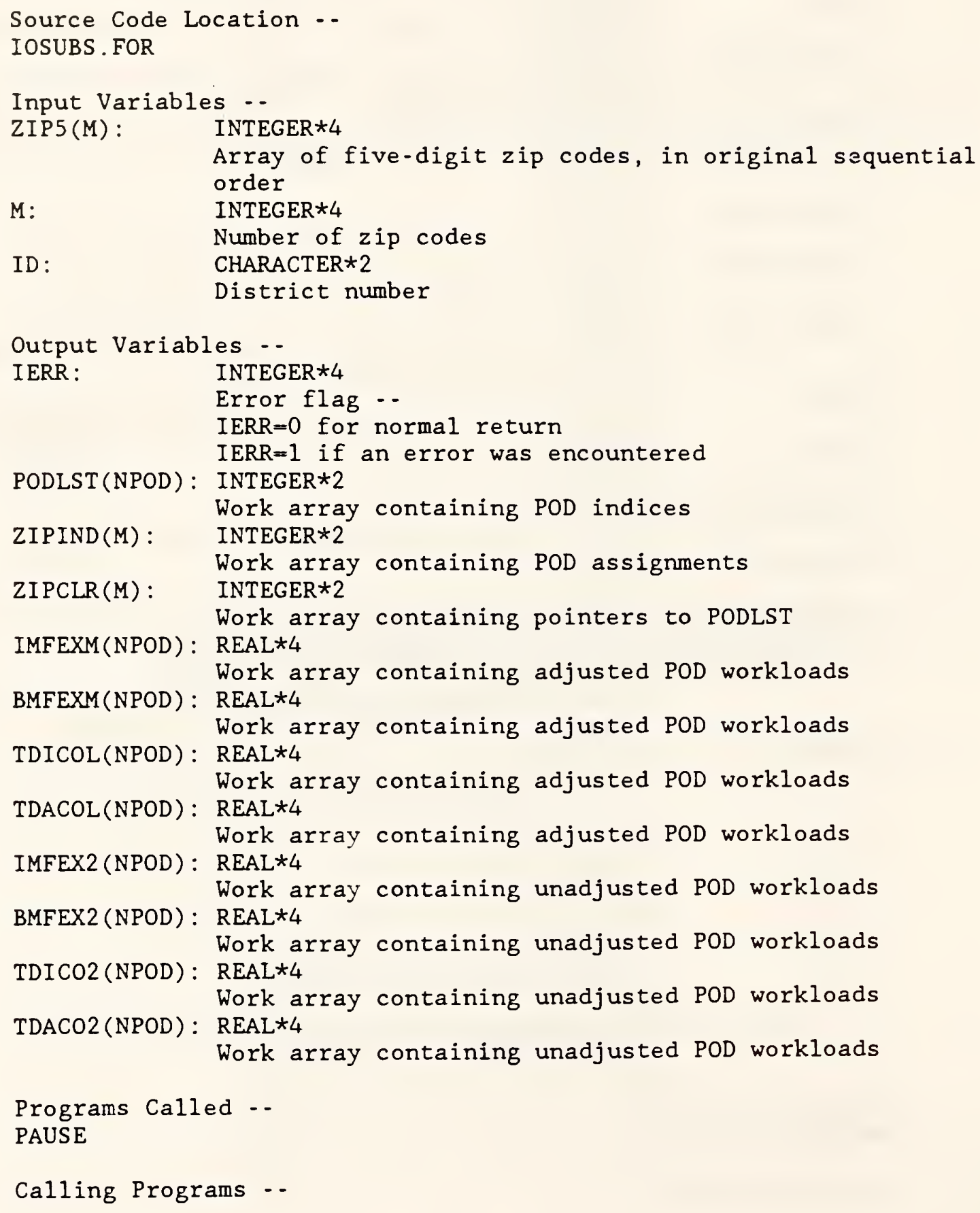


DRIVER

\section{FUNCTION REVERS ( $\mathrm{X}$, MIN, MAX) :}

This function reverses the direction of a coordinate axis. (This is necessary because the $x$ coordinates in the GDT files increase from right to left, but GKS assumes that they increase from left to right.)

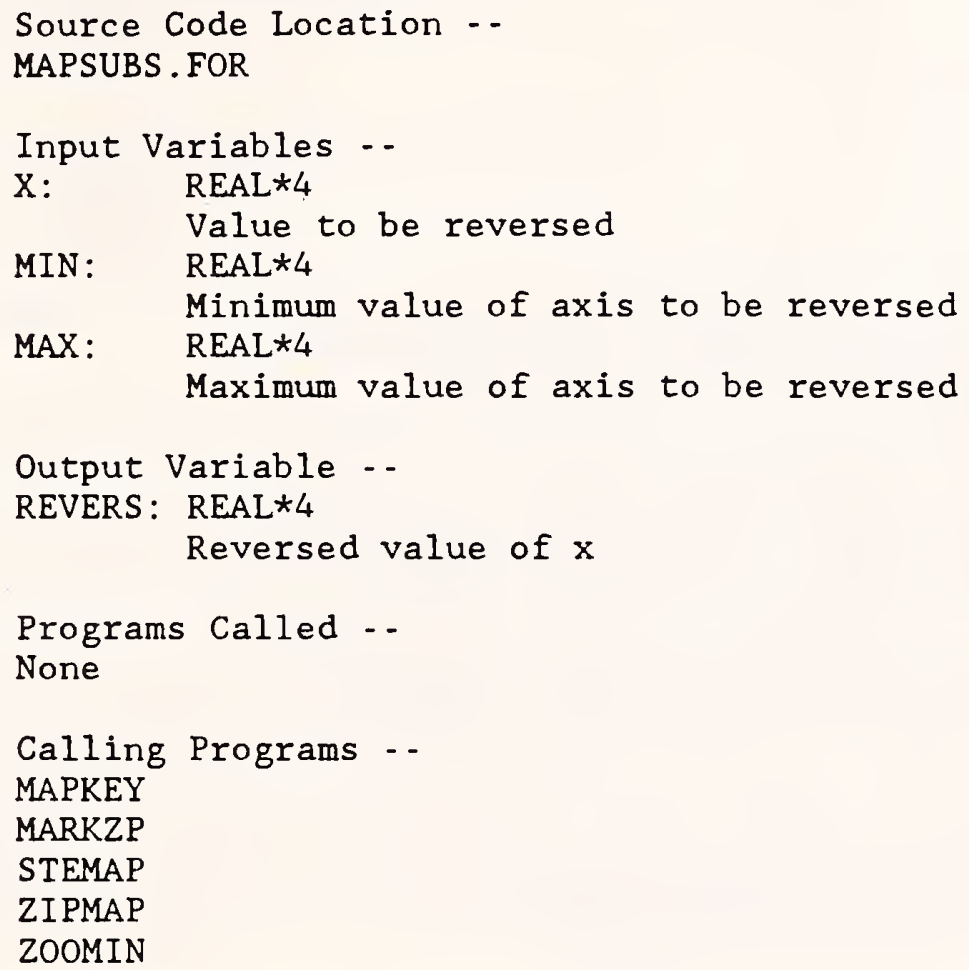

FUNCTION ROUND(X):

This subroutine rounds a real number to the nearest integer. Numbers ending in .5 are truncated.

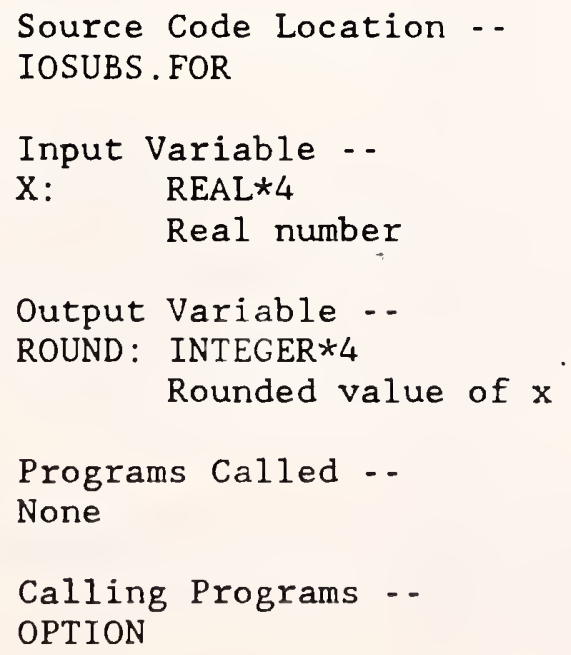




\section{SUBROUTINE SEARCH(XPT, YPT, $, X, Y, P O S)$ :}

This subroutine searches the list of sorted centroids to find the centroid closest to a given point. A binary search is done to find the nearest $x$ coordinate, and then a sequential search is done to find the nearest $y$ coordinate.

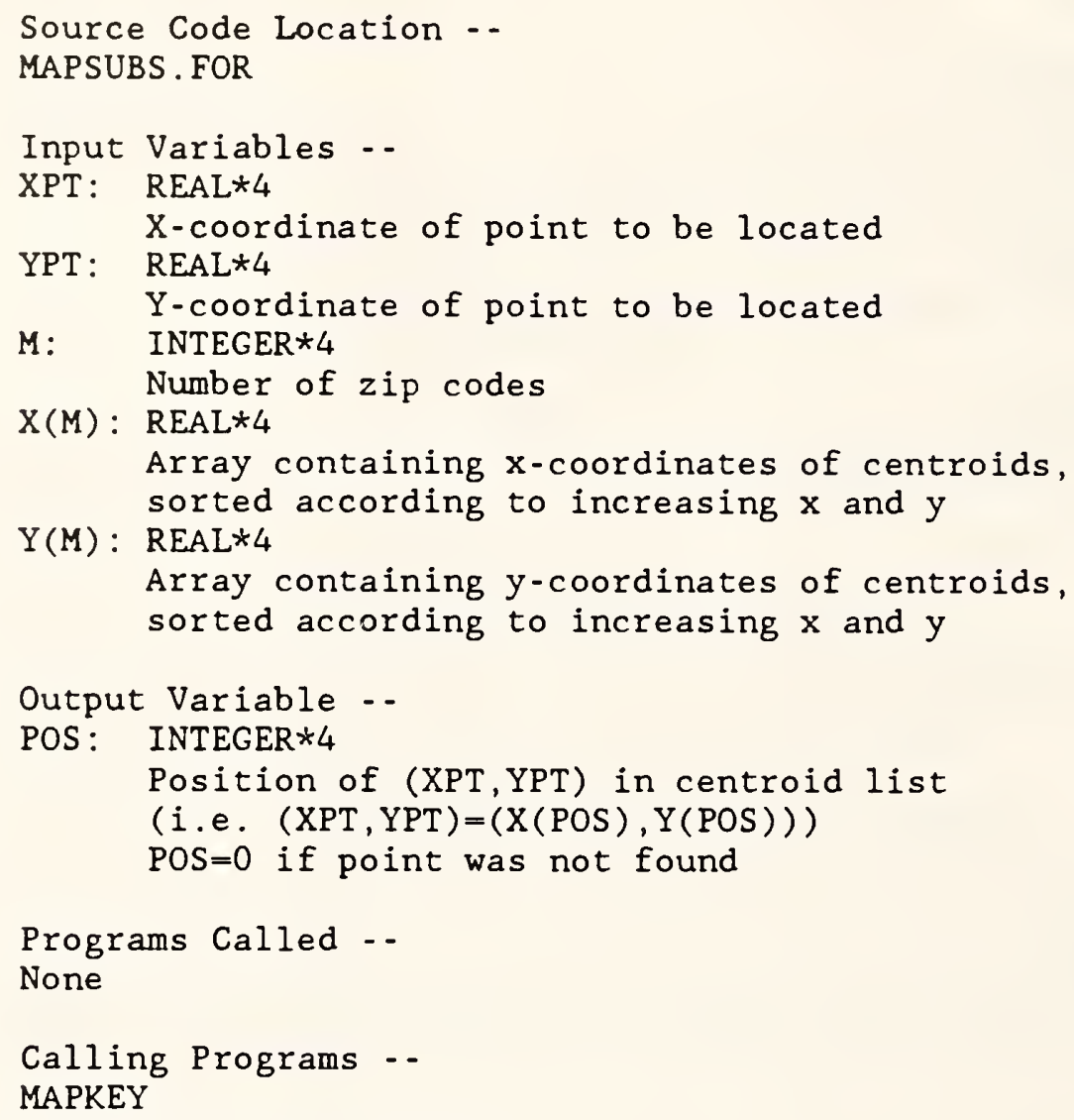

This subroutine defines the colors to be used by the display device. The type of display device in use is determined by a call to the GKS routine GQCF which returns the number of colors available on the current device driver. For a CGA display in medium-resolution four-color mode, this subroutine sets palette two with a blue background. For an EGA display, it sets sixteen colors in one of two possible palettes. (See the GKS manual for definitions of graphics terms.)

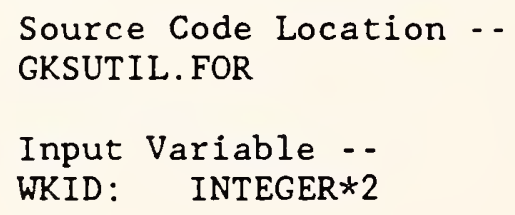


Workstation identifier

PALETT: INTEGER $* 2$

Palette identifier ( 1 or 2 ) -.

PALETT $=1: 16$ distinct colors

PALETT $=2$ : Colors 4 through 9 are shades of green

(Palett is not used in medium resolution mode)

Programs Called --

GQCF

GSCR

Calling Programs --

SPLTWN

WINDOW

SUBROUTINE SOLMAP (IERR, ID, M, XCENT , YCENT, INDEX, PNT , ZIPCLR, ZIP5, MAXPLT , XPLOT, YPLOT, LONG , PERM) :

This subroutine initializes the display of a solution map. It is executed when the user chooses "F5 - Display optimal POD locations" from the top menu. It checks the solution file soLUTION.id to see whether the graphcoloring algorithm was used by the solver. (This algorithm is used only if an input file ADJACENT.id is present.) If graph coloring was not used, then only zip codes which are POD sites (as determined by the solution) will be colored on the map (using color \#3); all other zip codes will be in the background color (color \#1). (Note: A negative color number indicates that the centroid will be drawn as a small box; otherwise the centroid is an asterisk.) If graph coloring was used, then a color for each zip code is read from the solution file (the color number is increased by one to avoid using the background color). The resulting map will show a POD and its assigned zip codes all in the same color. The subroutine DISPLY is called to draw the map.

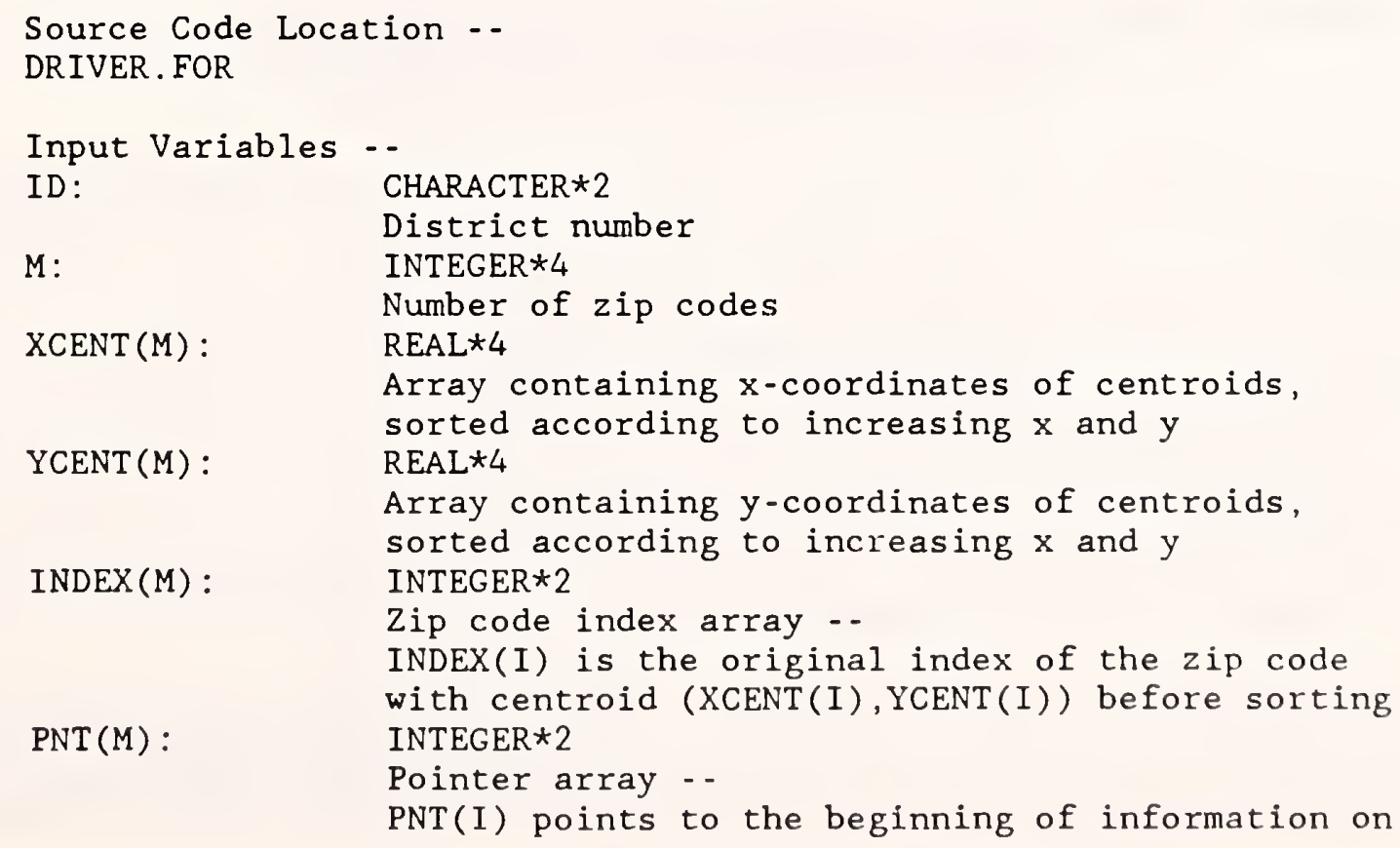


the $z$ ip code with centroid (XCENT(I), YCENT(I)) in the zip code boundary file

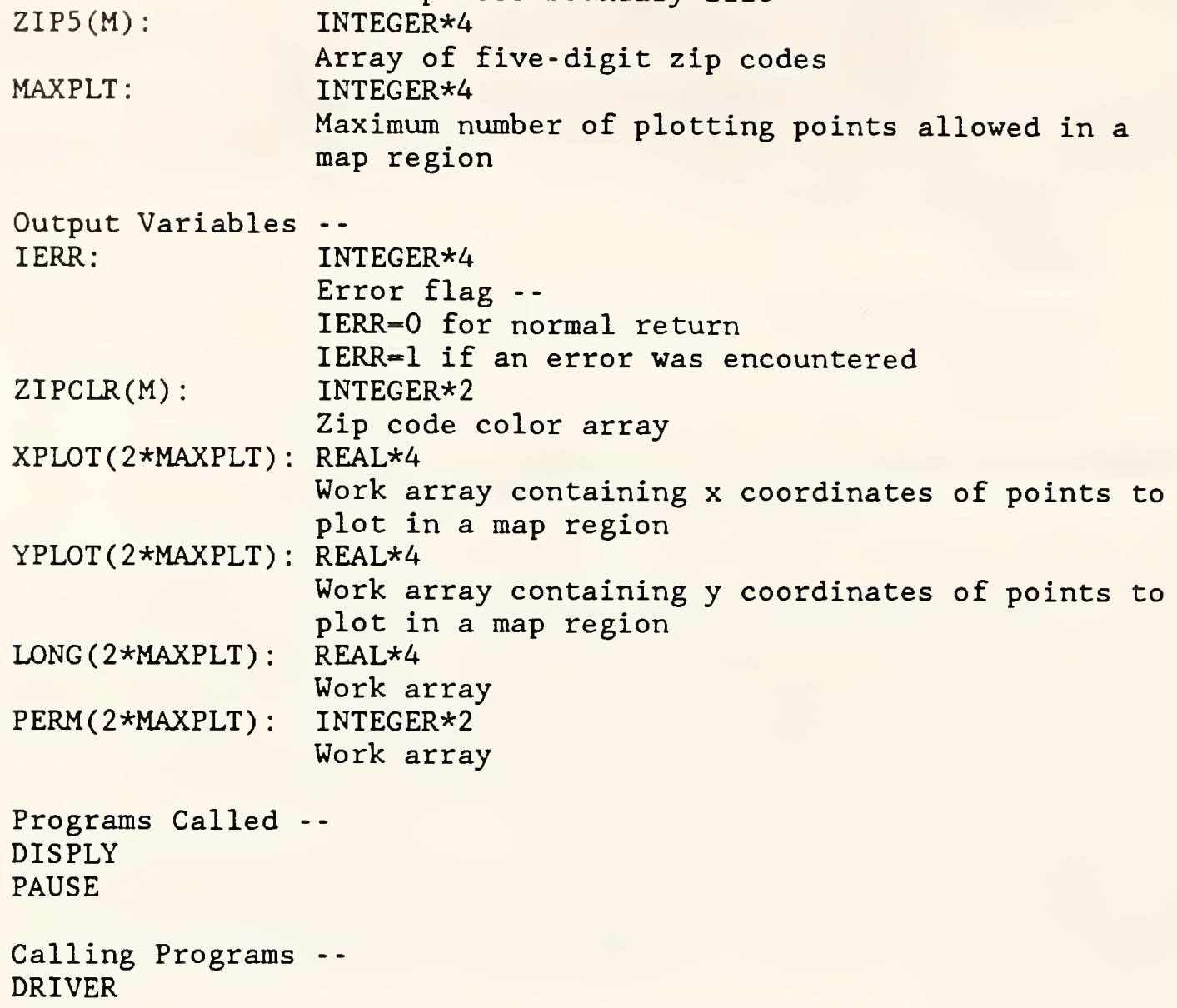

SUBROUTINE SOLVE (IERR, ID , PODSET, MAXPOD , PODZIP , XPOD , YPOD, H, HOLD , FXCOST, CSQRFT, TRVDIF, ZIPCLR, ZIP5, JCOEF, COST , MAXDIF , DIFZIP, DIFPOD, DIFFAC) :

This subroutine allows the user to set parameters to initialize a location problem and then calculates costs which are passed to the solution procedure SOLVER.EXE. It is executed when the user chooses "F4 - Solve for optimal POD locations" from the top menu. First, several parameters such as cost per mile, maximum travel distance, and staff totals are read from the file PODSITE.id. Then opening/closing costs and office rental costs for each POD site are read. If any $P O D$ sites exist which are not in the file, the user is asked to enter the costs. Then trip factors and staffing factors are read from the file WORKLOAD.id. The user is allowed to set weights for IRS and taxpayer costs, to turn categories of workload on or off, to change the distance limit and staff totals, and to set travel difficulty factors. The parameter settings are summarized in the report file REPORT.id.

After all parameters have been set, the program proceeds to calculate costs of assigning zip codes to POD sites. These costs are passed to the PASCAL solution procedure in the unformatted sequential file TRANSFER.id. For each zip code, the program finds all possible POD sites (current, potential and 
fixed) within the specified distance limit and calculates the cost of each assignment using the function COSTFN. The assignments are then sorted in order of decreasing cost; if a zip code is a possible POD site, its cost is last in the list. The list of costs and POD sites for a particular zip code is written as one record of the file TRANSFER.id. The type of the zip code (i.e., whether it is a potential POD site, a fixed POD site, etc.) is also included in the record. The record is padded with zeroes to make the file readable by a PASCAL program. If, for some zip code, there are no possible POD sites within the distance limit, an error message will appear on the screen. Otherwise, the subroutine is exited and control passes to the solution procedure. (The solution algorithm is described in "The Internal Revenue Service Post-of-Duty Location Modeling System: Programmer's Manual for PASCAL Solver".)

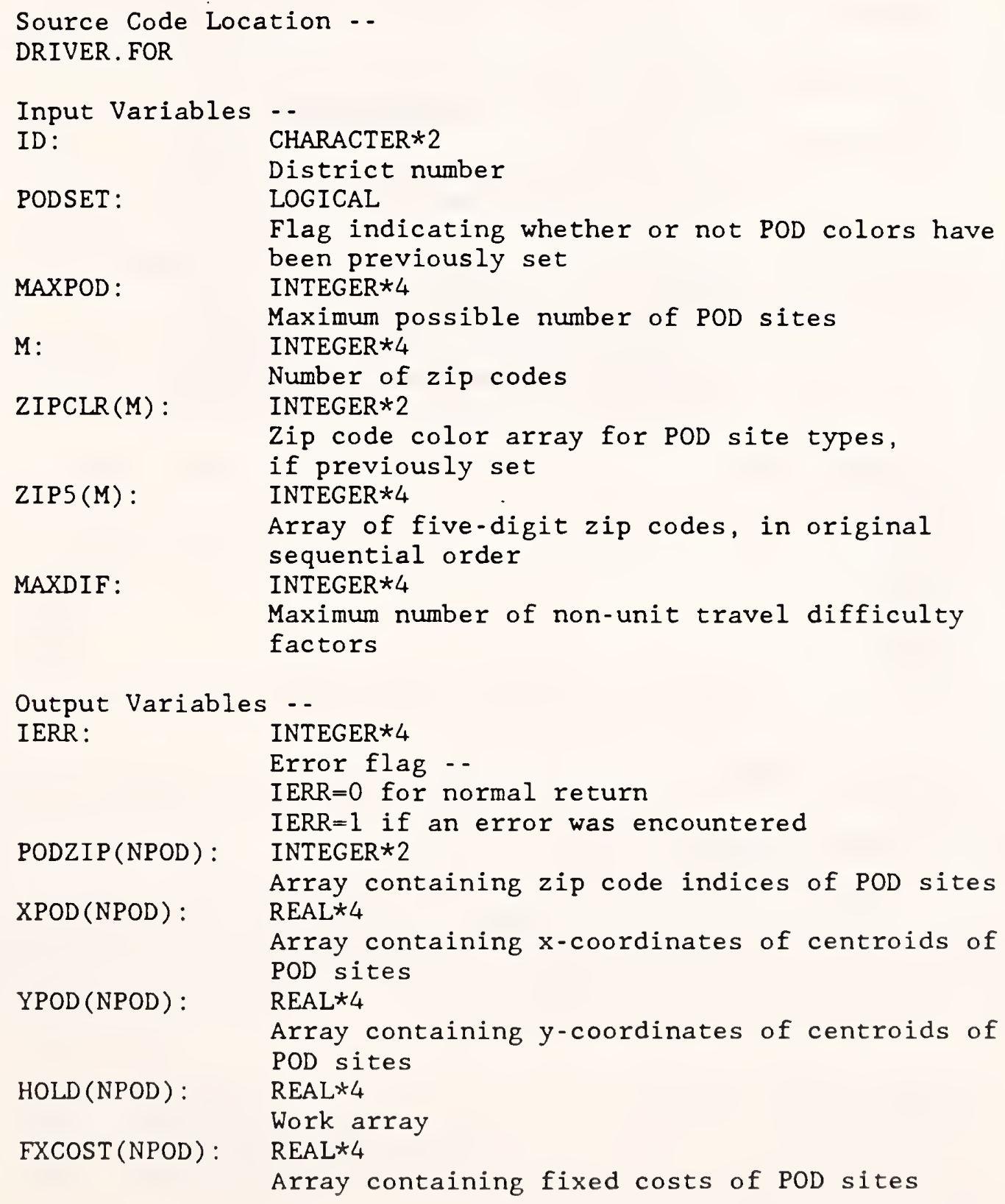




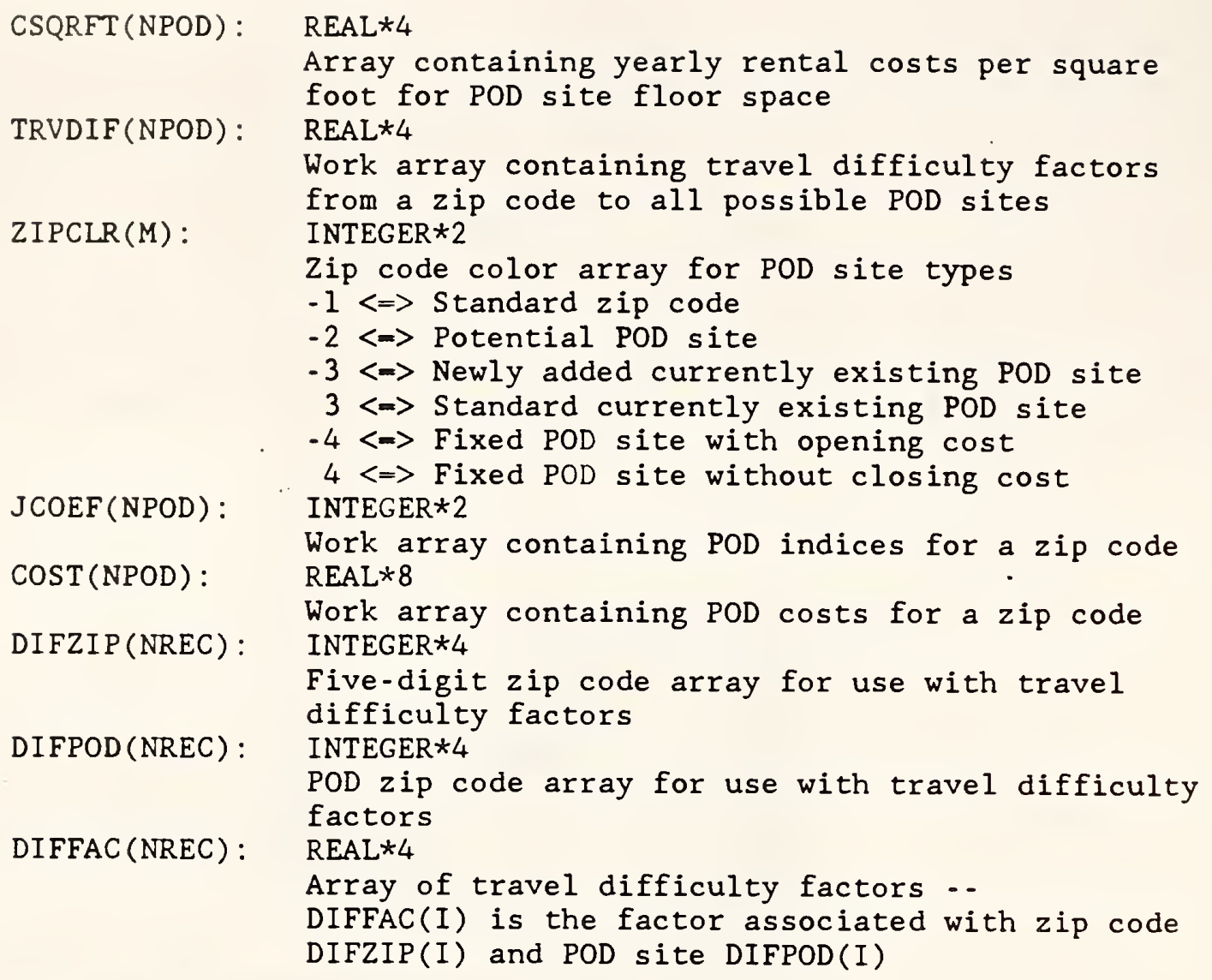

SUBROUTINE SORT ( $M, X, Y$, INDEX, PNT):

This subroutine uses a heapsort algorithm to sort the centroids according to increasing $x$ and $y$ coordinates. It is also used to sort other arrays. For a description of the heapsort algorithm, see, for example, An Introduction to Data Structures with Applications by J. P. Tremblay and P. G. Sorenson (McGraw-Hill, 1976, p. 475).

Source Code Location -.

DRIVER . FOR

Input Variables .. 


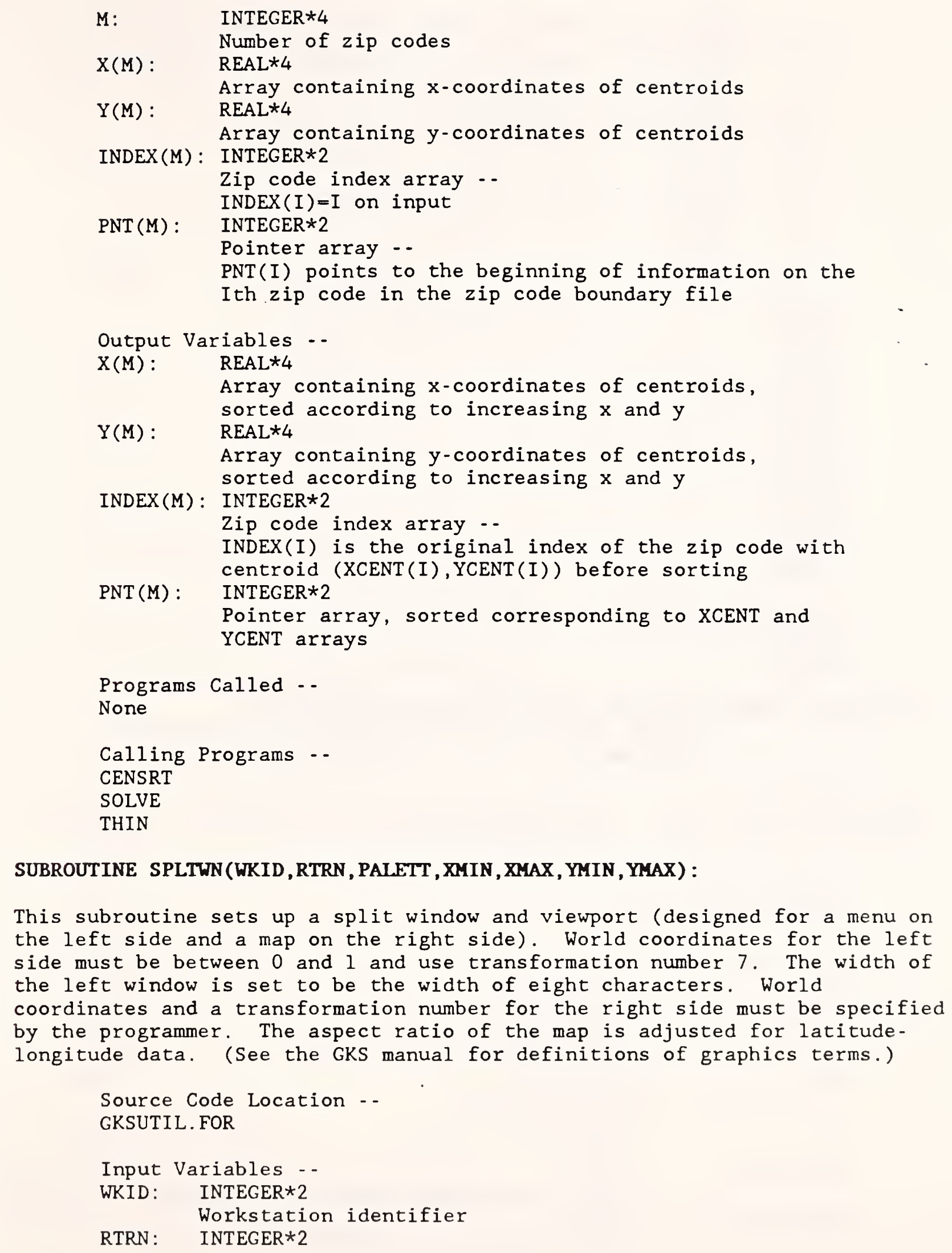

This subroutine sets up a split window and viewport (designed for a menu on the left side and a map on the right side). World coordinates for the left side must be between 0 and 1 and use transformation number 7 . The width of the left window is set to be the width of eight characters. World coordinates and a transformation number for the right side must be specified by the programmer. The aspect ratio of the map is adjusted for latitudelongitude data. (See the GKS manual for definitions of graphics terms.) 


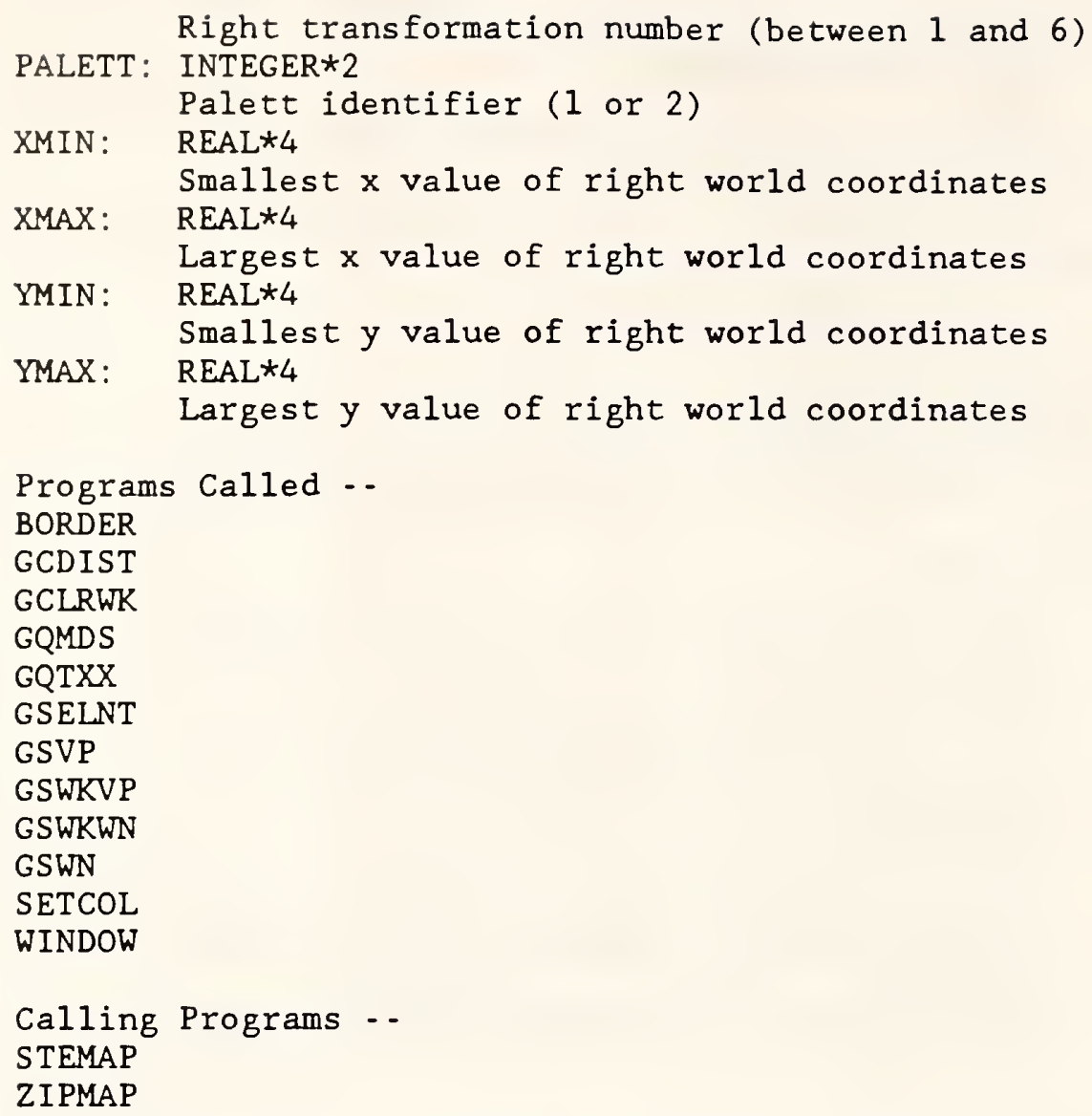

SUBROUTINE STEMAP (IERR, TRN, PALETT , ID , XMIN, XMAX, YMIN, YMAX, $M, X C E N T$, YCENT , INDEX, ZIPCLR , MAXPLT , XPLOT , YPLOT, LONG , PERM) :

This subroutine draws a state map, showing the outline of the state and centroids of zip codes. (Zip code boundaries are not drawn.) The state border is read from the file OUTLIN.id.

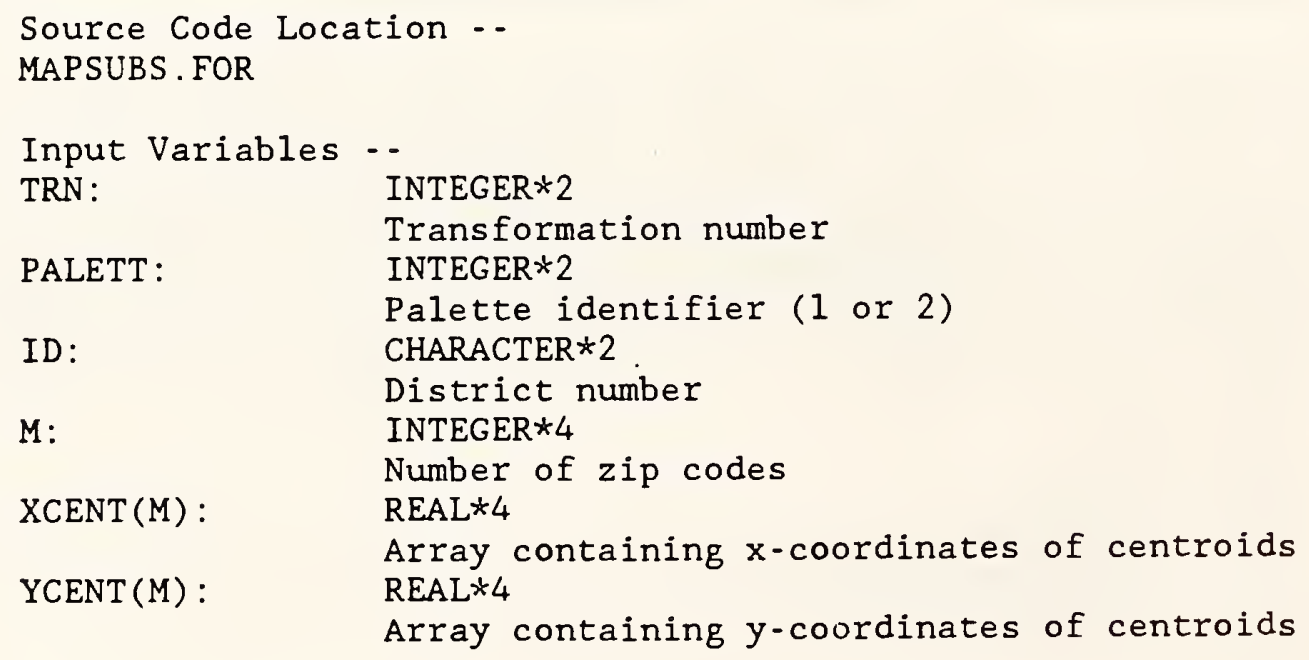




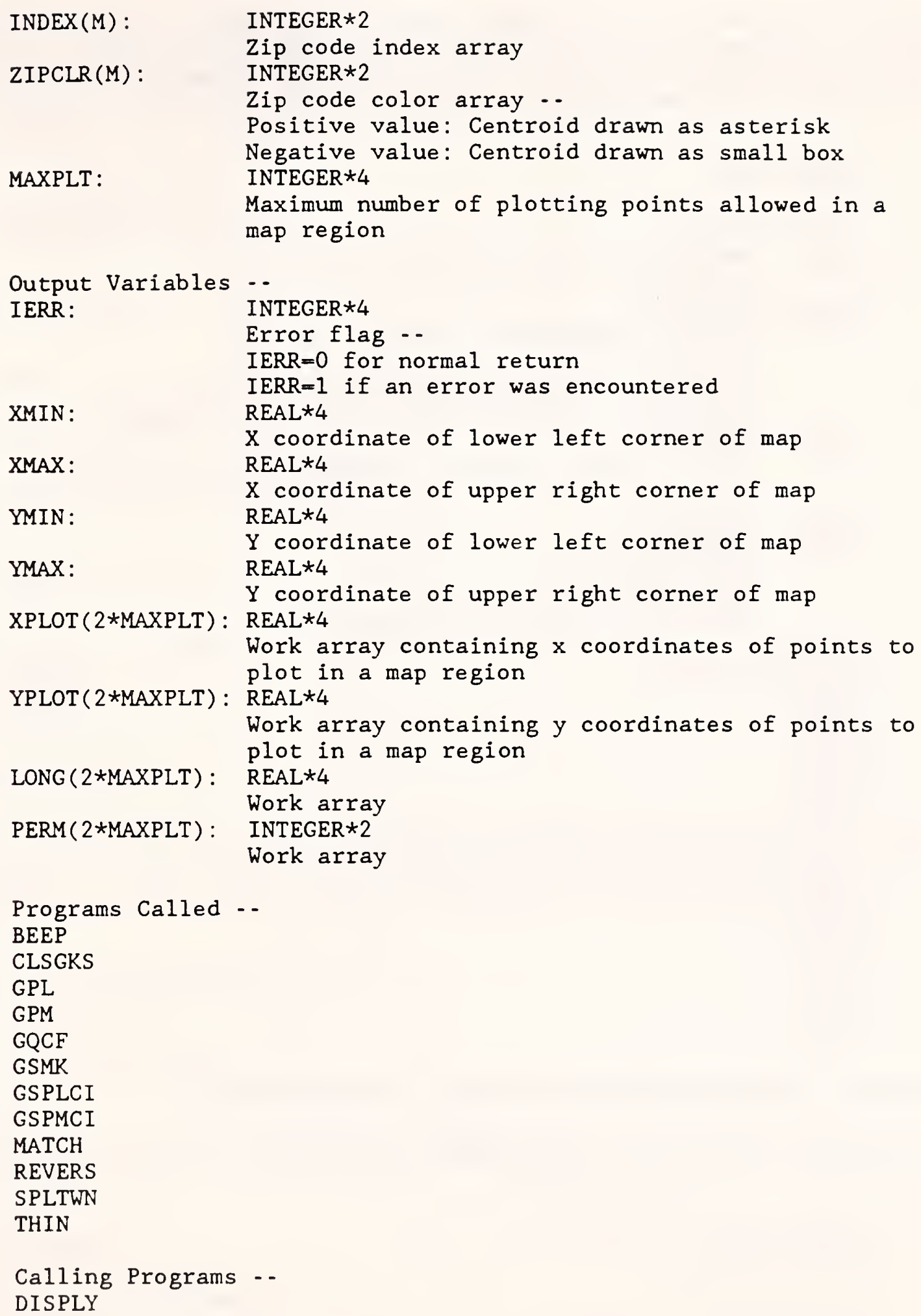

SUBROUTINE STYLE(IERR, WKID, PALETT, INDEX): 
This subroutine sets one of sixteen area-filling interior styles. For a CGA display in medium-resolution four-color mode, the style is either a solid color or a cross-hatch pattern. For an EGA display, the style is always a solid color. (See the GKS manual for definitions of graphics terms.)

Source Code Location -.

GKSUTIL. FOR

Input Variables -.

WKID: INTEGER*2

Workstation identifier

PALETT: INTEGER $* 2$

Palette identifier ( 1 or 2 ) - -

PALETT $=1: 16$ distinct colors

PALETT $=2$ : 6 shades of green plus 10 other colors

INDEX: INTEGER*4 (Palett is not used in medium resolution mode)

Index (between 1 and 16 ) of desired interior style

Output Variable --

IERR: INTEGER $* 4$

Error flag -.

$I E R R=0$ for normal return

$I E R R=1$ if an error was encountered

Programs Called --

CLSGKS

GQCF

GSFACI

GSFAIS

GSFASI

Calling Programs --

ERSMNU

MAPKEY

MENU20

MENU21

MENU22

MENU23

ZIPMAP

SUBROUTINE THIN (XPLOT, YPLOT, NPTS , MAXPLT, IPTS, WORK, PERM) :

This subroutine thins zip code boundaries which have more than the maximum allowed number of plotting points.

Source Code Location --

MAPSUBS .FOR

Input Variables - -

XPLOT(NPTS) : $\quad$ REAL 44

YPLOT(NPTS): $\quad$ Array containing $x$ coordinates of boundary points Array containing y coordinates of boundary points 


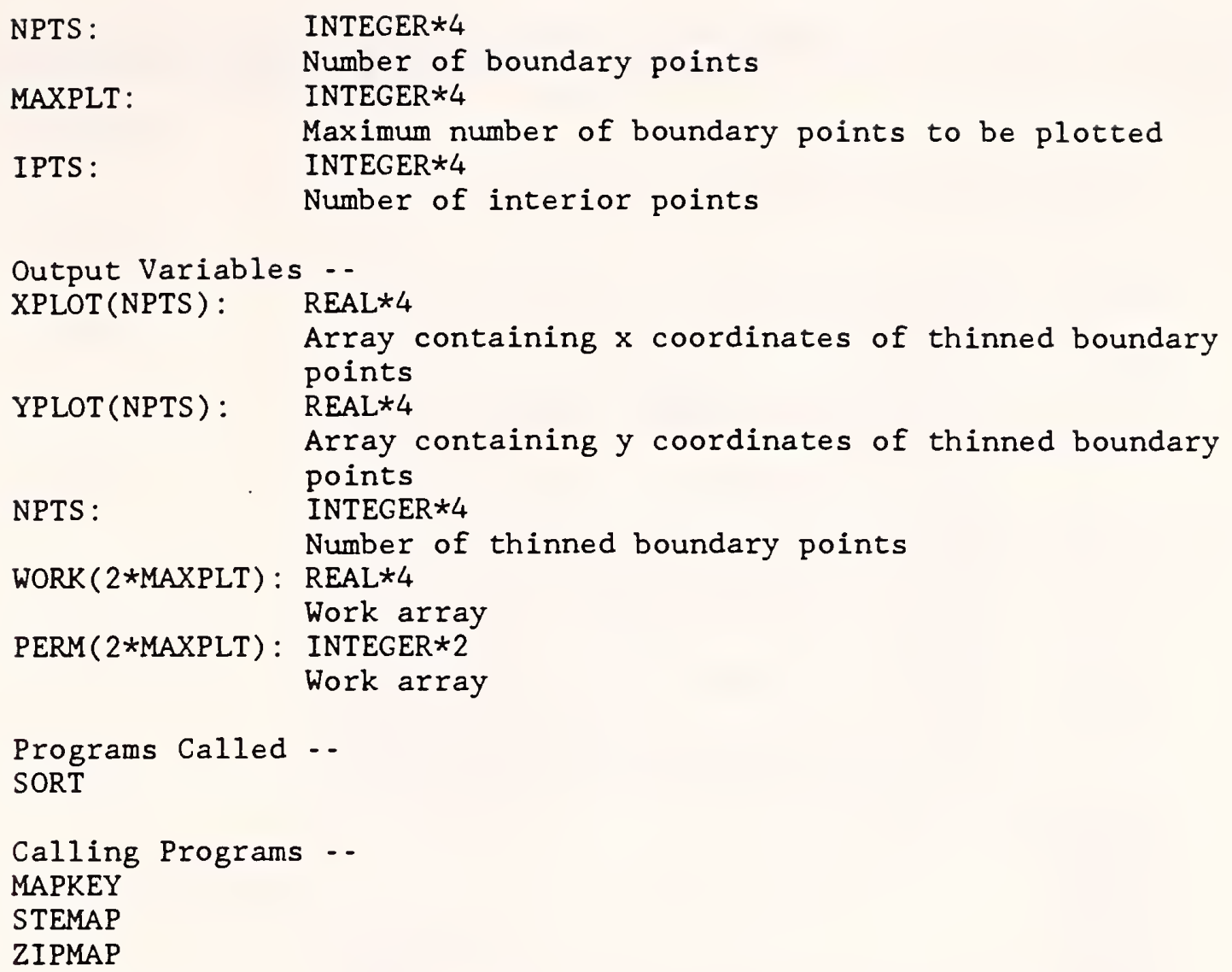

SUBROUTINE TOPMNU:

This subroutine writes the text for the top-level menu on the screen. The format of the menu is slightly different depending on whether a CGA or an EGA display is being used. This is determined by calling the GKS routine GQCF which finds the number of colors available on the current device driver.

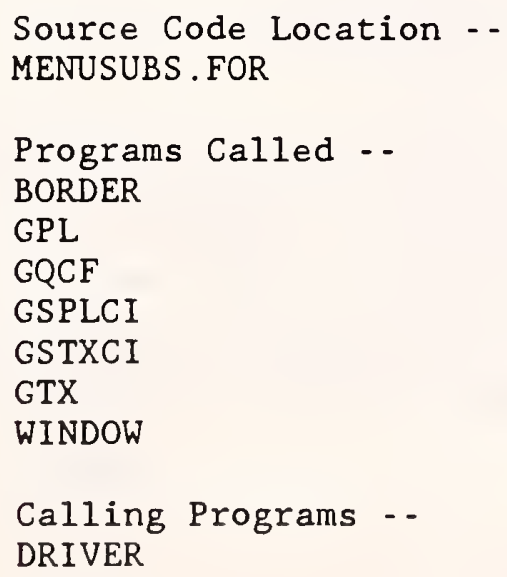

SUBROUTINE WINDOW (WKID, TRN, PALETT , XMIN, XMAX, YMIN, YMAX) : 
This subroutine sets a window and a viewport in a way that preserves the aspect ratio of the world coordinates. (See the GKS manual for definitions of graphics terms.)

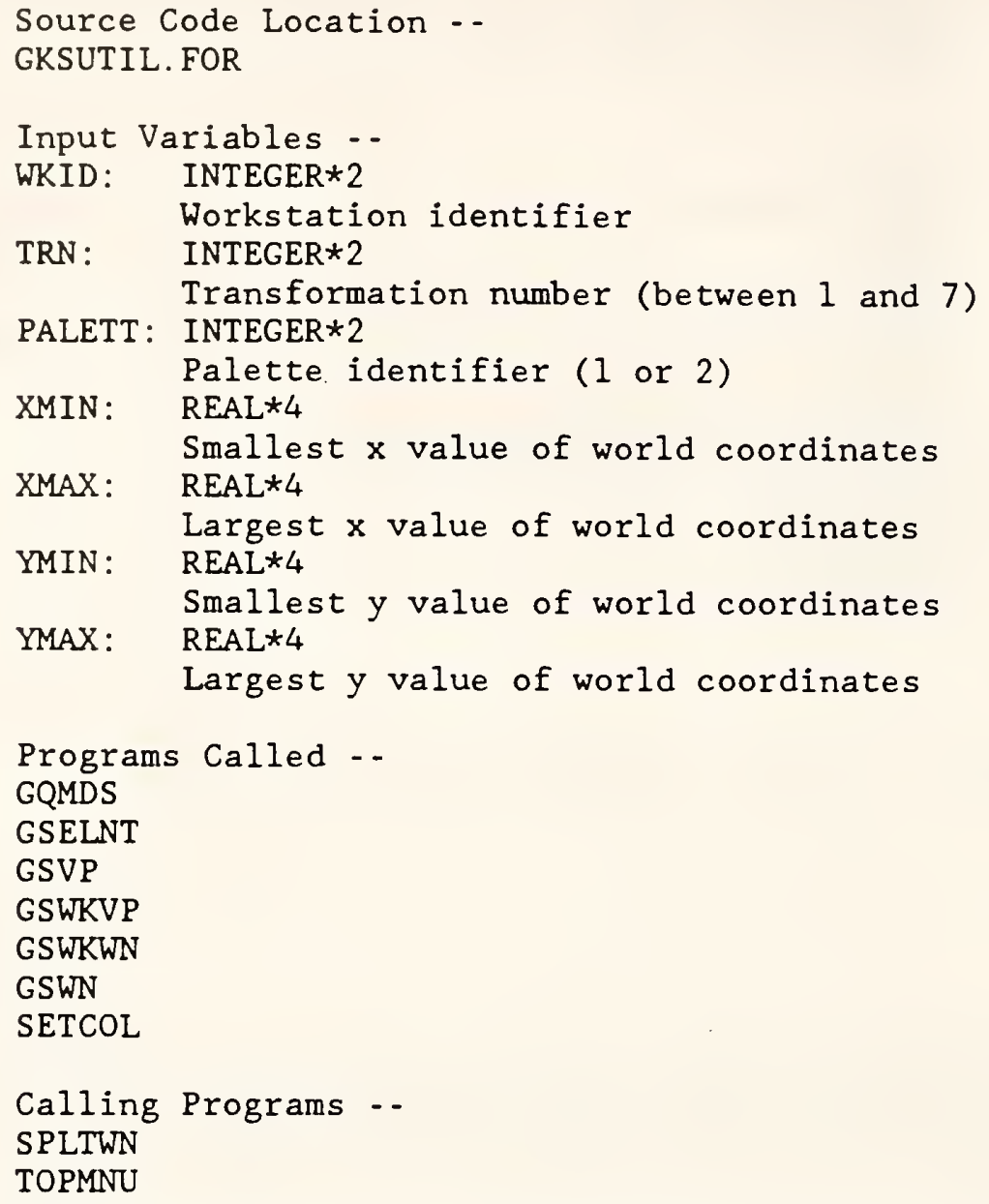

This subroutine initializes the display of a workload map. It is executed when the user chooses "F2 - Display workload" from the top menu. It first asks the user to choose the category of workload to be displayed and then sets a series of switches corresponding to the desired columns of the workload file WORKLOAD.id. These columns are read and summed for each zip code. Then the workloads are divided into six equally spaced ranges (or the user may specify other ranges). Each zip code is assigned a color according to the range its workload falls into. The colors are passed in an array to the subroutine DISPLY which draws the map.

Source Code Location --

DRIVER. FOR

Input Variables --

ID :

CHARACTER *2 


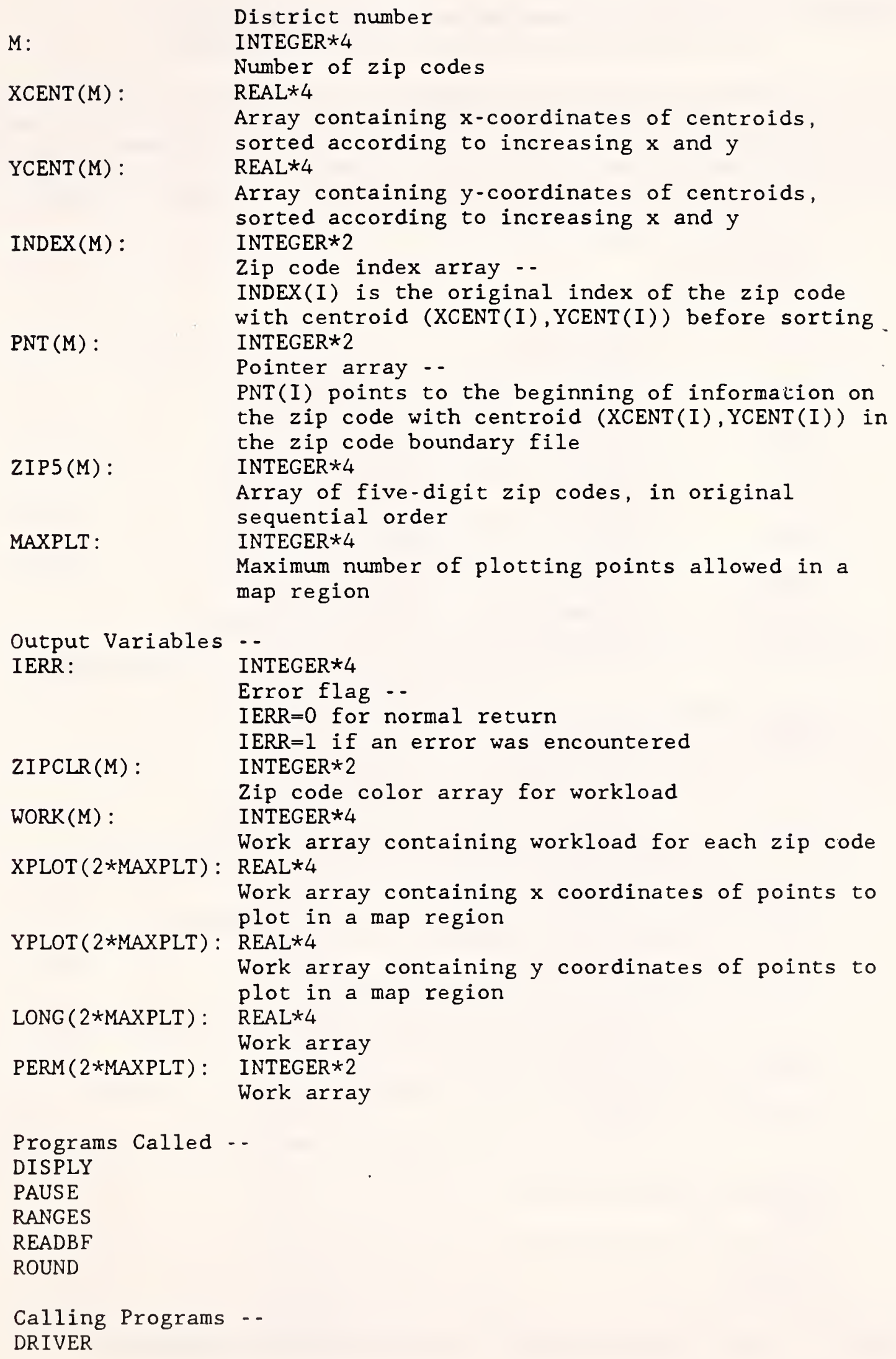


This subroutine converts the GDT zip code boundary file (in URBAN format) to binary direct access form. For zip codes which contain holes, it reorders the interior points so the connector segment will be as short as possible. It also inserts pointers in each zip code header record (Type 3 record) to point to the location of further information on the same $z i p$ code, if any.

Source Code Location - -

GDTINST1.FOR

Input Variables ..

ID :

CHARACTER $* 2$

XMIN :

Two-digit district identification number

Minimum $x$ coordinate of state map

YMIN : $\quad$ REAL*4

XMAX: $\quad$ Minimum y coordinate of state map

Maximum $x$ coordinate of state map

YMAX: $\quad$ REAL*4

Maximum y coordinate of state map

MAXZPS: INTEGER $* 4$

MAXPTS: $\quad$ Maximum number of $z$ ip codes allowed

Maximum number of points allowed in a map region

Output Variables -

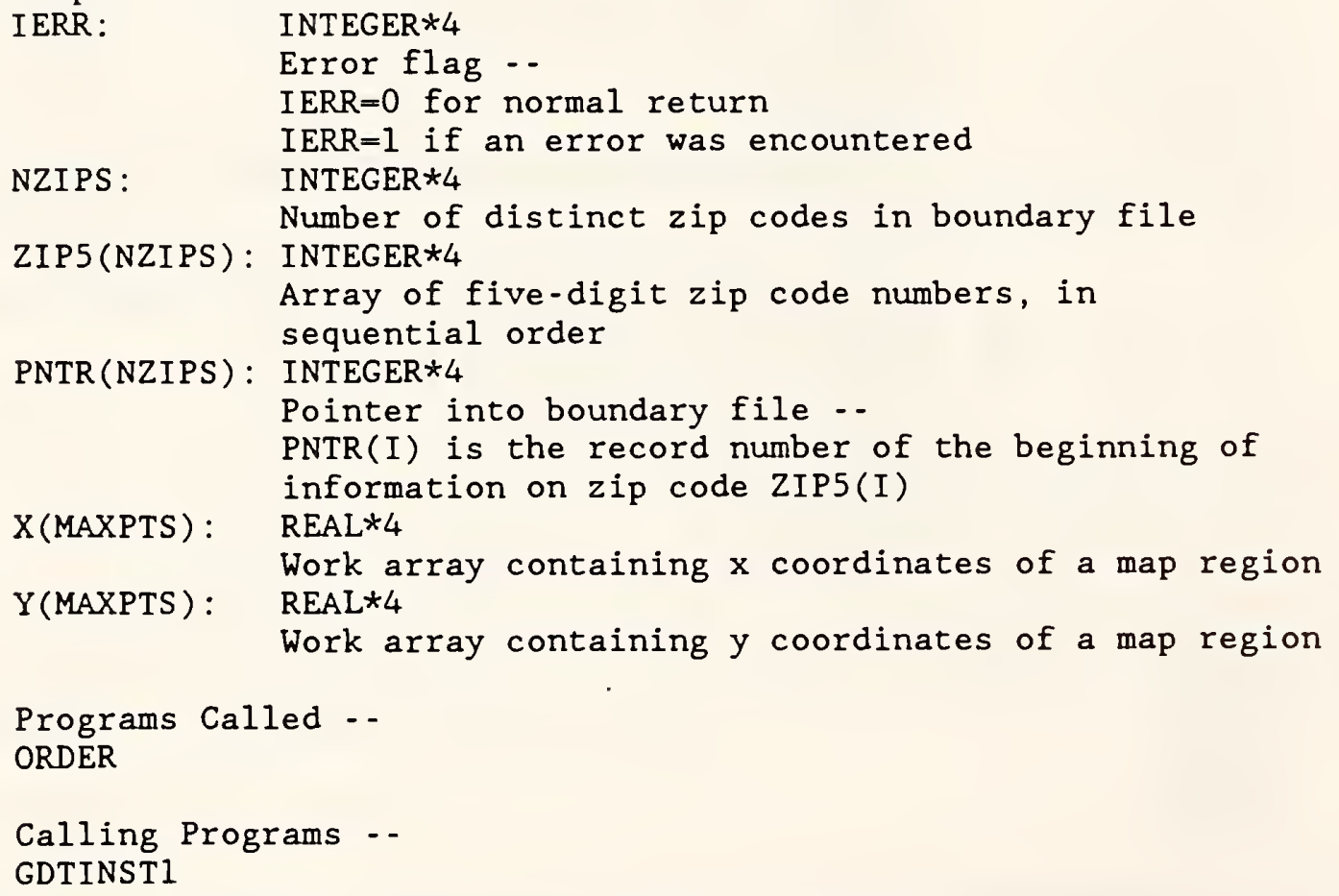

SUBROUTINE ZIPMAP (IERR, TRN, PALETT , ID , MENU, ZOOM , COLOR , XMIN , XMAX, 
This subroutine draws a zip code map either for a full state or for a smaller area. Centroids are included, and the zip codes are colored if specified. The zip code boundaries are read from the file ZIPCODE.id. If the whole state is not to be drawn, but only a smaller region specified by a zoom rectangle, a search is done first to find the first and last zip codes (as given in the sorted centroid list) included in the rectangle.

Source Code Location --

MAPSUBS . FOR

Input Variables - -

TRN :

PALETT :

ID :

MENU :

ZOOM :

COLOR:

XMIN :

XMAX :

YMIN :

YMAX :

M:

$\operatorname{XCENT}(M)$ :

YCENT (M) :

$\operatorname{INDEX}(M):$

$\operatorname{PNT}(M)$ :

\section{INTEGER *2}

Transformation number INTEGER *2

Palette identifier ( 1 or 2 ) CHARACTER $* 2$

District number

INTEGER $* 2$

Menu type switch

LOGICAL

Zoom indicator -.

$\mathrm{ZOOM}=$.FALSE. if entire state is to be drawn

$Z O O M=$.TRUE. if only part of state is to be drawn LOGICAL

Color indicator - -

COLOR $=$. TRUE. if $z$ ip codes are to be colored as they are drawn

COLOR=.FALSE. if just zip code boundaries are to be drawn

REAL*4

$X$ coordinate of lower left corner of zoom rectangle (used only if $200 M=$. TRUE.)

\section{REAL*4}

$X$ coordinate of upper right corner of zoom rectangle (used only if $\mathrm{ZOOM}=$.TRUE.)

REAL*4

$Y$ coordinate of lower left corner of zoom rectangle (used only if $200 M=$.TRUE.)

REAL*4

$Y$ coordinate of upper right corner of zoom rectangle (used only if $\mathrm{ZOOM}=$.TRUE.)

INTEGER *4

Number of $z$ ip codes

REAL *4

Array containing $x$-coordinates of centroids

REAL*4

Array containing $y$-coordinates of centroids INTEGER *2

Zip code index array

INTEGER *2

Pointer array -- 
PNT(I) points to the beginning of information on the zip code with centroid (XCENT(I), YCENT(I)) in the zip code boundary file

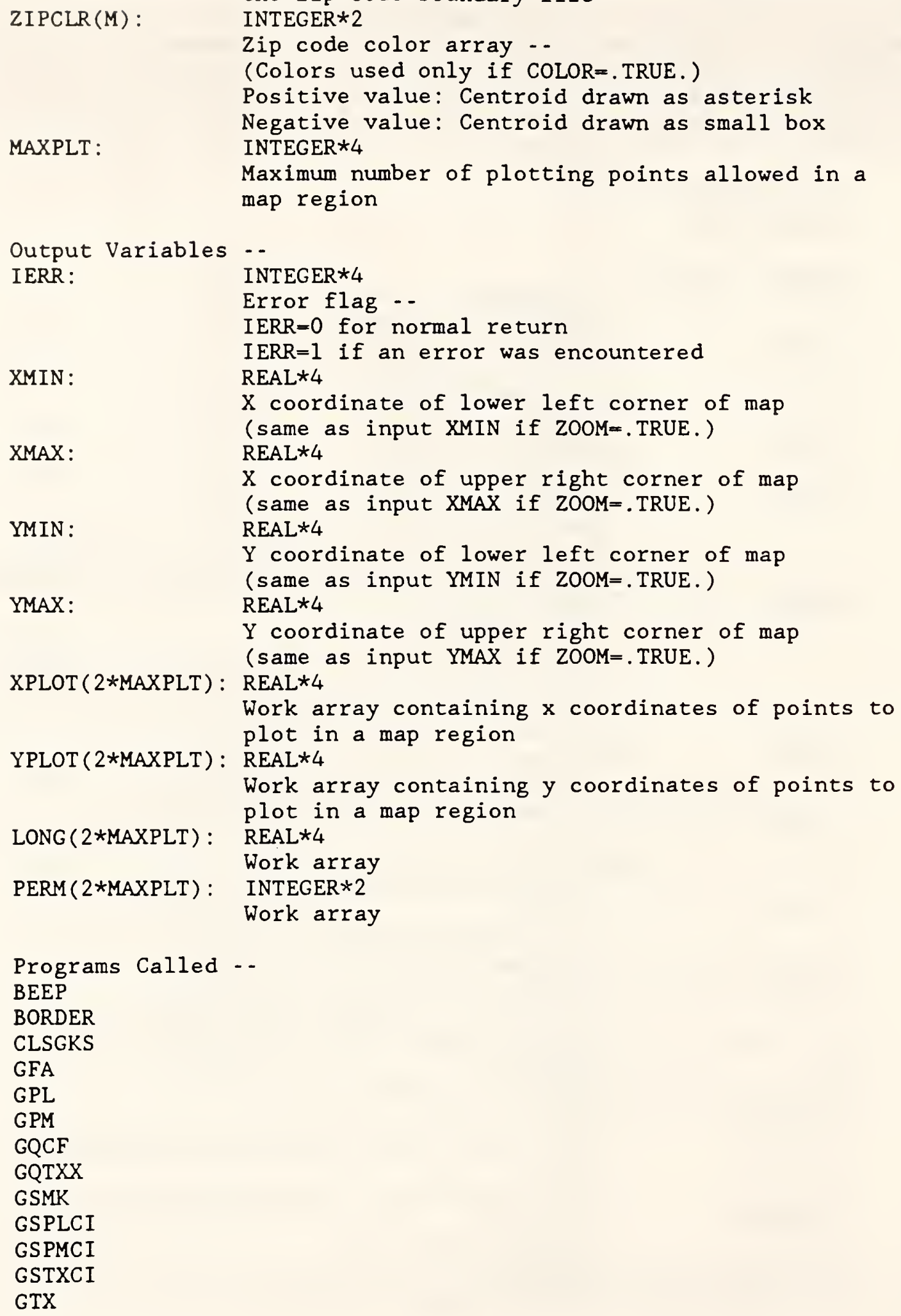


REVERS

SPLTWN

STYLE

THIN

Calling Programs --

DISPLY

ZOOMIN

SUBROUTINE ZOOMIN (IERR, TRN, PALETT , ID , MENO, XMIN , XIAX, YMIN, YMAX, I, XCENT, YCENT, INDEX , PNT , ZIPCLR, YAXPLT , XPLOT, YPLOT, LONG, PERM) :

This subroutine allows the user to draw a box on a previously drawn map and then zooms in on the boxed area.

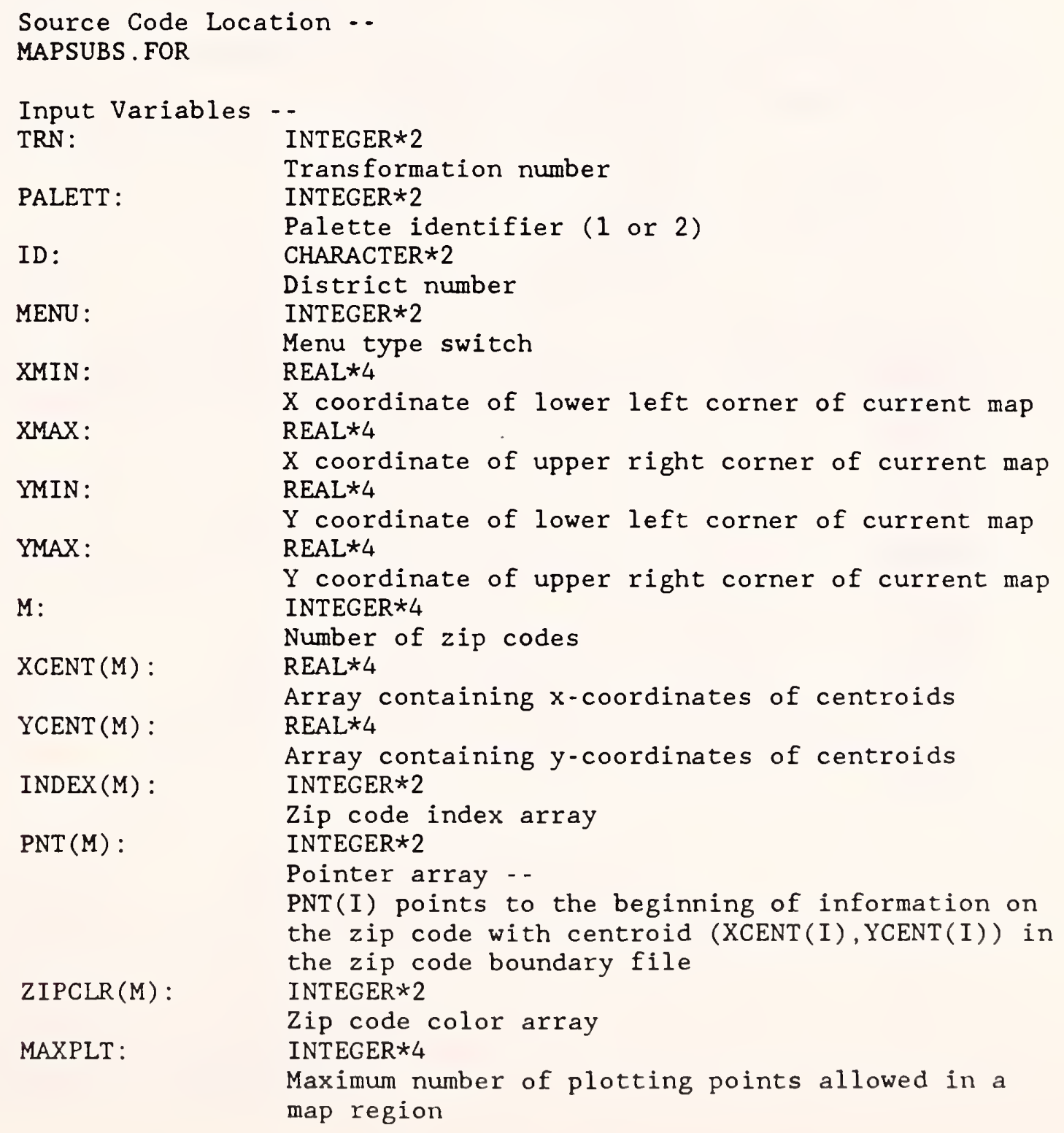


Error flag -.

IERR $=0$ for normal return

IERR $=1$ if an error was encountered

$I E R R=2$ if zoom was cancelled by user

TRN : INTEGER *2

Transformation number

XMIN :

REAL *4

$X$ coordinate of lower left corner of zoom region REAL $\star 4$

XMAX :

$X$ coordinate of upper right corner of zoom region

YMIN : REAL $\star 4$

YMAX :

$Y$ coordinate of lower left corner of zoom region REAL *4

XPLOT (2*MAXPLT) : REAL*4

$Y$ coordinate of upper right corner of zoom region

Work array containing $x$ coordinates of points to plot in a map region

YPLOT $(2 *$ MAXPLT $):$ REAL *4

Work array containing y coordinates of points to plot in a map region

LONG (2*MAXPLT) : REAL $\star 4$

Work array

PERM (2*MAXPLT) : INTEGER $* 2$

Work array

Programs Called -.

CRSBOX

ERSMNU

GCLRWK

GINST

GQCF

GQMDS

GRQST

GSELNT

GSTXCI

GTX

REVERS

ZI PMAP

Calling Programs -

DISPLY 
Section V: Changing the Program to Correspond to Changes in the Workload File Format

The current version of the POD location system (5.0) assumes that the workload file WORKLOAD.id contains three header records followed by a workload record for each $z$ ip code. Each workload record contains a $z$ ip code followed by 36 items: 14 BMF Examination entries, 10 IMF Examination entries, 4 BMF Collection entries, 2 IMF Collection entries, and 6 entries for display purposes only. From year to year this format may change, and if so, some subroutines in the $P O D$ location system must be revised. The following routines may need to be changed.

Subroutine COMP in file GDTINST1.FOR -.

$$
\begin{array}{lr}
\text { Line 293: } & \text { DO } 200 \mathrm{I}=1,3 \\
\text { Line 294: } & \operatorname{READ}(2, *)
\end{array}
$$

Line 295: 200 CONTINUE

This loop skips over the three header records at the beginning of the workload file. It only needs to be changed if the number of header records changes.

Function COSTFN in file DRIVER.FOR - -

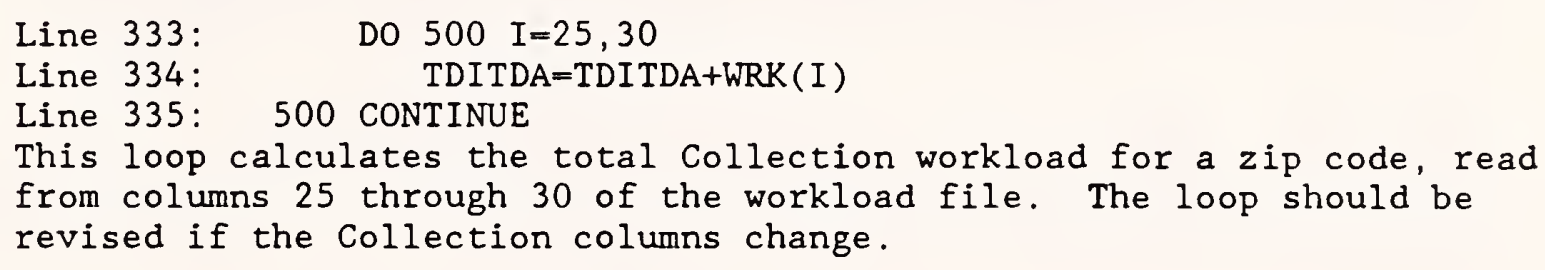

Subroutine SOLVE in file DRIVER.FOR - -

Line 799: PARAMETER (NCLASS $=30$ )

The parameter NCLASS defines the number of categories of workload in the workload file, not including display-only categories.

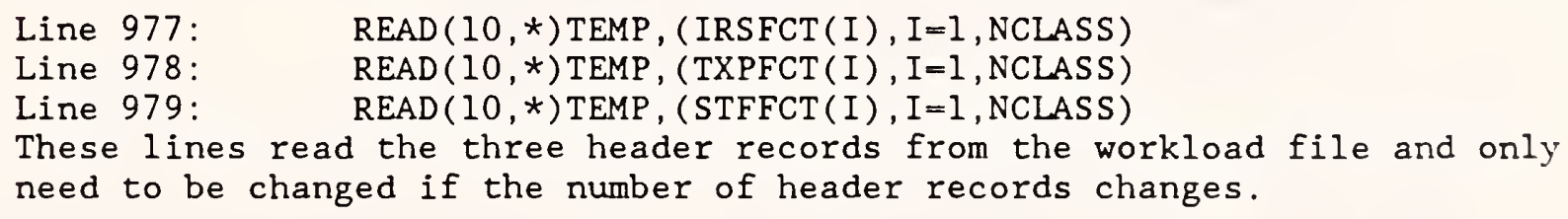


This loop turns on a switch for each category of Examination workload, read from columns 1 through 24 of the workload file. The loop should be revised if the Examination columns change.

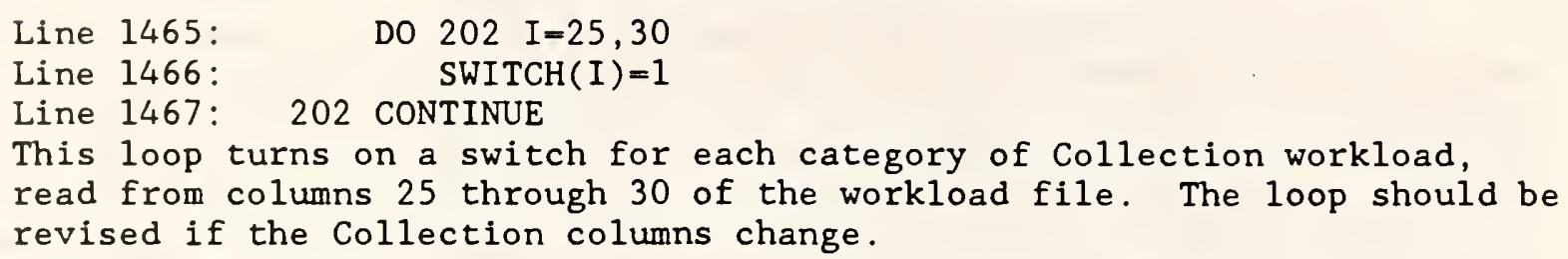

Line 1469:

\section{PRIN}

PRINT *,' $1-14$ BMF EXAMINATION

PRINT *,'15-24 IMF EXAMINATION

Line 1471:

Line 1472:

PRINT *,' 25,27 BMF TDI COLLECTION

DESCRIPTIONS -....................

26,28 BMF TDA COLLECTION'

29 IMF TDI COLLECTION'

30 IMF TDA COLLECTION'
Line 1473:

(Lines 1500-1504 are identical.)

These lines should be modified to correspond to any changes in the workload file format.

Line 1477: PRINT *,'Enter number (from 1 to 36 of column to be ', Line 1478: + 'displayed:

Line 1492: PRINT *,'Error -- please enter a number between 1 and 36.'

The "36" in these lines represents the total number of workload

categories in the workload file, including display-only categories.

Line 1509: PRINT *,' 111111111122222222223333333'

Line 1510: PRINT *,'123456789012345678901234567890123456'

These lines print column labels for each category of workload, including display-only columns.

Line 1564: $\quad$ DO $600 \mathrm{I}=1,3$

Line 1565: $\quad \operatorname{READ}(10, *)$

Line 1566: 600 CONTINUE

This loop skips over the three header records at the beginning of the workload file. It only needs to be changed if the number of header records changes.

Subroutine OPTION in file IOSUBS.FOR -.

Line 496:

Line 497:

Line 498:

$\operatorname{SWITCH}(I)=1$

DO $200 \quad I=1,14$ SWITCH

This loop turns on a switch for each category of BMF Examination workload, read from columns 1 through 14 of the workload file. The loop should be revised if the BMF Examination columns change.

Line 501:

Line 502:

Line 503:

201 CONTINUE

DO $201 \mathrm{I}=15,24$ $\operatorname{SWITCH}(I)=1$

This loop turns on a switch for each category of IMF Examination workload, read from columns 15 through 24 of the workload file. The loop should be revised if the IMF Examination columns change. 
Line 506:

Line 507:

Line 508:

202 CONTINUE

This loop turns on a switch for each category of BMF Collection workload, read from columns 25 through 28 of the workload file. The loop should be revised if the BMF Collection columns change.

Line 511: $\quad$ DO $203 \mathrm{I}=29,30$

Line 512:

Line 513:

203 CONTINUE

$\operatorname{SWITCH}(I)=1$

This loop turns on a switch for each category of IMF Collection workload, read from columns 29 and 30 of the workload file. The loop should be revised if the IMF Collection columns change.

Subroutine REPPRB in file IOSUBS.FOR --

Lines 1022-1107 contain labels for each category of workload, to be listed in the report file. These labels should be updated each year.

Subroutine REPSOL in file IOSUBS.FOR - -

Line 1160:

PARAMETER (NCLASS $=30$ )

The parameter NCLASS defines the number of categories of workload in the workload file, not including display-only categories.

Line 1329:

Line 1330:

Line 1331:

600 CONTINUE

DO $600 \quad I=1,2$

$\operatorname{READ}(10, *)$

Line 1332:

$\operatorname{READ}(10, *) \operatorname{TEMP},(\operatorname{STFFAC}(I), I=1$, NCLASS)

These lines skip over the first two header records at the beginning of the workload file and then read the staffing factors from the third line. These lines only need to be changed if the organization of the header information changes.

Line 1347:

Line 1348:

DO $700 \quad I=15,24$

Line 1349:

Line 1350:

Line 1351:

Line 1352:

700 CONTINUE

$Z 1=\operatorname{STFFAC}(I) * W R K(I)$

$\operatorname{IMFEXM}(Z I P C L R(P O D))=\operatorname{IMFEXM}(Z \operatorname{IPCLR}(P O D))+Z 1$

$\operatorname{IMFEX} 2(\operatorname{ZIPCLR}(P O D))=\operatorname{IMFEX} 2(\operatorname{ZIPCLR}(P O D))+W R K(I)$

TOTEXM=TOTEXM+Z1

This loop calculates staffing information for IMF Examination workload, read from columns 15 through 24 of the workload file. The loop should be revised if the IMF Examination columns change.

Line 1354:

Line 1355:

Line 1356:

Line 1357:

Line 1358:

Line 1359:

This loop calculates staffing information for BMF Examination workload, read from columns 1 through 14 of the workload file. The loop should be revised if the BMF Examination columns change. 
Line 1361:

$Z 1=\operatorname{STFFAC}(29) *$ WRK $(29)$

Line 1362:

$\operatorname{TDICOL}(\mathrm{ZIPCLR}(\mathrm{POD}))=\operatorname{TDICOL}(\mathrm{ZIPCLR}(\mathrm{POD}))+\mathrm{Zl}$

Line 1363:

$\operatorname{TDICO} 2(Z \operatorname{IPCLR}($ POD) ) $=\operatorname{TDICO} 2(\mathrm{ZIPCLR}(\mathrm{POD}))+\mathrm{WRK}(29)$

These lines calculate staffing information for IMF TDI Collection

workload, read from column 29 of the workload file. These lines should be changed if the IMF TDI Collection column changes.

Line 1366: $\quad$ Zl-STFFAC (25)*WRK(25)+STFFAC (27)*WRK(27)

Line 1367: $\quad \operatorname{TDICOL}(Z \operatorname{IPCLR}(P O D))=\operatorname{TDICOL}(Z \operatorname{IPCLR}(P O D))+Z 1$

Line 1368: $\quad \operatorname{TDICO2}(\operatorname{IIPCLR}(P O D))=\operatorname{TDICO2}(\operatorname{ZIPCLR}(P O D))+W R K(25)+W R K(27)$

These lines calculate staffing information for BMF TDI Collection

workload, read from columns 25 and 27 of the workload file. These lines should be changed if the BMF TDI Collection columns change.

Line 1371: $\quad$ Z1 $=\operatorname{STFFAC}(30) * W R K(30)$

Line 1372: $\quad \operatorname{TDACOL}(Z \operatorname{IPCLR}(P O D))=\operatorname{TDACOL}(Z \operatorname{IPCLR}(P O D))+Z 1$

Line 1373: $\quad \operatorname{TDACO2(ZIPCLR(POD))~}=\operatorname{TDACO2}$ (ZI PCLR (POD)) +WRK(30)

These lines calculate staffing information for IMF TDA Collection

workload, read from column 30 of the workload file. These lines should

be changed if the IMF TDA Collection column changes.

Line 1376: $\quad$ Z1=STFFAC (26)*WRK (26) $+\operatorname{STFFAC}(28) * W R K(28)$

Line 1377: $\quad \operatorname{TDACOL}(Z I P C L R(P O D))=\operatorname{TDACOL}(Z \operatorname{IPCLR}(P O D))+Z 1$

Line 1378: $\quad \operatorname{TDACO2}(Z \operatorname{IPCLR}(P O D))=\operatorname{TDACO2}(\mathrm{ZIPCLR}(\mathrm{POD}))+W R K(26)+W R K(28)$

These lines calculate staffing information for BMF TDA Collection

workload, read from columns 26 and 28 of the workload file. These lines should be changed if the BMF TDA Collection columns change.

Subroutine ZIPMAP in file MAPSUBS.FOR -.

Line 1090: CHARACTER TITLE $\star 20$, VECTOR $\star 36$

The "36" in this line represents the total number of workload categories in the workload file, including display-only categories. 
NBS.IILA IREV. $20 C$ )

U.S. DEPT. OF COMM

BIBLIOGRAPHIC DATA

SHEET (See instructions)
1. PUBLICATION OR REPORT NO.

NISTIR 86-3473-1
2. Performing Organ. Report Noy 3. Publication Date

FEBRUARY 1989

4. TITLE AND SUBTITLE

The Internal Revenue Service Post-of-Duty Location Modeling System (Version 5.0) -

Programmer's Manual for FORTRAN Driver

5. $A \cup T H O R(S)$

Paul D. Domich, Richard H. F. Jackson, Marjorie A. McClain

6. PERFORMING ORGANIZATION (If joint or other than NBS. see instructions)

7. Contracd Grant No.

\section{NATIONAL BUREAU OF STANDARDS \\ U.S. DEPARTMENT OF COMMERCE \\ GAITHERSBURG, MD 20899}

9. SPONSORING ORGANIZATION NANE AND COMPLETE ADORESS (STret, City, STOTE, ZIP)

The Research Division

U.S. Internal Revenue Service

1201 E Street, NW

Washington, DC 20224

10. SUPPLEMENTARY NOTES

Document describes a computer program, SF-185, FIPS Software Summary, is attached.

11. ABSTRACT (A 200-word or less foctual summory of most significant information. If document includes o significont bibliogrophy or literoture survey, mention it here)

This report is a programer's manual for a microcomputer package which was designed by the National Institute of Standards and Technology to assist the Internal Revenue Servic in choosing locations for its posts-of-duty which will minimize costs to the IRS and to the taxpayer. The package was written in two sections of code, one in FORTRAN and the other in PASCAL. This manual describes the FORTRAN driver which handles graphics displays and controls input and output for the solution procedure.

12. KEY WORDS (Six to iwelve entries; olphobelicol order: copitolize only proper nomes; ond seporote key words by semicolons) facility location, Graphical Kernel System (GKS), interactive graphics, microcomputer, personal computer

13. AVAILABILITY

XX Unlimited

$\square$ For Official Distribution. Do Not Release to NTIS

$\square$ Order From Superintendent of Documents, U.S. Government Printirg. Office, Washington. D.C. 20402.

XXXrder From National Technical Information Service (NTIS), Springfield, VA. 2216I
14. NO. OF

PRINTED PAGES

66

15. Price

$\$ 14.95$ 


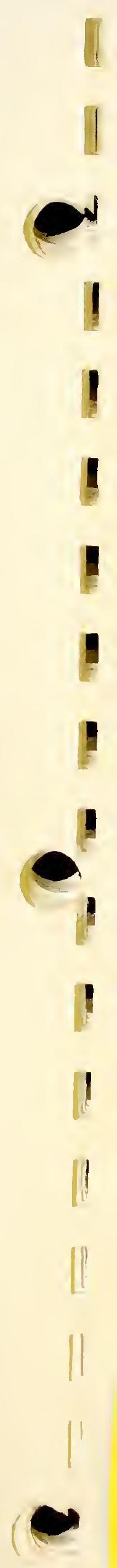




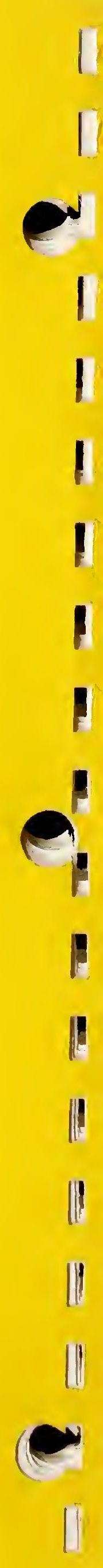


